\title{
Uncaging alcohols using UV or visible light photoinduced electron transfer to 9-phenyl-9-tritylone ethers
}

Derek M. Denning, Nichole J. Pedowitz, Matthew D. Thum and Daniel E. Falvey*

Department of Chemistry and Biochemistry, University of Maryland, College Park, Maryland 20742, United States

Supporting Information.

\section{Table of Contents:}

- Synthesis of tritylone alcohol and ethers $\quad$ S4

- Gas chromatography analysis of deprotected alcohols S9

- Laser flash photolysis and kinetic decay plots $\quad$ S13

$\begin{array}{ll}\text { - Visible light deprotection } & \text { S15 }\end{array}$

- Mass spectrometry experiment $\quad$ S25

$\begin{array}{ll}\text { - Characterization spectra } & \text { S27 }\end{array}$

\section{General Information:}

All chemicals and solvents used were purchased from commercial suppliers and used without any further purification. Reactions and photolyses were done in oven dried $\left(\sim 370^{\circ} \mathrm{C}\right)$ round bottom flasks or quartz cuvettes. Solvents used consisted of HPLC grade methanol (Sigma Aldrich, $\geq 99.9 \%$ ), HPLC grade acetonitrile (Fisher, 99.9\%) distilled over $\mathrm{CaH}_{2}$ before use, spectroscopic grade 1,4-dioxane (Acros, 99+\%), tert-butanol (Alfa Aesar, 99+\%), benzene (EMD, 99\%), glacial acetic acid (Fisher, 99.9\%) and methanol- $d_{4}$ (Cambridge Isotopes, 99.8\%). Chemicals used consisted of 9-phenylanthracene (Alfa Aesar, 98\%), sodium dichromate dihydrate (J.T. Baker Chemical Co.), 1-octanol (Sigma Aldrich, 99+\%), 3'-O-acetoxythymidine (Sigma Aldrich, 99\%), benzyl alcohol (Fisher), 4-(4'-methyoxyphenyl)-1-butanol (Sigma Aldrich, 99\%), cyclohexanol (Acros, 98\%), benzhydrol (Sigma Aldrich, 98\%), cholesterol (Alfa Aesar, 95\%), N,N-dimethylaniline (Alfa Aesar, 99\%), triethylamine (Fisher, 99\%), 1,8- 
diazabicyclo[5.4.0]undec-7-ene (Sigma Aldrich, 98\%), triphenylamine (Sigma Aldrich, 98\%), and $f a c-\operatorname{Ir}(\text { ppy })_{3}$ (Sigma Aldrich, 99\%).

${ }^{1} \mathrm{H}$ and ${ }^{13} \mathrm{C}$ NMR experiments were conducted on a Bruker $400 \mathrm{MHz}$ instrument. All peaks are referenced to the solvent peak $\left(\mathrm{C}_{6} \mathrm{D}_{5} \mathrm{H}\right.$ or $\left.\mathrm{CHCl}_{3}\right)$ and the splitting is represented by ( $\mathrm{s}=$ singlet, $\mathrm{d}=$ doublet, $\mathrm{t}=$ triplet, $\mathrm{q}=$ quartet, $\mathrm{sep}=$ septet, $\mathrm{dd}=$ doublet of doublets, $\mathrm{dt}=$ doublet of triplets and $\mathrm{m}=$ multiplet or not well resolved peaks). Water peaks for deuterated benzene and chloroform are 0.4 and $1.6 \mathrm{ppm}$ respectively. ${ }^{13} \mathrm{C}$ experiments were conducted under broadband proton decoupled conditions resulting in all the signals appearing as singlets and referenced to the solvent peak. High-resolution mass spectrometry was conducted on a JEOL AccuTOF-CS ESI-TOF. IR-spectra were collected on a Nexus 670 FT-IR.

Tritylone ethers 2a-g were photolyzed in an RPR-100 rayonet reactor (12-bulb, 32 watt, $\sim 33{ }^{\circ} \mathrm{C}$ operating temperature, $350 \mathrm{~nm}$ max output) supplied by Southern New England Ultraviolet. Three samples were prepared in 4-sided quartz cuvettes each capped with a septum and purged with $\mathrm{N}_{2(\mathrm{~g})}$ both in the solution and in the headspace of the cuvette. $1 \mathrm{~mL}$ of the photolysis solution was placed in each of the three cuvettes and irradiated at $350 \mathrm{~nm}$ for the allotted time. Each cuvette was rotated evenly throughout the course of the photolysis to allow for ample light distribution to each solution. Upon completion of the photolysis time, approximately $250 \mu \mathrm{L}$ of each sample was transferred to an appropriate GC vial and analyzed.

Gas chromatography analysis was done using a Shimadzu GC-17A, containing a RTX-5 stationary phase column (length $=15 \mathrm{~m}$, inner diameter (i.d.) $=0.25 \mathrm{~mm}$, film thickness $=0.25$ $\mu \mathrm{m})$, equipped with a FID detection system, and using the following method specifications: equipped with a FID detection system, and using the following method specifications: column temperature $=60^{\circ} \mathrm{C}$, injection temperature $=280^{\circ} \mathrm{C}$, and detector temperature $=300{ }^{\circ} \mathrm{C}$, with a temperature/pressure profile for injection of: $67 \mathrm{kPa}, 3.0$ minutes, $3.9 \mathrm{~mL} /$ minute, $98 \mathrm{kPa}, 9.0$ minutes, column of: $60^{\circ} \mathrm{C}, 3$ minutes, $30 \mathrm{~mL} /$ minute, $300^{\circ} \mathrm{C}, 9.0$ minutes, injector pressure of $60 \mathrm{kPa}$, total flow of $31 \mathrm{~mL} / \mathrm{min}$., column flow of $1.45 \mathrm{~mL} / \mathrm{min}$, and a linear velocity of 39.1 $\mathrm{cm} / \mathrm{s}$. 
UV-Vis data (below) was collected on a Shimadzu UV-1800 spectrometer using UVProbe 2.43 software. Samples were scanned from $800 \mathrm{~nm}$ to $190 \mathrm{~nm}$ using a fast scanning speed and a sampling interval $(\mathrm{nm})$ of 1.0. Each sample was pre-blanked with the solvent of choice used in solvating the compound.

More specific information can be found under the experimental data found below.

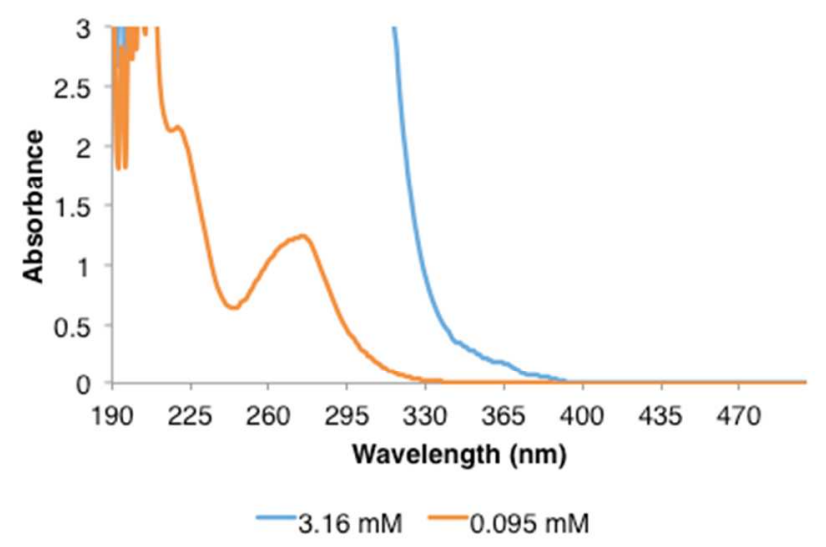

Absorption spectrum of octyl ether 2a in HPLC grade methanol at a high and low concentration.

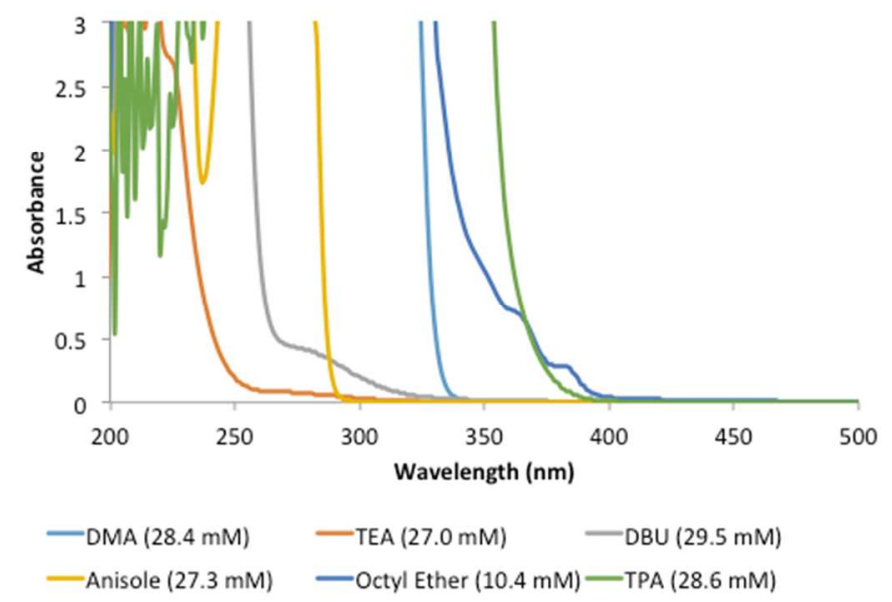

DMA $=N, N$-dimethylaniline

TEA $=$ triethylamine

DBU $=1,8$-diazabicyclo[5.4.0]undec-7-ene

$\mathrm{TPA}=N, N, N$-triphenylamine

All spectra above were taken and blanked with HPLC grade methanol except TPA, which used spectroscopic grade 1,4-dioxane. These spectrums represent the concentrations of both the donor and tritylone ether used in the photolysis experiments. 


\section{- Synthesis of tritylone ethers:}

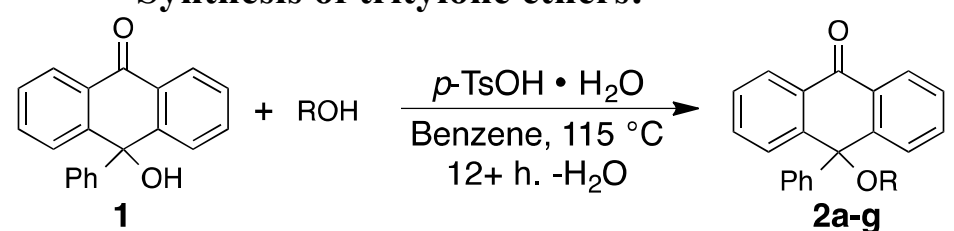

The following general procedure was used for the synthesis of ethers $\mathbf{2 a - g}$. More specific details can be found under the corresponding ether. Tritylone alcohol 1, $p$-toluenesulfonic acid monohydrate $\left(p\right.$ - $\left.\mathrm{Ts} \mathrm{OH} \cdot \mathrm{H}_{2} \mathrm{O}\right)$ and the alcohol are added to benzene in an oven dried round bottom flask with a stir bar. The solution is heated while stirring at $115^{\circ} \mathrm{C}$ under reflux equipped with a Dean-Stark trap for the removal of water. The reaction can be monitored by the disappearance of 1 via gas chromatography, and all the syntheses listed below were heated for $12+$ hours. Upon completion of the reaction, the solution was left to cool to room temperature and the solvent was removed under reduced pressure with heating. The resulting black solid was purified using flash column chromatography with silica gel and a mobile phase of petroleum ether/diethyl ether unless otherwise noted.

\section{9-hydroxy-9-phenylanthrone (1):}

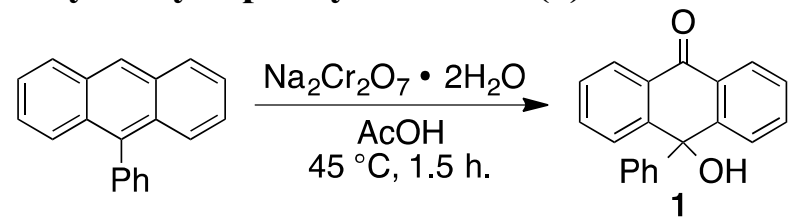

To an oven dried $50 \mathrm{~mL}$ round bottom flask with a stir bar, 9-phenylanthracene $(2.3065 \mathrm{~g}, 9.07$ mmol) was added to approximately $30 \mathrm{~mL}$ of glacial acetic acid. To the slurry solution, sodium dichromate dihydrate $(3.9610 \mathrm{~g}, 13.3 \mathrm{mmol})$ was added and placed in an oil bath where it was heated at $45^{\circ} \mathrm{C}$ for 90 minutes with stirring. Soon after the addition of sodium dichromate the solution goes from a tan/brownish color to dark green. After the allotted time, the solution was poured into $100 \mathrm{~mL}$ of deionized water and vacuum filtered. The white/off white powder is washed with generous portions of deionized water and placed under vacuum to dry $(2.5433 \mathrm{~g}$, 97.9\%). If necessary the white powder can be recrystallized from hexanes/ethyl acetate. GC $\mathrm{R}_{\mathrm{T}}$ of tritylone alcohol is 14.1 minutes. ${ }^{1} \mathrm{H}$ NMR $\left(400 \mathrm{MHz}, \mathrm{CDCl}_{3}\right) \delta=8.31-8.29(\mathrm{dd}, J=1.2,6.8$ $\mathrm{Hz}, 2 \mathrm{H}), 7.65-7.56(\mathrm{~m}, 4 \mathrm{H}), 7.48-7.44(\mathrm{~m}, 2 \mathrm{H}), 7.38-7.35(\mathrm{~m}, 2 \mathrm{H}), 7.26-7.22(\mathrm{~m}, 2 \mathrm{H}), 7.18(\mathrm{~m}$, 1H), $2.84(\mathrm{~s}, 1 \mathrm{H}) .{ }^{13} \mathrm{C} \mathrm{NMR}\left(400 \mathrm{MHz}, \mathrm{CDCl}_{3}\right) \delta=183.90,147.89,146.11,134.34,130.04$, 
128.61, 128.56, 128.48, 127.16, 127.08, 125.63, 73.34. m.p. $=215-217^{\circ} \mathrm{C} . \mathrm{HRMS}(\mathrm{ESI}-\mathrm{TOF})$ Calcd for $\mathrm{C}_{20} \mathrm{H}_{14} \mathrm{O}_{2}[\mathrm{M}+\mathrm{H}]^{+}: 287.1072$, Found: 287.1055, FTIR(neat): 3405.35, 1738.24, $1650.83,1599.61 \mathrm{~cm}^{-1}$

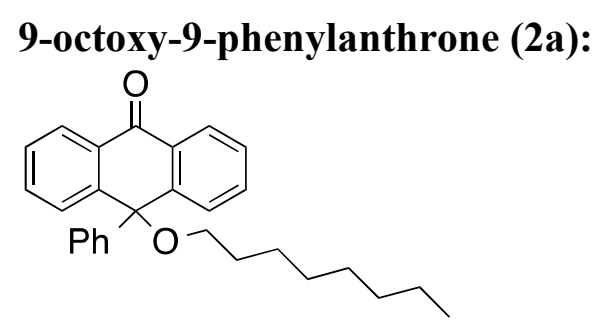

Tritylone alcohol (1.242 g, $4.34 \mathrm{mmol}), p-\mathrm{TsOH} \cdot \mathrm{H}_{2} \mathrm{O}(60.2 \mathrm{mg}, 0.316 \mathrm{mmol})$ and 1-octanol ( $0.684 \mathrm{~mL}, 4.33 \mathrm{mmol}$ ) was added to $80 \mathrm{~mL}$ of benzene in a $100 \mathrm{~mL}$ round bottom flask. Purified to white crystals with mobile phase of (1:9 ether:petroleum ether) to give (1.5690 g, $90.8 \%$ ) of ether. GC $\mathrm{R}_{\mathrm{T}}$ of octyl ether is 16.7 minutes. ${ }^{1} \mathrm{H}$ NMR $\left(400 \mathrm{MHz}, \mathrm{C}_{6} \mathrm{D}_{6}\right) \delta=8.64-8.62$ (dd, $J=1.6,6.2 \mathrm{~Hz}, 2 \mathrm{H}), 7.50-7.46$ (m, 4H), 7.06-6.97 (m, 6H), 6.91-6.87 (m, 1H), 2.98 (t, $J=$ $6.3 \mathrm{~Hz}, 2 \mathrm{H}), 1.53-1.46(\mathrm{~m}, 2 \mathrm{H}), 1.28-1.20(\mathrm{~m}, 10 \mathrm{H}), 0.916(\mathrm{t}, J=6.9 \mathrm{~Hz}, 3 \mathrm{H}) .{ }^{13} \mathrm{C}$ NMR $(400$ $\left.\mathrm{MHz}, \mathrm{CDCl}_{3}\right) \delta=183.84,146.83,145.85,134.13,131.86,128.84,128.42,128.22,127.17$, $126.79,125.92,77.99,63.77,32.06,30.17,29.57,29.46,26.46,22.87,14.32$. m.p. $=42-43{ }^{\circ} \mathrm{C}$. HRMS (ESI-TOF) Calcd for $\mathrm{C}_{28} \mathrm{H}_{30} \mathrm{O}_{2}[\mathrm{M}+\mathrm{H}]^{+}: 399.2324$, Found: 399.2305, FTIR(neat): $2929.24,2854.98,1738.38,1663.93,1599.67 \mathrm{~cm}^{-1}$

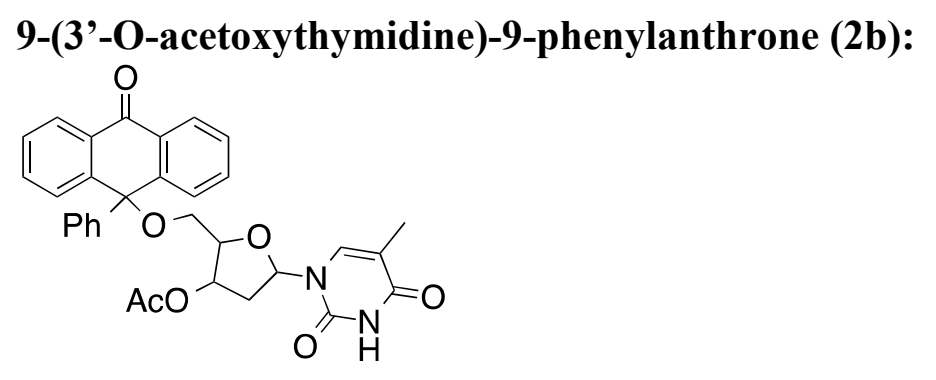

Tritylone alcohol $(0.1847 \mathrm{~g}, 0.645 \mathrm{mmol}), p-\mathrm{TsOH} \cdot \mathrm{H}_{2} \mathrm{O}(22.4 \mathrm{mg}, 0.118 \mathrm{mmol})$ and 3'-Oacetoxythymidine $(0.2047 \mathrm{~g}, 0.720 \mathrm{mmol})$ was added to $30 \mathrm{~mL}$ of benzene in a $50 \mathrm{~mL}$ round bottom flask. Purified to white crystals with a mobile phase of ethyl acetate to give $(0.2733 \mathrm{~g}$, $76.7 \%$ ) of ether ${ }^{1} \mathrm{H}$ NMR $\left(400 \mathrm{MHz}, \mathrm{CDCl}_{3}\right) \delta=8.93(\mathrm{~s}, 1 \mathrm{H}), 8.42-8.40(\mathrm{dd}, J=1.3,6.5 \mathrm{~Hz}$, $1 \mathrm{H}), 8.37-8.35$ (dd, $J=1.2,6.7 \mathrm{~Hz}, 1 \mathrm{H}), 7.70,(\mathrm{~d}, J=1.2 \mathrm{~Hz}, 1 \mathrm{H}), 7.63-7.47$ (m, $5 \mathrm{H}), 7.40-7.38$ (m, 1H), 7.29-7.27 (m, 2H * partly buried under solvent peak), 7.26-7.16 (m, 3H), $6.43(\mathrm{~m}, 1 \mathrm{H})$, 
5.43, (m, 1H), 4.08 (q, $J=2.5 \mathrm{~Hz}, 1 \mathrm{H}), 3.44-3.29$ (ABX, $J=2.8,7.6 \mathrm{~Hz}, 2 \mathrm{H}), 2.59-2.45(\mathrm{~m}, 2 \mathrm{H})$, $2.08(\mathrm{~s}, 3 \mathrm{H}), 1.68(\mathrm{~d}, J=0.96 \mathrm{~Hz}, 3 \mathrm{H}) .{ }^{13} \mathrm{C}$ NMR $\left(400 \mathrm{MHz}, \mathrm{CDCl}_{3}\right) \delta=183.14,170.53,163.50$, $150.38,146.05,144.15,143.86,135.16,134.58,132.26,131.68,129.06,128.91,128.82,128.54$, $128.23,127.68,127.63,127.58,125.62,111.88,84.65,83.57,79.17,74.80,63.81,38.35,21.16$, 12.36 (3 peaks not accounted for and could be overlapping with previous peaks). m.p. $=219-221$ ${ }^{\circ} \mathrm{C}$. HRMS (ESI-TOF) Calcd for $\mathrm{C}_{32} \mathrm{H}_{29} \mathrm{~N}_{2} \mathrm{O}_{7}\left[\mathrm{M}+\mathrm{NH}_{4}\right]^{+}:$570.2240, Found: 570.2233, FTIR(neat): 3067.15, 1738.23, 1687.43, 1663.28, $1599.78 \mathrm{~cm}^{-1}$

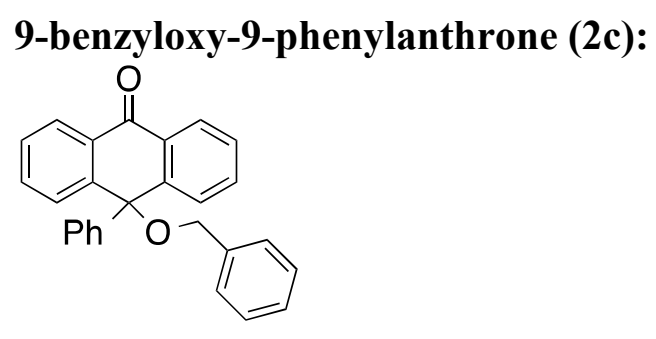

Tritylone alcohol $(0.5850 \mathrm{~g}, 2.04 \mathrm{mmol}), p-\mathrm{TsOH} \cdot \mathrm{H}_{2} \mathrm{O}(45.7 \mathrm{mg}, 0.240 \mathrm{mmol})$ and benzyl alcohol $(0.320 \mathrm{~mL}, 3.08 \mathrm{mmol})$ was added to $60 \mathrm{~mL}$ of benzene in a $100 \mathrm{~mL}$ round bottom flask. Purified to white crystals with mobile phase of (1:9 ether:petroleum ether) to give $(0.5650 \mathrm{~g}$, $73.5 \%)$ of ether. GC $\mathrm{R}_{\mathrm{T}}$ of benzyl ether is 17.7 minutes. ${ }^{1} \mathrm{H}$ NMR $\left(400 \mathrm{MHz}, \mathrm{C}_{6} \mathrm{D}_{6}\right) \delta=8.65$ $8.63(\mathrm{~m}, 2 \mathrm{H}), 7.51-7.45$ (m, 4H), 7.22-7.19 (m, 3H), 7.12-7.10 (m, 1H), 7.04-6.93 (m, 6H), 6.89$6.87(\mathrm{~m}, 1 \mathrm{H}), 4.03(\mathrm{~s}, 1 \mathrm{H}) .{ }^{13} \mathrm{C} \mathrm{NMR}\left(400 \mathrm{MHz}, \mathrm{CDCl}_{3}\right) \delta=183.70,146.44,145.27,138.56$, 134.40, 131.92, 128.88, 128.55, 128.53, 128.51, 127.70, 127.51, 127.35, 126.96, 125.96, 78.58, 65.97. m.p. $=144-146{ }^{\circ} \mathrm{C}$. HRMS (ESI-TOF) Calcd for $\mathrm{C}_{27} \mathrm{H}_{20} \mathrm{O}_{2}[\mathrm{M}+\mathrm{H}]^{+}: 377.1542$, Found: 377.1545, FTIR(neat): 3031.93, 2871.04, 1738.15, 1659.64, $1599.59 \mathrm{~cm}^{-1}$

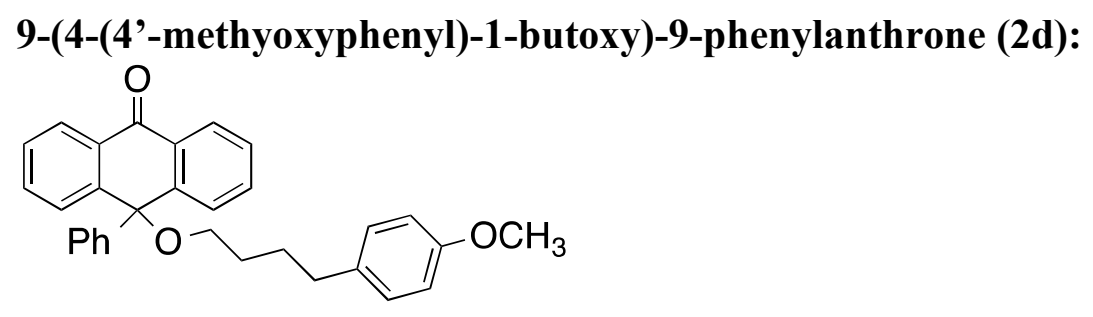

Tritylone alcohol (0.1897 g, $0.663 \mathrm{mmol}), p-\mathrm{TsOH}^{\circ} \mathrm{H}_{2} \mathrm{O}(20.7 \mathrm{mg}, 0.109 \mathrm{mmol})$ and 4-(4'methyoxyphenyl)-1-butanol $(0.130 \mathrm{~mL}, 0.752 \mathrm{mmol})$ was added to $30 \mathrm{~mL}$ of benzene in a $50 \mathrm{~mL}$ round bottom flask. Purified to white crystals with mobile phase of (1:9 ether:petroleum ether) to give $(0.2733 \mathrm{~g}, 92.0 \%)$ of ether. $\mathrm{GC} \mathrm{R}_{\mathrm{T}}$ of ether is 16.6 minutes ${ }^{1} \mathrm{H}$ NMR $\left(400 \mathrm{MHz}, \mathrm{C}_{6} \mathrm{D}_{6}\right) \delta=$ 
8.64-8.61 (dd, $J=1.5,6.0 \mathrm{~Hz}, 2 \mathrm{H}), 7.46-7.43(\mathrm{~m}, 4 \mathrm{H}), 7.04-6.94(\mathrm{~m}, 8 \mathrm{H}), 6.90-6.88(\mathrm{~m}, 1 \mathrm{H})$, 6.82-6.79 (m, 2H), $3.35(\mathrm{t}, J=6.2 \mathrm{~Hz}, 2 \mathrm{H}), 2.39(\mathrm{t}, J=7.4,2 \mathrm{H}), 1.60-1.46(\mathrm{~m}, 4 \mathrm{H}) .{ }^{13} \mathrm{C}$ NMR $\left(400 \mathrm{MHz}, \mathrm{CDCl}_{3}\right) \delta=183.78,157.93,146.74,145.74,134.64,134.17,131.86,129.46,128.82$, $128.43,128.26,127.19,126.82,125.89,113.92,78.02,63.48,55.46,34.87,29.67,28.42$. m.p. $=$ 117-118 ${ }^{\circ} \mathrm{C}$. HRMS (ESI-TOF) Calcd for $\mathrm{C}_{31} \mathrm{H}_{28} \mathrm{O}_{3}[\mathrm{M}+\mathrm{H}]^{+}: 449.2117$, Found: 449.2111, FTIR(neat): 2935.00, 2867.45, 1738.38, 1655.71, $1598.49 \mathrm{~cm}^{-1}$

\section{9-cyclohexoxy-9-phenylanthrone (2e):}

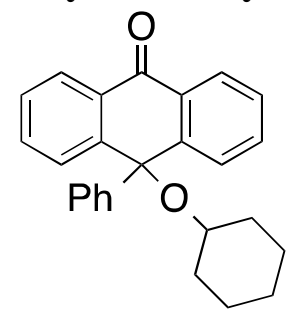

Tritylone alcohol $(0.3175 \mathrm{~g}, 1.11 \mathrm{mmol}), p-\mathrm{TsOH} \cdot \mathrm{H}_{2} \mathrm{O}(36.7 \mathrm{mg}, 0.193 \mathrm{mmol})$ and cyclohexanol $(0.17 \mathrm{~mL}, 1.63 \mathrm{mmol})$ was added to $40 \mathrm{~mL}$ of benzene in a $100 \mathrm{~mL}$ round bottom flask. Purified to white crystals with mobile phase of (1:9 ether:petroleum ether) to give $(0.2529 \mathrm{~g}, 61.8 \%)$ of ether. GC $\mathrm{R}_{\mathrm{T}}$ of ether is 15.8 minutes. ${ }^{1} \mathrm{H}$ NMR $\left(400 \mathrm{MHz}, \mathrm{C}_{6} \mathrm{D}_{6}\right) \delta=8.62-8.60(\mathrm{~m}, 2 \mathrm{H}), 7.48-$ $7.41(\mathrm{~m}, 4 \mathrm{H}), 7.04-6.96(\mathrm{~m}, 7 \mathrm{H}), 3.35-3.30(\mathrm{~m}, 1 \mathrm{H}), 1.53-1.47(\mathrm{~m}, 2 \mathrm{H}), 1.26-1.21(\mathrm{~m}, 4 \mathrm{H}), 1.11-$ $1.06(\mathrm{~m}, 2 \mathrm{H}), 0.842-0.809(\mathrm{~m}, 2 \mathrm{H}) .{ }^{13} \mathrm{C} \mathrm{NMR}\left(400 \mathrm{MHz}, \mathrm{CDCl}_{3}\right) \delta=183.88,147.62,146.50$, $133.59,131.45,130.75,128.30,128.23,126.83,126.73,126.23,77.58,73.10,34.02,25.73$, 24.12. m.p. $=172-175^{\circ} \mathrm{C}$. HRMS (ESI-TOF) Calcd for $\mathrm{C}_{26} \mathrm{H}_{24} \mathrm{O}_{2}[\mathrm{M}+\mathrm{H}]^{+}: 369.1855$, Found: 369.1858, FTIR(neat): 2923.45, 2867.45, 1738.44, 1663.62, $1599.92 \mathrm{~cm}^{-1}$

\section{9-benzhydryloxy-9-phenylanthrone (2f):}

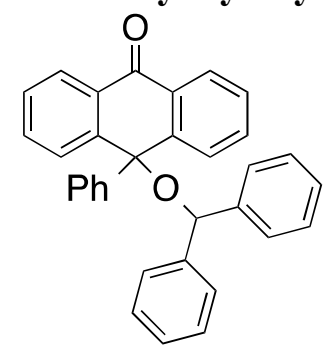

Tritylone alcohol $(0.2180 \mathrm{~g}, 0.761 \mathrm{mmol}), p-\mathrm{TsOH} \cdot \mathrm{H}_{2} \mathrm{O}(30.3 \mathrm{mg}, 0.159 \mathrm{mmol})$ and benzhydrol $(0.1502 \mathrm{~g}, 0.815 \mathrm{mmol})$ was added to $30 \mathrm{~mL}$ of benzene in a $50 \mathrm{~mL}$ round bottom flask. Purified to white crystals with mobile phase of (1:9 ether:petroleum ether) to give $(0.1819 \mathrm{~g}, 52.8 \%)$ of ether. GC $\mathrm{R}_{\mathrm{T}}$ of benzhydrol ether is 17.9 minutes ${ }^{1} \mathrm{H}$ NMR $\left(400 \mathrm{MHz}, \mathrm{CDCl}_{3}\right) \delta=8.29-8.27$ (dd, 
$J=0.96,7.6 \mathrm{~Hz}, 2 \mathrm{H}), 7.52-7.50(\mathrm{~m}, 2 \mathrm{H}), 7.32-7.30(\mathrm{~m}, 4 \mathrm{H}), 7.21-7.04(\mathrm{~m}, 15 \mathrm{H}), 5.16(\mathrm{~s}, 1 \mathrm{H})$.

${ }^{13} \mathrm{C}$ NMR $\left(400 \mathrm{MHz}, \mathrm{CDCl}_{3}\right) \delta=183.73,147.10,144.81,143.30,133.38,131.51,130.93$, $128.48,128.29,128.10,127.06,127.00,126.95,126.61,126.24,79.32,79.28$. m.p. $=148-150$ ${ }^{\circ} \mathrm{C}$. HRMS (ESI-TOF) Calcd for $\mathrm{C}_{33} \mathrm{H}_{24} \mathrm{O}_{2}[\mathrm{M}+\mathrm{H}]^{+}:$453.1855, Found: 453.1851, FTIR(neat): $3026.22,1738.33,1662.50,1599.97 \mathrm{~cm}^{-1}$

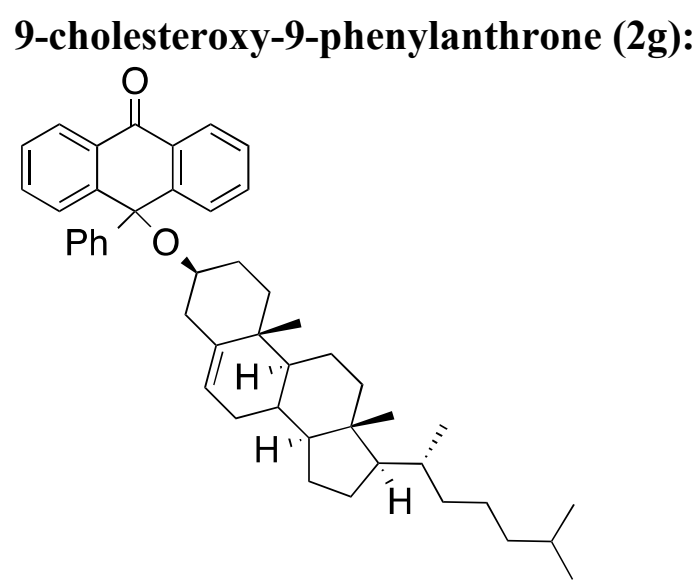

Tritylone alcohol $(0.2400 \mathrm{~g}, 0.838 \mathrm{mmol}), p-\mathrm{TsOH} \cdot \mathrm{H}_{2} \mathrm{O}(30.7 \mathrm{mg}, 0.161 \mathrm{mmol})$ and cholesterol $(0.4973 \mathrm{~g}, 1.29 \mathrm{mmol})$ was added to $50 \mathrm{~mL}$ of benzene in a $100 \mathrm{~mL}$ round bottom flask. Purified clearish/white crystals by recrystallization from hexanes/ethyl acetate to give $(0.2177 \mathrm{~g}, 39.7 \%)$ of ether. A prior column using 1:10 ether:petroleum ether did not completely purify the product ether. Ether did not elute via GC in 20 minutes. ${ }^{1} \mathrm{H}$ NMR (400 MHz, $\left.\mathrm{C}_{6} \mathrm{D}_{6}\right) \delta=8.61-8.58$ (dt, $J=$ 1.9, 7.6 Hz), 7.52-7.47 (m, 4H), 7.08-6.96 (m, 7H), 5.04 (d, $J=5.1 \mathrm{~Hz}, 1 \mathrm{H}), 3.35$ (sep, 1H), 2.55-2.49 (m, 1H), 1.97-1.94 (m, 2H), 1.81-1.78 (m, 2H), 1.63-1.17 (m, 16H), 1.08-0.911 (m, $16 \mathrm{H}), 0.828-0.754(\mathrm{~m}, 1 \mathrm{H}), 0.618-0.543(\mathrm{~m}, 4 \mathrm{H}), 0.485-0.401(\mathrm{~m}, 1 \mathrm{H}) .{ }^{13} \mathrm{C} \mathrm{NMR}(400 \mathrm{MHz}$, $\left.\mathrm{CDCl}_{3}\right) \delta=183.79,147.36,146.55,146.38,140.94,133.60,133.59,131.40,131.35,130.72$, $130.65,128.31,128.24,126.90,126.86,126.76,126.19,121.61,77.61,75.18,56.82,56.21$, $50.03,42.44,41.03,39.86,39.71,37.42,36.50,36.36,35.94,31.95,30.36,28.38,28.20,24.43$, 23.97, 23.02, 22.76, 21.09, 19.43, 18.89, 12.00 (4 peaks not accounted for and could be overlapping with previously mentioned peaks). m.p. $=199-201{ }^{\circ} \mathrm{C}$. HRMS (ESI-TOF) Calcd for $\mathrm{C}_{47} \mathrm{H}_{58} \mathrm{O}_{2}[\mathrm{M}+\mathrm{H}]^{+}:$655.4515, Found: 655.4522, FTIR(neat): 2933.86, 2866.04, 1668.78, 1601.31 $\mathrm{cm}^{-1}$ 


\section{- Gas chromatography analysis of deprotected alcohols}

Ethers 2a and c-g were analyzed for the deprotection of the corresponding alcohol by gas chromatography. For each alcohol a calibration curve was performed and an example of this can be seen below for 1-octanol. Also shown below are representative GC chromatograms for the ethers previously mentioned. Ether $\mathbf{2 b}$ was analyzed by HPLC. 3'-O-acetylthymidine was detected at $260 \mathrm{~nm}$ using a Shimadzu LC-20AT with an SPD-20AV detector and 20 microliter injection loop. An Eclipse Plus C18, 5 micrometer, 4.6 x 155 mm column was used. A flow rate of $0.8 \mathrm{~mL} / \mathrm{min}$ with $75 \%$ methanol and $25 \%$ water. Integration of the alcohol peak was done from $\sim 1.6$ to 2.8 minutes.

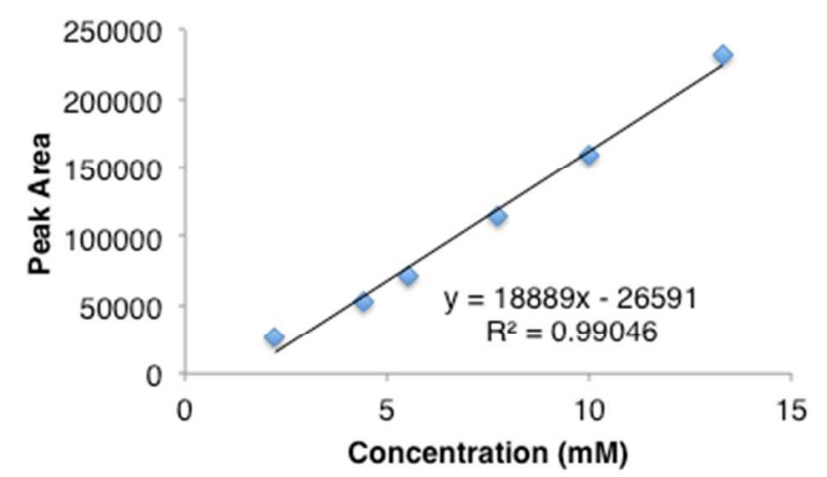

GC calibration curve for 1-octanol

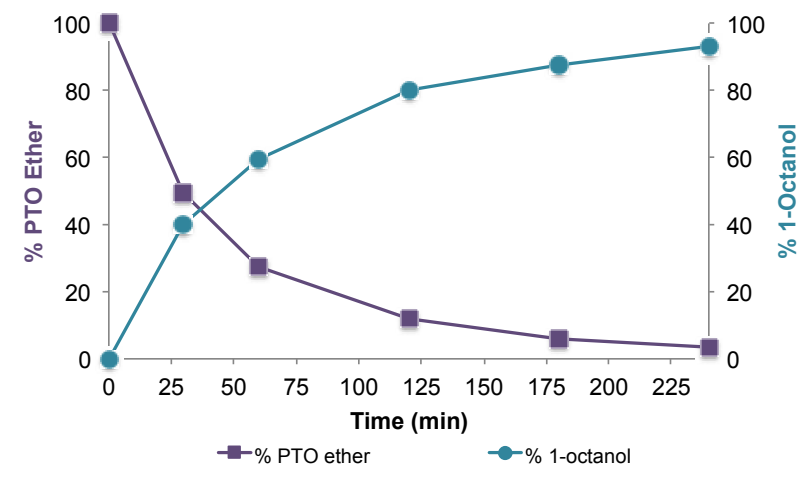

Time course photolysis of $\mathbf{2 a}(13.3 \mathrm{mM})$ and TEA $(28.7 \mathrm{mM})$ at $350 \mathrm{~nm}$. Conversion of $\mathbf{2 a}$ and yield of 1octanol represented as a percent. 


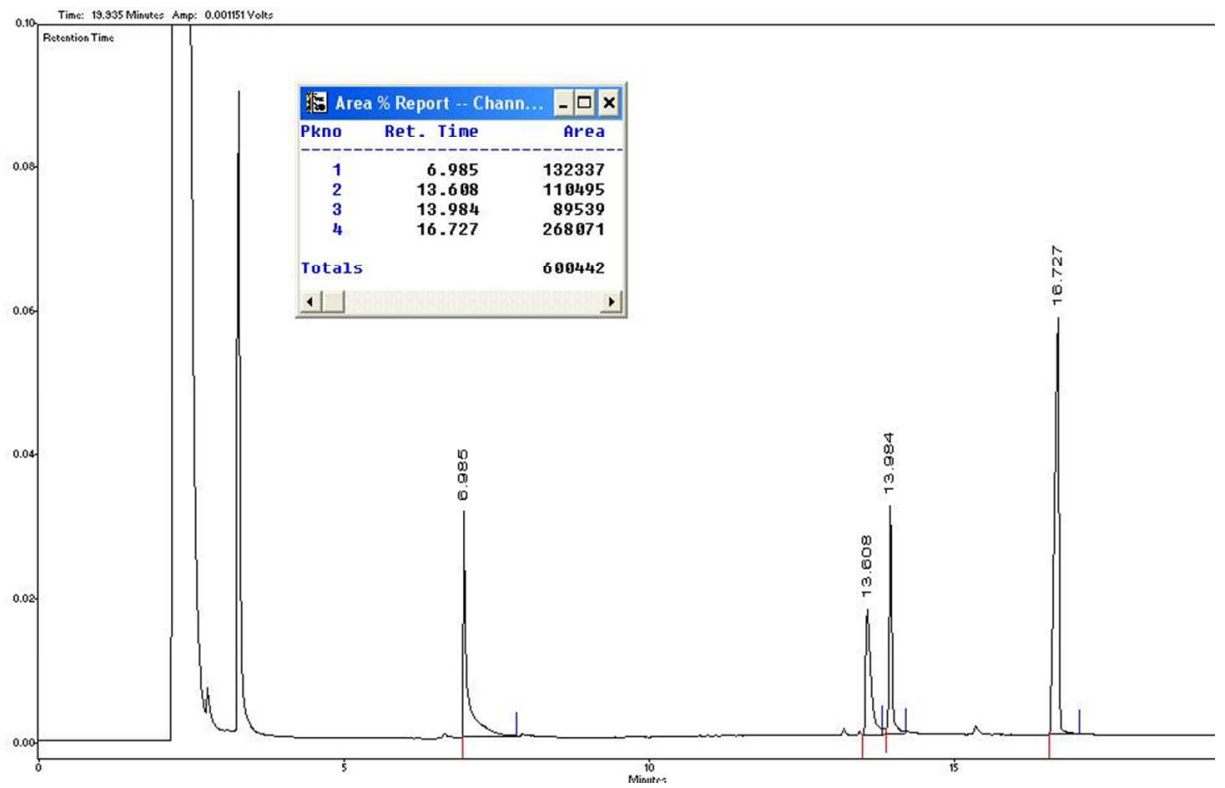

Representative GC chromatogram for the photolysis of octyl ether 2a (11.3 mM) and triethylamine $(28.7 \mathrm{mM})$ for 60 minutes at $350 \mathrm{~nm}$. Peak $\sim 7$ minutes is attributed to 1-octanol and the peak $\sim 16.7$ minutes is attributed to the tritylone ether starting material.

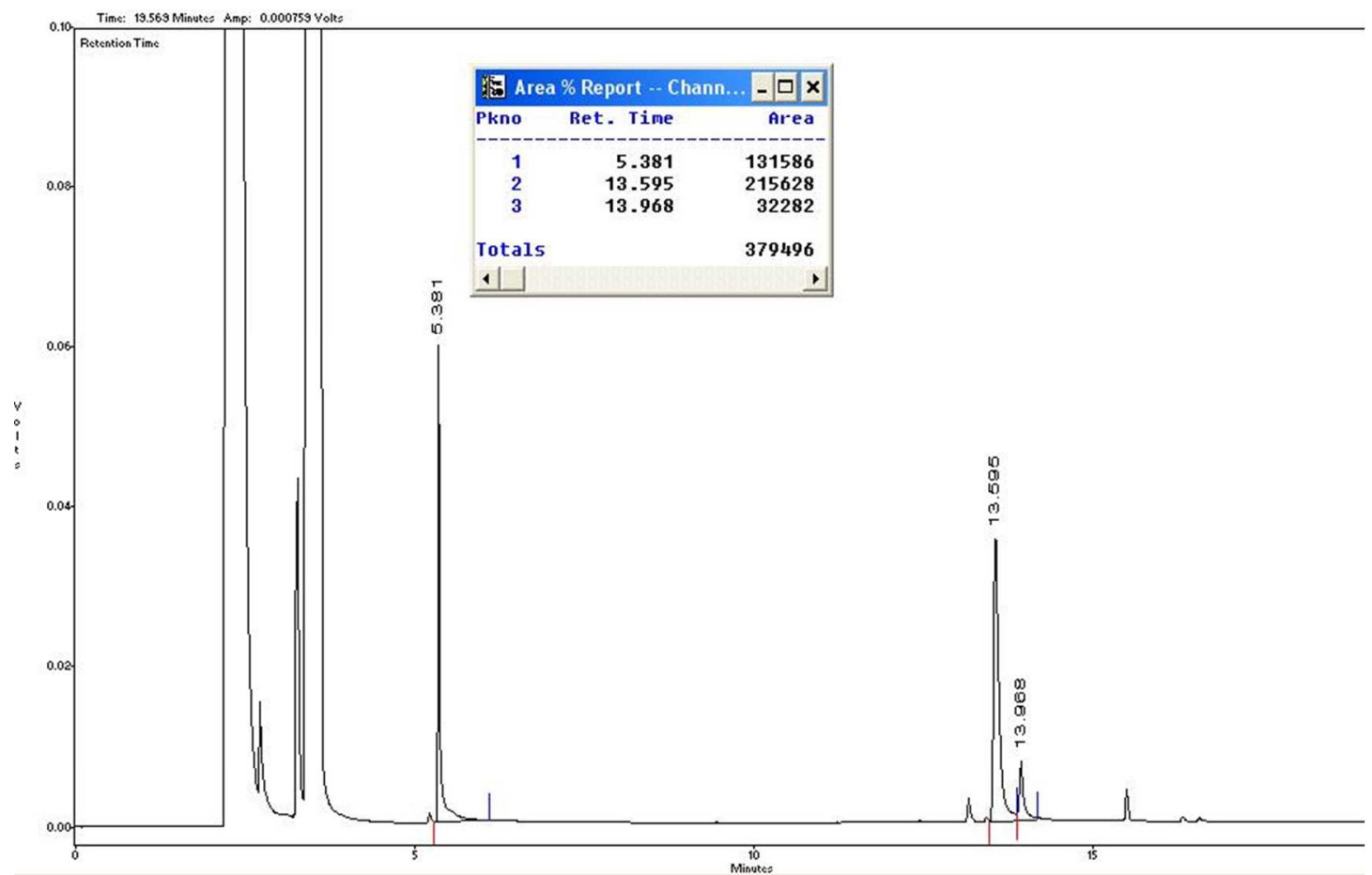

Representative GC chromatogram for the photolysis of cyclohexyl ether $2 \mathbf{e}(11.9 \mathrm{mM})$ and triethylamine $(21.5 \mathrm{mM})$ for 240 minutes at $350 \mathrm{~nm}$. Peak $\sim 5.4$ minutes is attributed to cyclohexanol and the peak $\sim 15.5$ minutes is attributed to the tritylone ether starting material. 


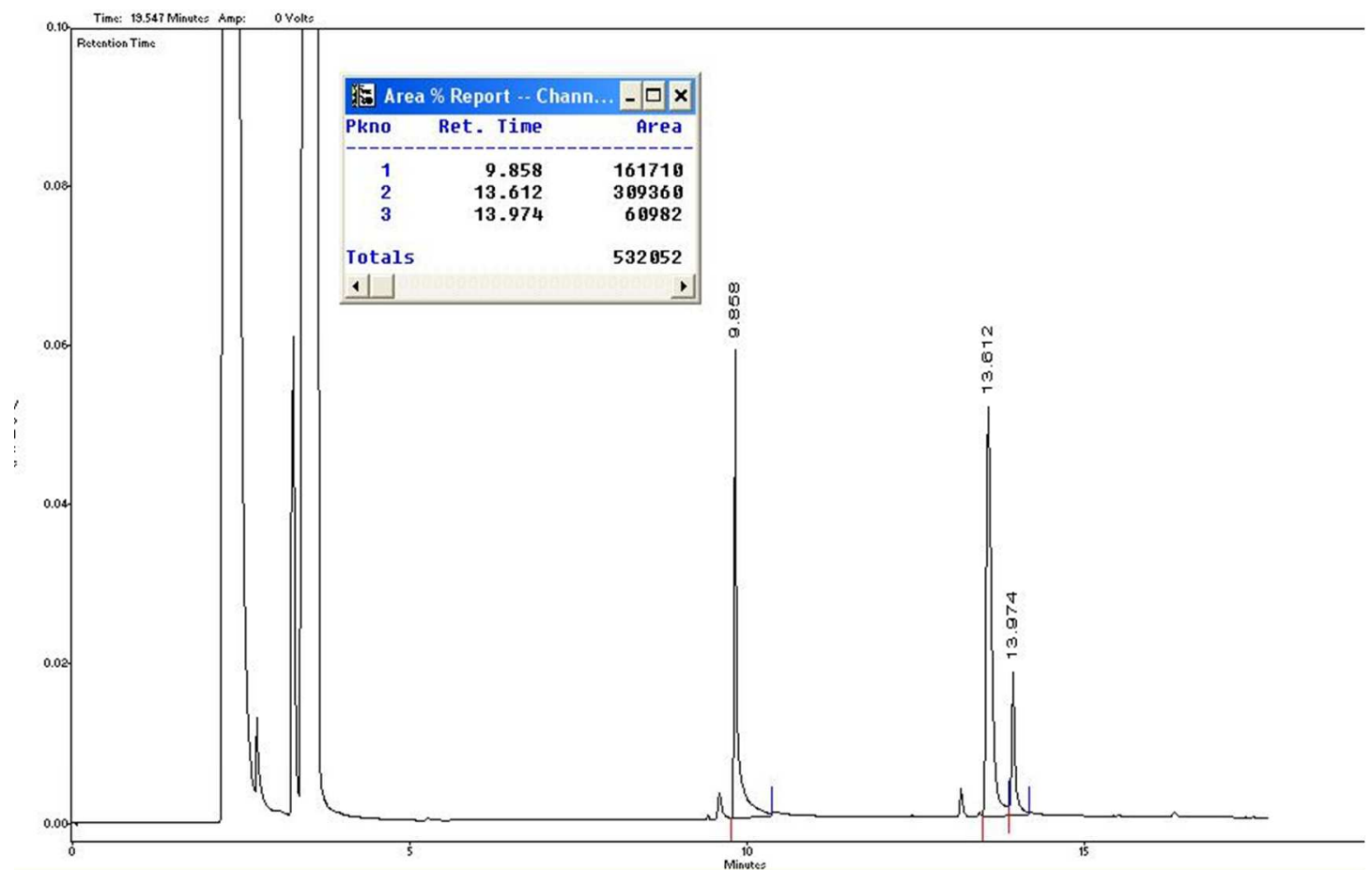

Representative GC chromatogram for the photolysis of 4-(4'-methyoxyphenyl)-1-butanol ether 2d $(11.8 \mathrm{mM})$ and triethylamine $(21.5 \mathrm{mM})$ for 240 minutes at $350 \mathrm{~nm}$. Peak $\sim 9.8$ minutes is attributed to 4-(4'-methyoxyphenyl)-1-butanol and the starting ether peak is not visible.

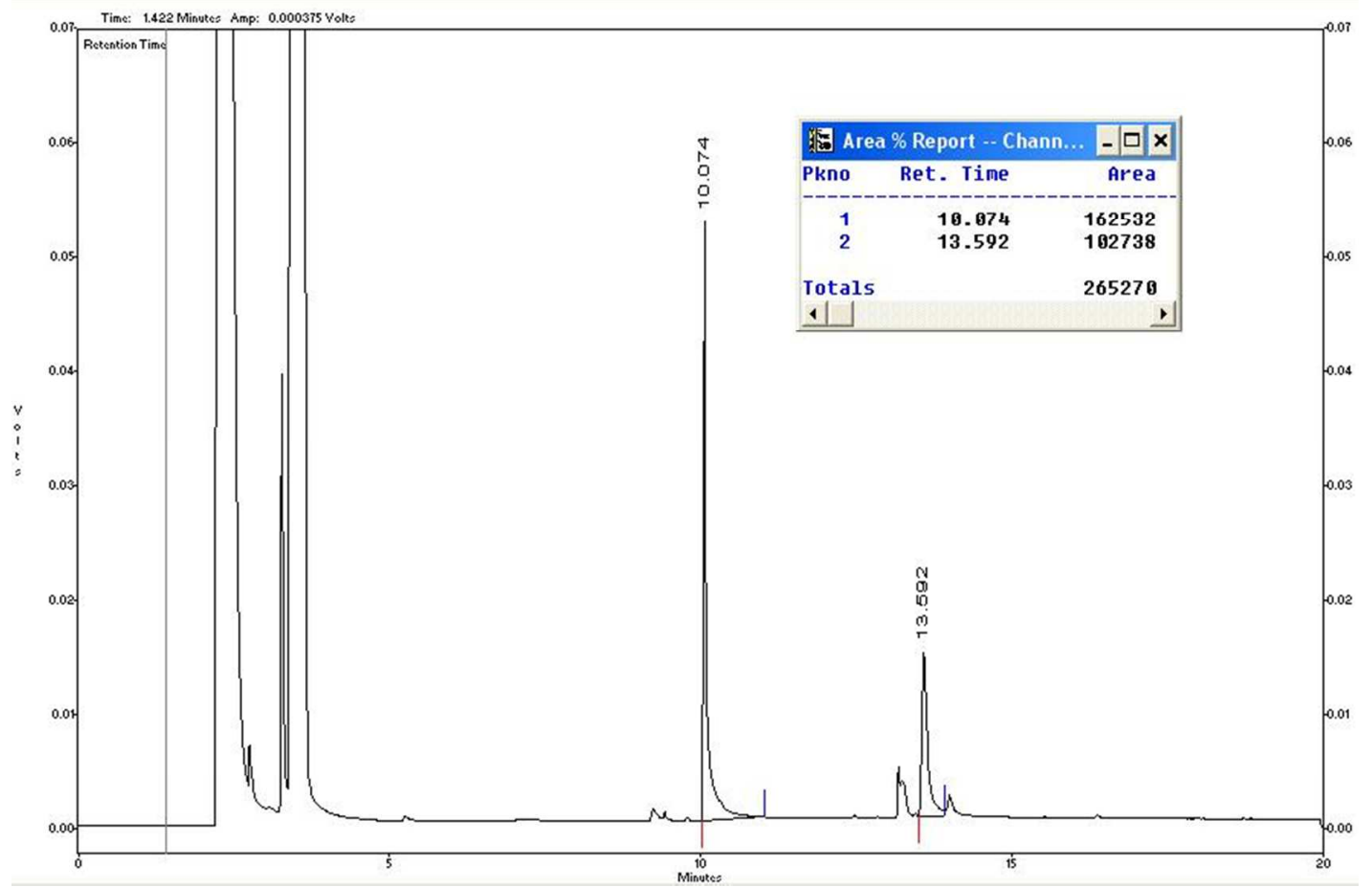

Representative GC chromatogram for the photolysis of benzhydrol ether $\mathbf{2 f}(7.24 \mathrm{mM})$ and triethylamine $(17.9 \mathrm{mM})$ for 240 minutes at $350 \mathrm{~nm}$. Peak $\sim 10$ minutes is attributed to benzhydrol and the starting ether peak is not visible. 


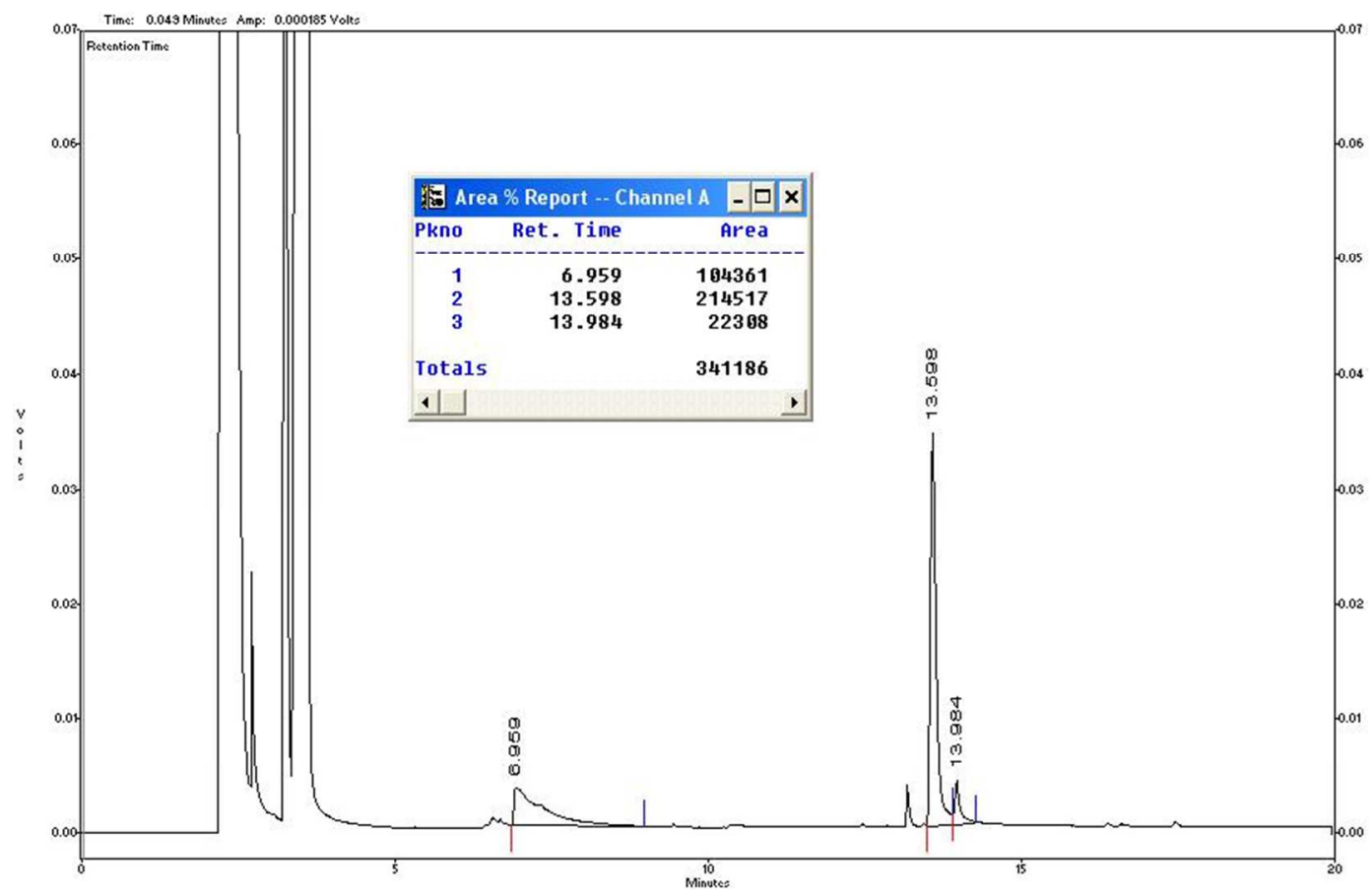

Representative GC chromatogram for the photolysis of benzyl ether $2 \mathrm{c}(8.99 \mathrm{mM})$ and triethylamine $(26.9 \mathrm{mM})$ for 240 minutes at $350 \mathrm{~nm}$. Peak $\sim 7$ minutes is attributed to benzyl alcohol and the starting ether peak is not visible.

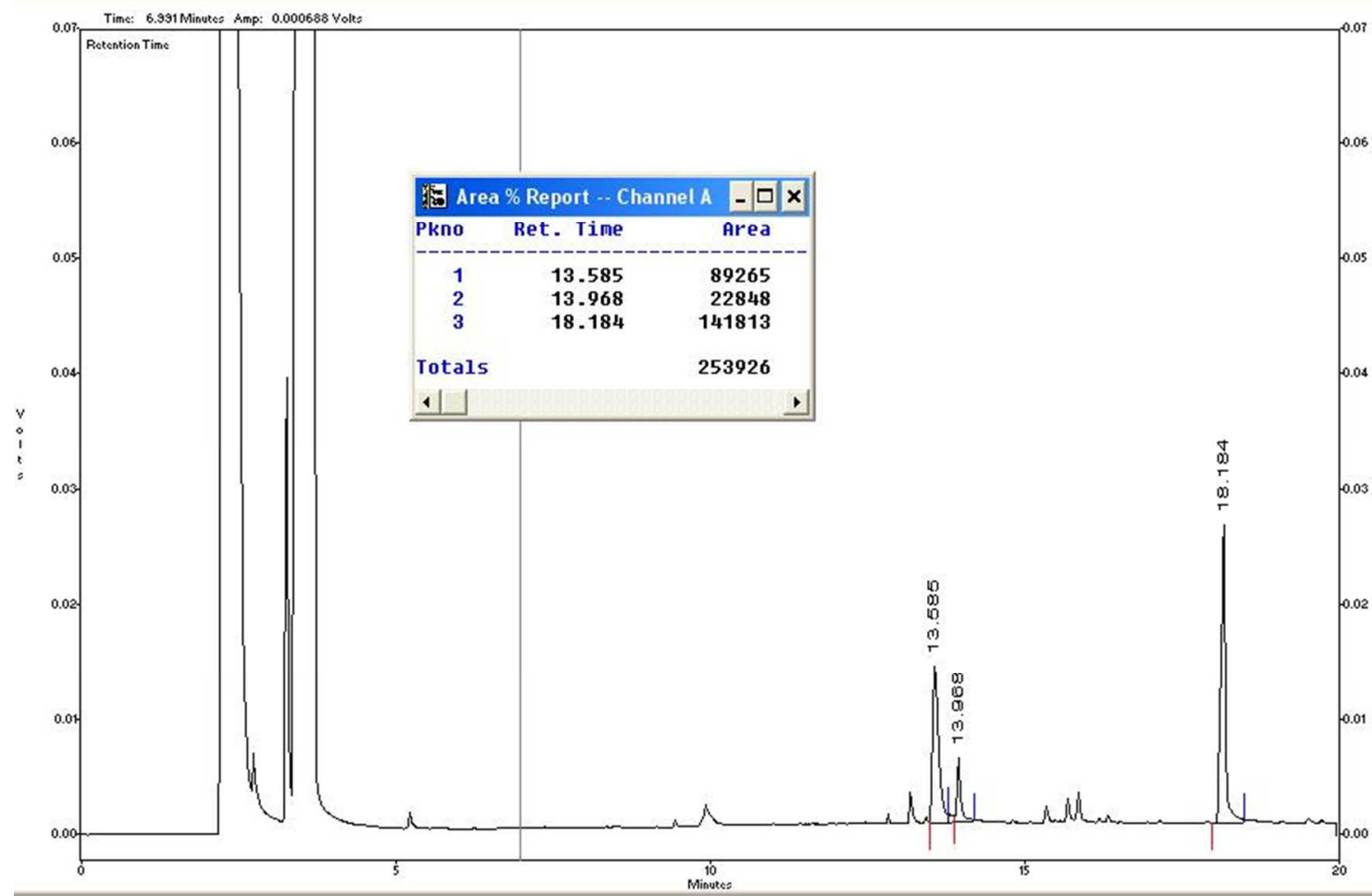

Representative GC chromatogram for the photolysis of cholesterol ether $2 \mathrm{~g}(5.75 \mathrm{mM})$ and triethylamine $(17.9 \mathrm{mM})$ for 240 minutes at $350 \mathrm{~nm}$. Peak $\sim 18.1$ minutes is attributed to cholesterol and the starting ether peak is not visible. 


\section{- Laser Flash Photolysis Results:}

The following laser studies used the benzyl tritylone ether $\mathbf{2 c}$ and were conducted using a $\mathrm{Nd}$ :YAG laser (355 nm output) supplied by Continuum with pulses 4-6 ns in duration as the excitation source. The probe beam that was used was a $350 \mathrm{~W}$ Xe arc lamp that passed through a monochromator to a PMT detector. The solvents used came from the aforementioned commercial sources and used without any purification. Solutions were purged with $\mathrm{N}_{2}$, both in the solution (minimum of 10 minutes) and the headspace (minimum of 3 minutes). For $\mathrm{O}_{2}$ quenching, the septum was removed and exposed to the air for 20 minutes then shaken slightly. The following kinetic decay curves were fitted using MATLAB software. All laser studies were conducted with an ether concentration range of 5 to $8 \mathrm{mM}$, which corresponds to an absorbance of 0.397 to 0.867 at $355 \mathrm{~nm}$ for $4.97 \mathrm{mM}$ and $8.02 \mathrm{mM}$ respectively. For the benzyl ether $2 \mathrm{c}, 5 \%$ 1,4-dioxane was used to aid in the solubility of the ether in methanol.

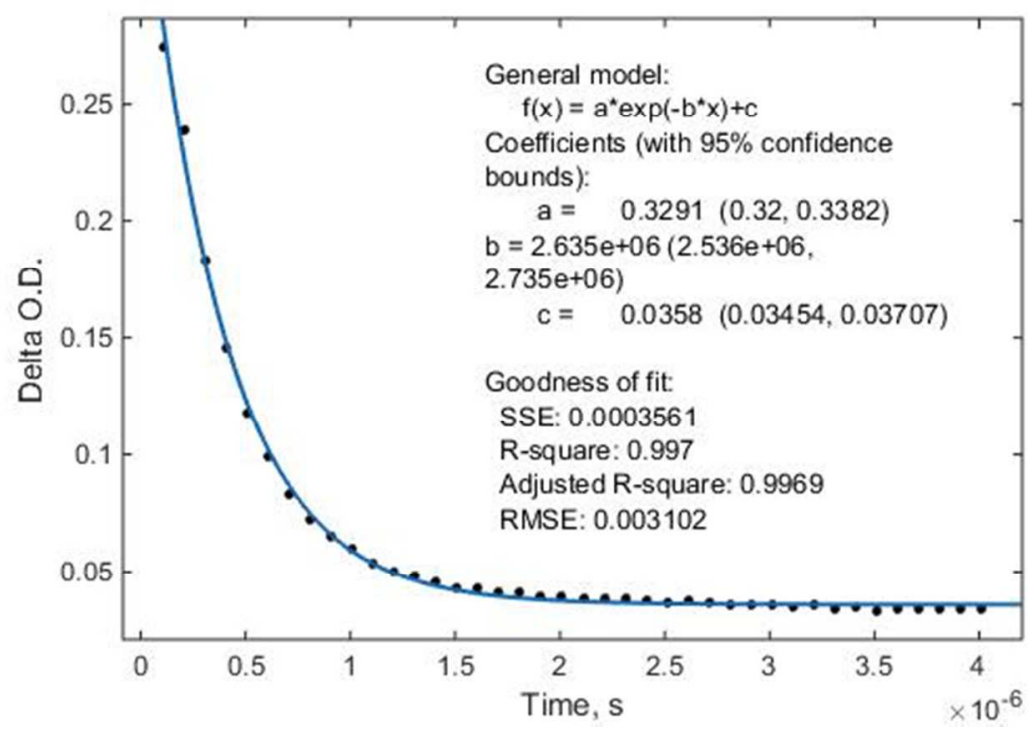

Benzyl Ether 2c in benzene without donor monitored at $530 \mathrm{~nm}$ under $\mathrm{N}_{2}$. 


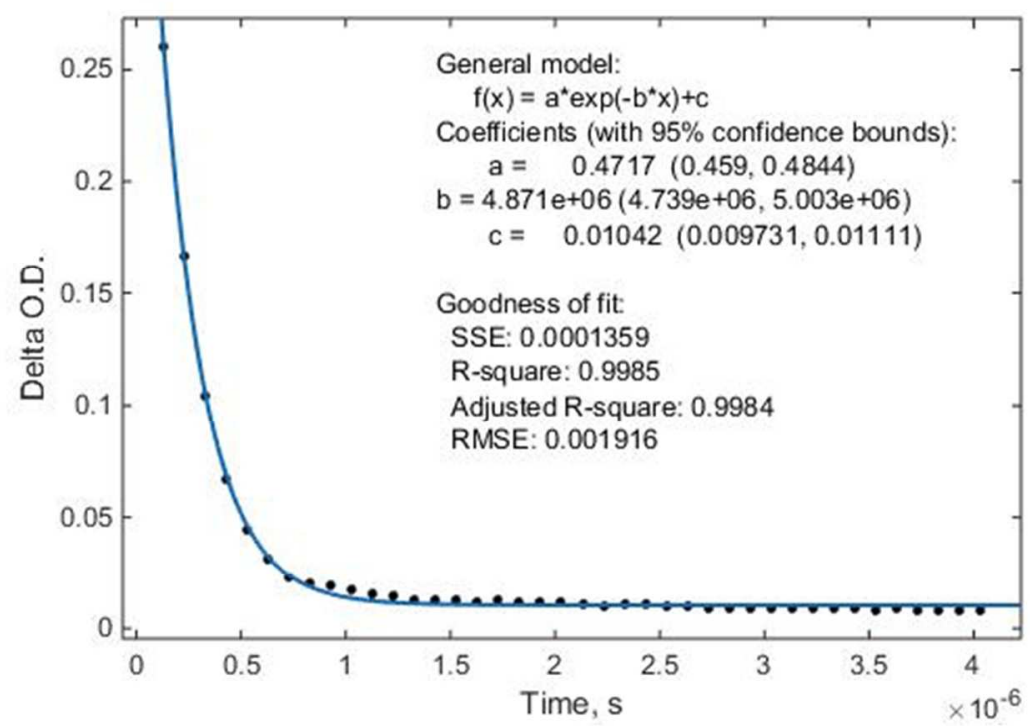

Benzyl Ether $2 \mathbf{c}$ in benzene without donor monitored at $530 \mathrm{~nm}$ under $\mathrm{O}_{2}$.

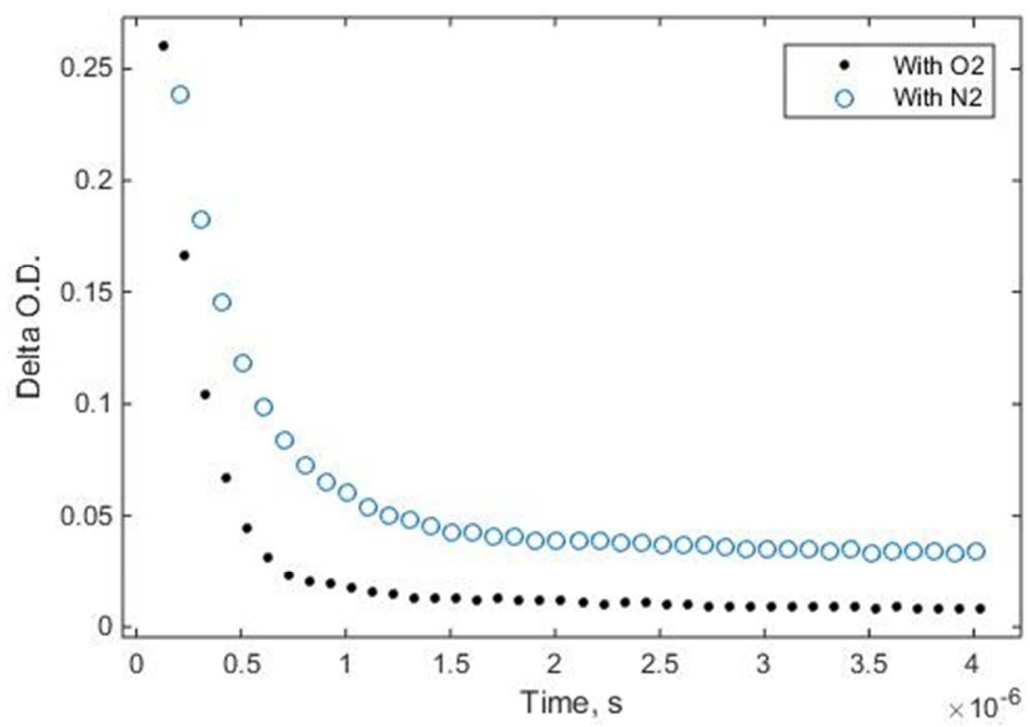

Benzyl Ether 2c in benzene without donor monitored at $530 \mathrm{~nm}$ under $\mathrm{N}_{2}$ and $\mathrm{O}_{2}$ plotted together. 


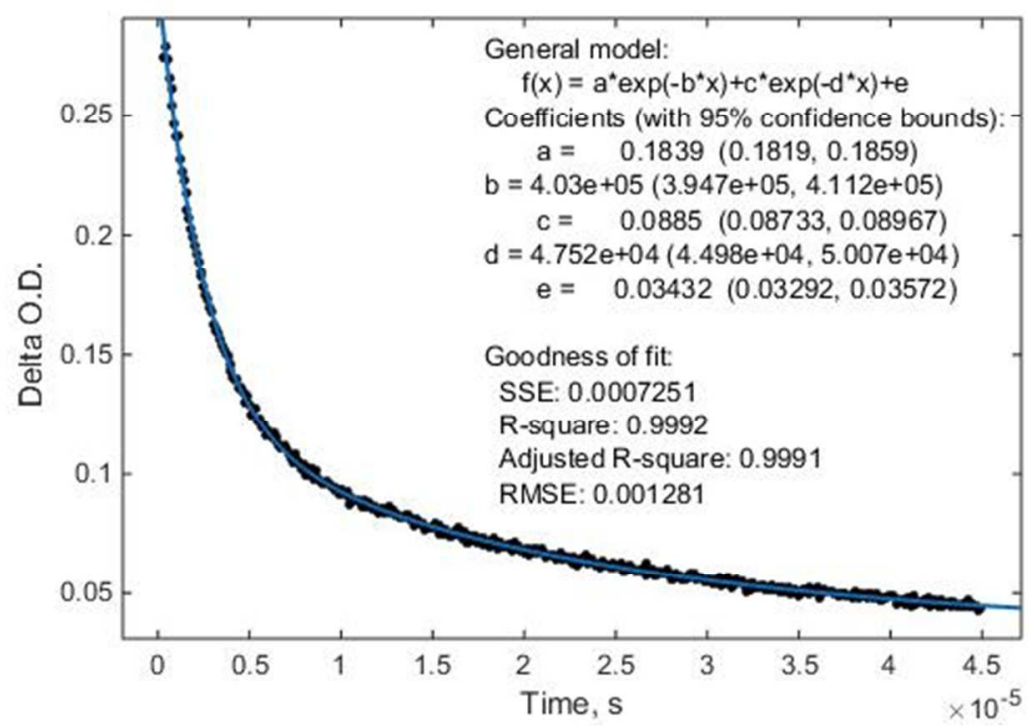

Benzyl Ether $2 \mathrm{c}$ in acetonitrile with triethylamine monitored at $620 \mathrm{~nm}$ under $\mathrm{N}_{2}$.

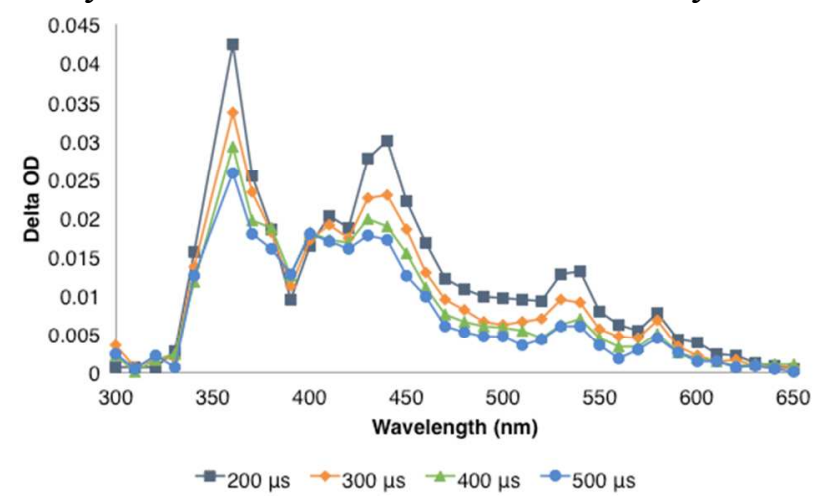

Transient absorption spectrum of benzyl ether $\mathbf{2 c}$ in $\mathrm{MeCN}$ with TEA under $\mathrm{N}_{2}$ at long time scales

\section{- Visible light release of alcohol:}

Photolysis on ether 2a was conducted using a 1-watt, $447 \mathrm{~nm}$ laser provided by Laserglow Technologies and using a 35-watt, $419 \mathrm{~nm}$ maximum output, 16 bulb rayonet reactor supplied by Southern New England Rayonet company. The sample was prepared in a 4-sided, $1 \mathrm{~cm}$ quartz cuvette capped with a septum and purged with $\mathrm{N}_{2}$. The sample using the $447 \mathrm{~nm}$ laser was placed in a temperature controlled cuvette holder at $20^{\circ} \mathrm{C}$ and stirring occurred while being irradiated, while the sample irradiated on the rayonet was not stirred or cooled (temperature reaches approx. 35 degrees Celsius). Approximately, 200 microliter aliquots were taken out of the photolysis solutions at designated times and subjected to gas chromatography for analysis.

For the $447 \mathrm{~nm}$ photolysis: [Octyl Ether 2a] $=9.94 \mathrm{mM}$, [TEA] $=93.2 \mathrm{mM}$ For the $419 \mathrm{~nm}$ photolysis: [Octyl Ether 2a] $=10.3 \mathrm{mM}$, [TEA] $=93.2 \mathrm{mM}$ 
For the $447 \mathrm{~nm}$ photolysis control (NO DONOR): [Octyl Ether 2a] $=10.2 \mathrm{mM}$

The visible light photocatalyst used in these experiments is $f a c$-(tris- $\left(2,2^{\prime}-\right.$ phenylpyridine))iridium(III) and its structure is shown below.

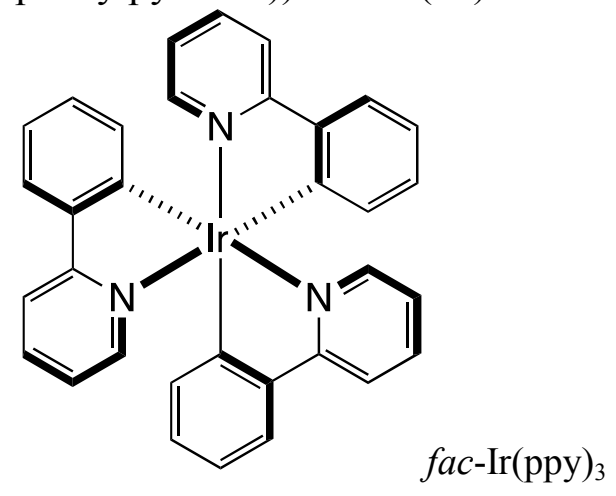

The photocatalyst is difficult to solubilize in solvents like acetonitrile and methanol. For the photolysis reactions, an unknown amount of photocatalyst was solubilized in acetonitrile (essentially saturated) to maximize visible light absorption and transferred to dissolve ether 2a and TEA. The absorbance of the photolysis solutions measured at $419 \mathrm{~nm}$ was 1.298. Based on the diluted absorbance spectrum below (Abs@ $419 \mathrm{~nm}=0.122$ for $0.022 \mathrm{mM}$ ) we estimate the concentration of $f a c-\operatorname{Ir}(\mathrm{ppy})_{3}$ used in the photolysis mixtures at $0.234 \mathrm{mM}(\sim 200 \mu \mathrm{M})$.

\section{Spectroscopic and electrochemical properties of $f a c-\operatorname{Ir}(\mathbf{p p y})_{3}$ :}

Absorption $\lambda_{\max }=375 \mathrm{~nm}, \varepsilon\left(10^{3} \mathrm{M}^{-1} \mathrm{~cm}^{-1}\right)=7.2$

Emission $\lambda_{\max }=494$ (at 77K, in alcoholic solvent), $\phi=0.38, \tau(\mu \mathrm{s})=1.9$

$\mathrm{E}^{00, \mathrm{~d}}(\mathrm{eV})=2.50, \operatorname{Ir}^{\mathrm{IV} / \mathrm{III}}(\mathrm{V})=+0.77, \operatorname{Ir}^{\mathrm{III} / \mathrm{II}}(\mathrm{V})=-2.19$.

Spectroscopic data above provided via: Flamigni, L.; Barbieri, A.; Sabatini, C.; Ventura, B.; Barigelletti, F. Top. Curr. Chem. 2007, 281, 143-203.

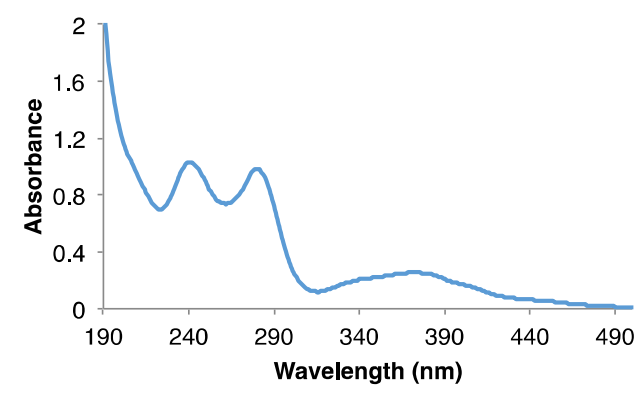

Above is the absorbance spectrum of $f a c$ - $\operatorname{Ir}(\mathrm{ppy})_{3}(0.022 \mathrm{mM})$ solution in acetonitrile. 


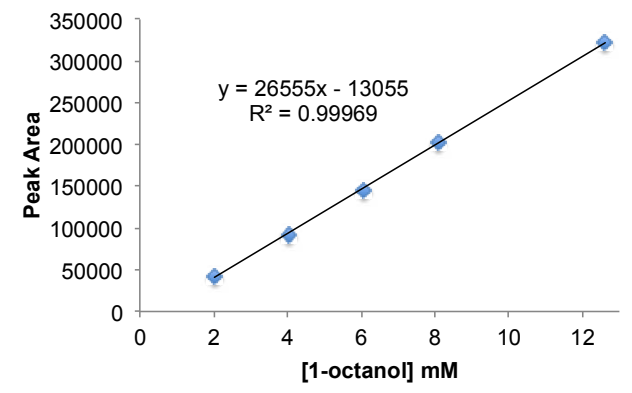

GC calibration curve for visible light release of 1-octanol.

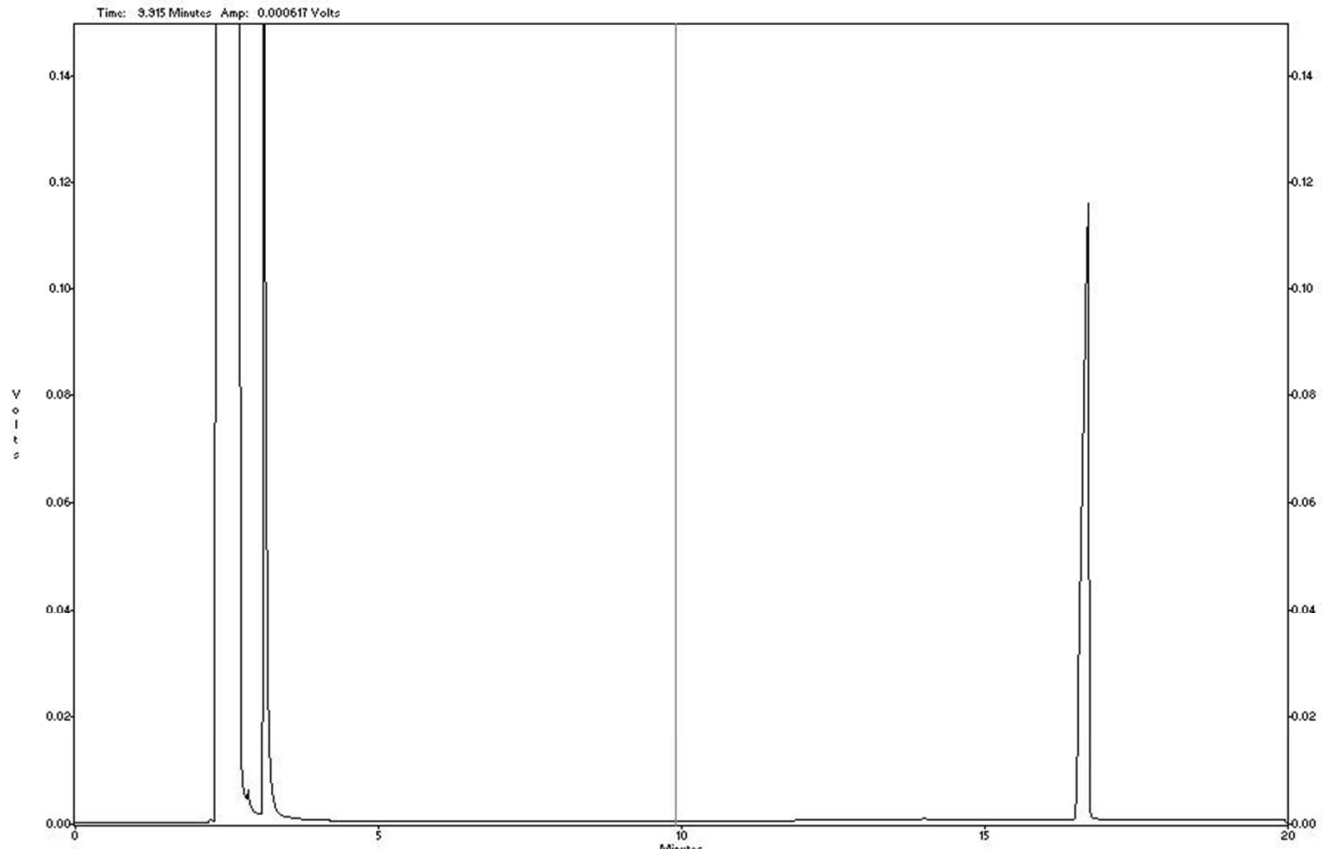

Irradiation using $419 \mathrm{~nm}$ rayonet. Time $=0$ mins (no irradiation). Peak represents octyl ether $2 \mathbf{a}$. 


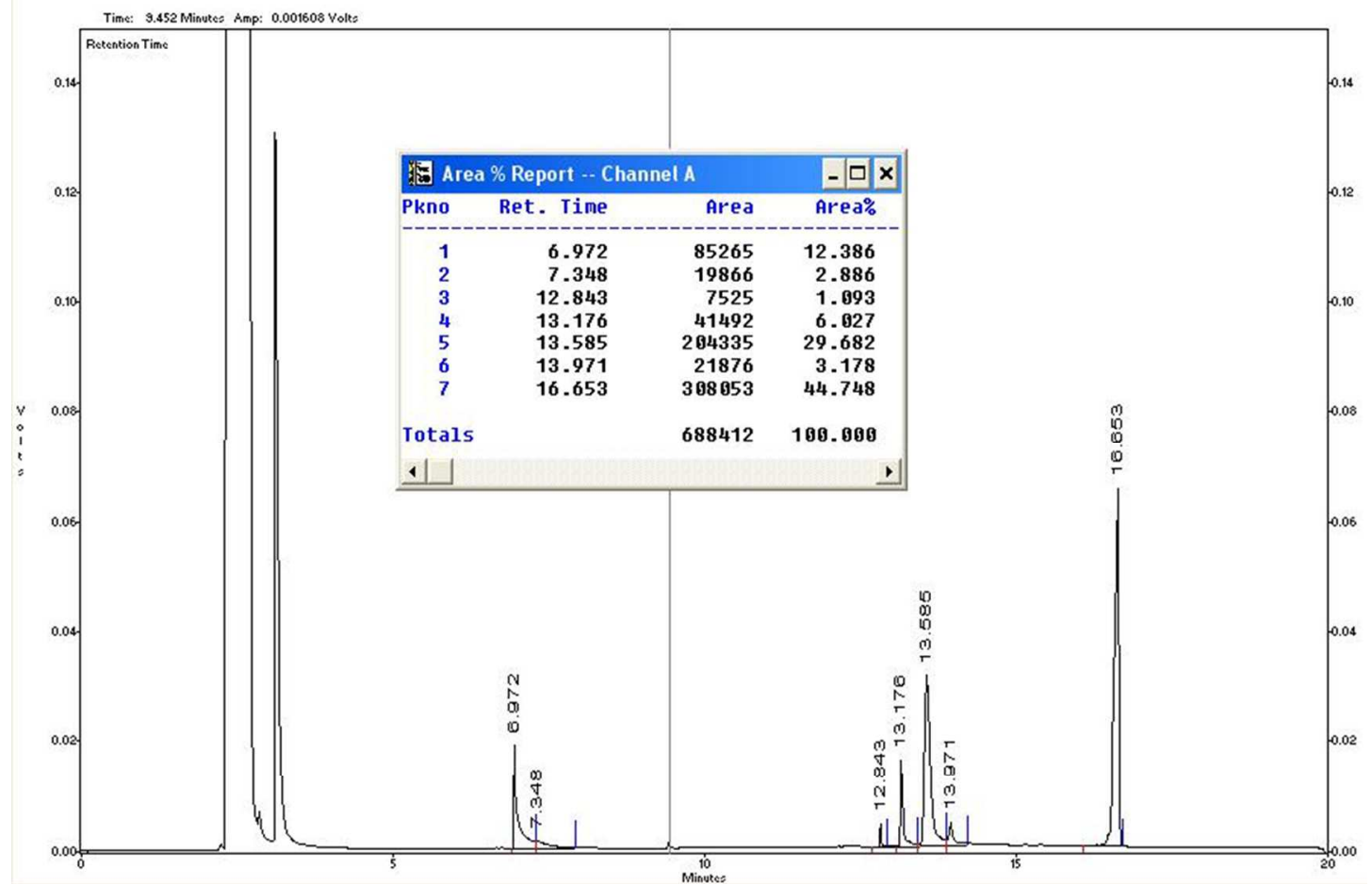

Irradiation using $419 \mathrm{~nm}$ rayonet. Time $=4$ hours. Peak at 7 minutes represents 1 -octanol release.

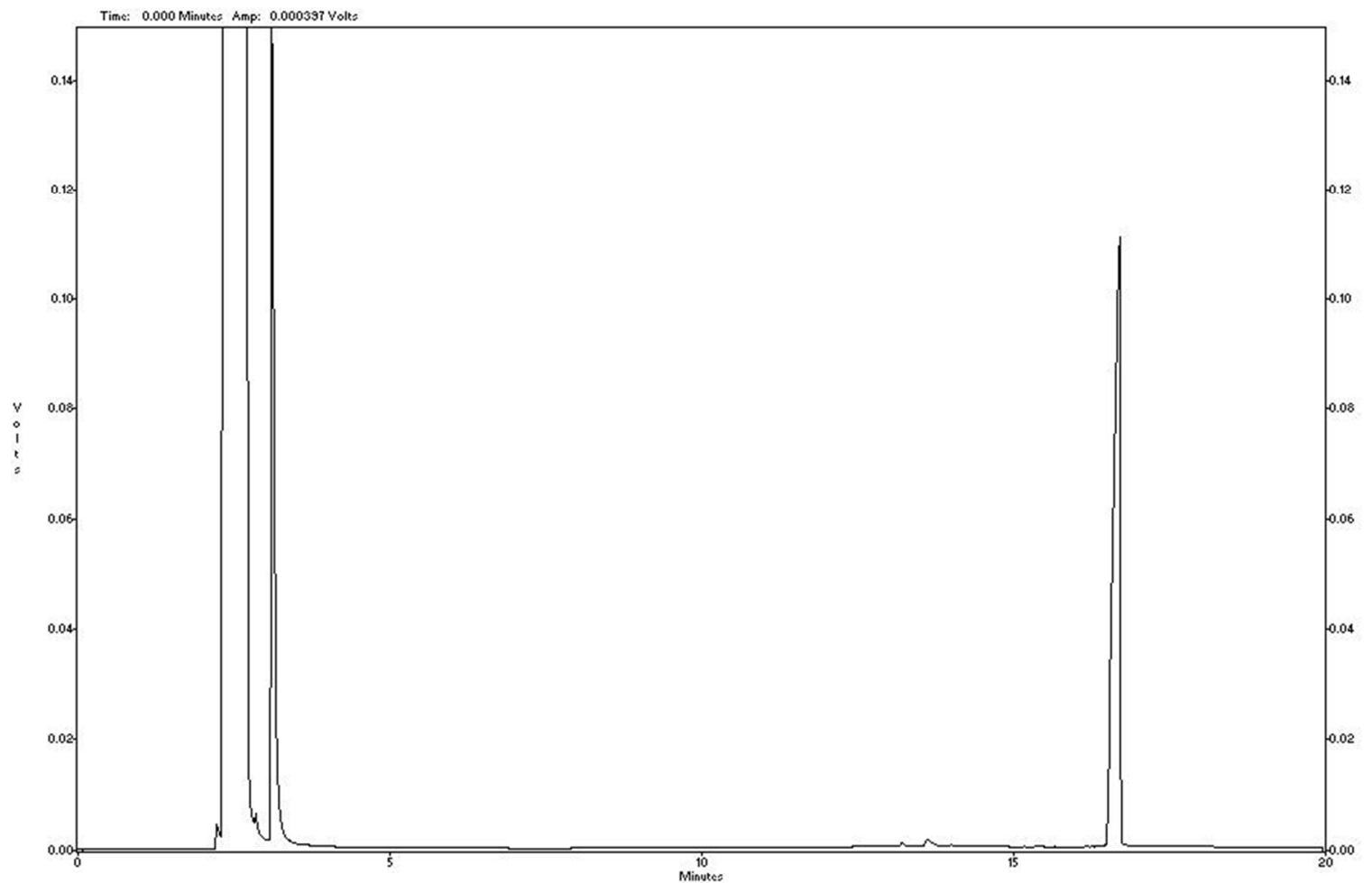

Irradiation using $447 \mathrm{~nm}$ laser. Time $=0 \mathrm{mins}$ (no irradiation). Peak represents octyl ether 2a. 


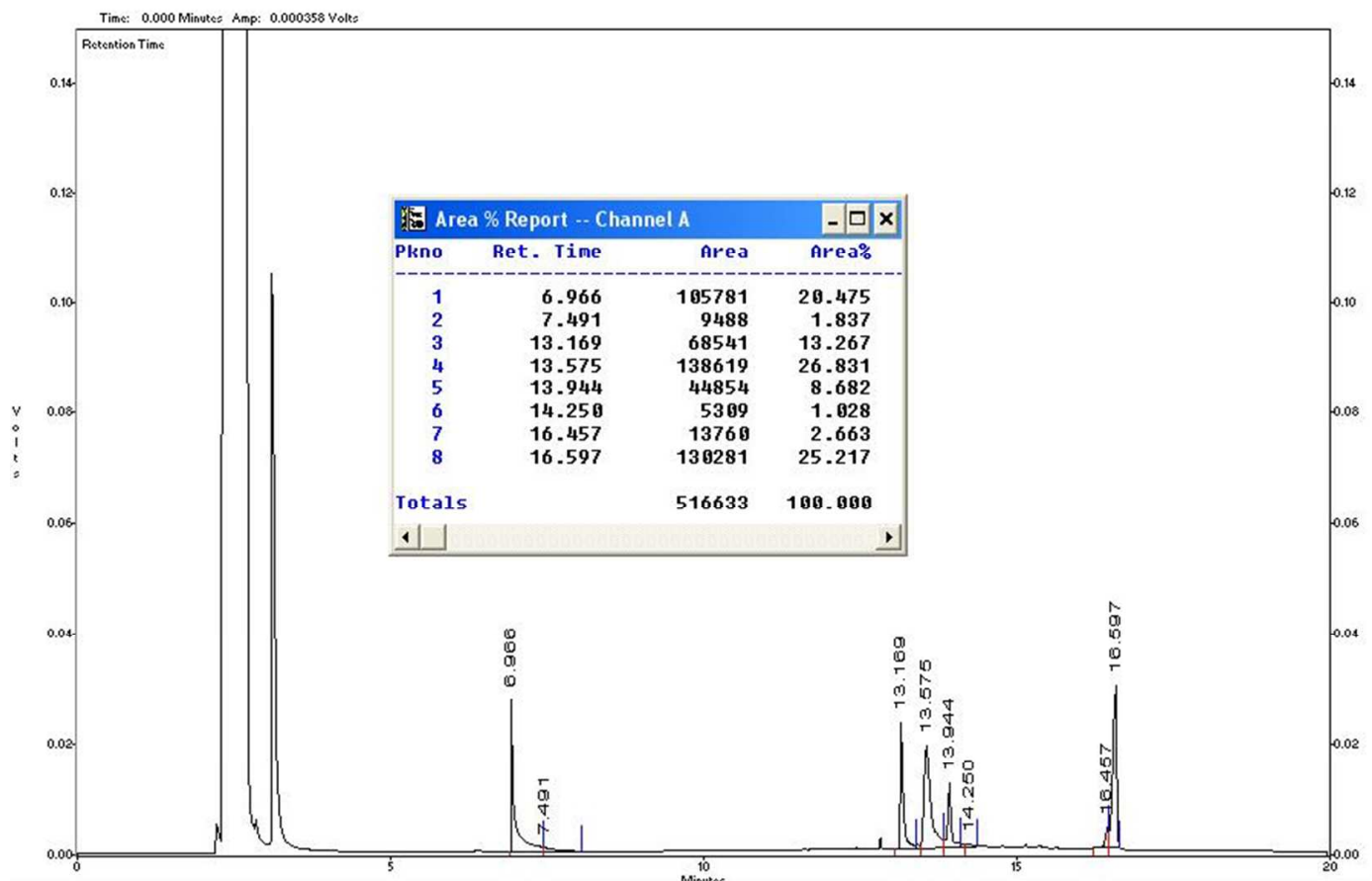

Irradiation using $447 \mathrm{~nm}$. Time $=90$ mins. Peak at 7 minutes represents 1 -octanol release.

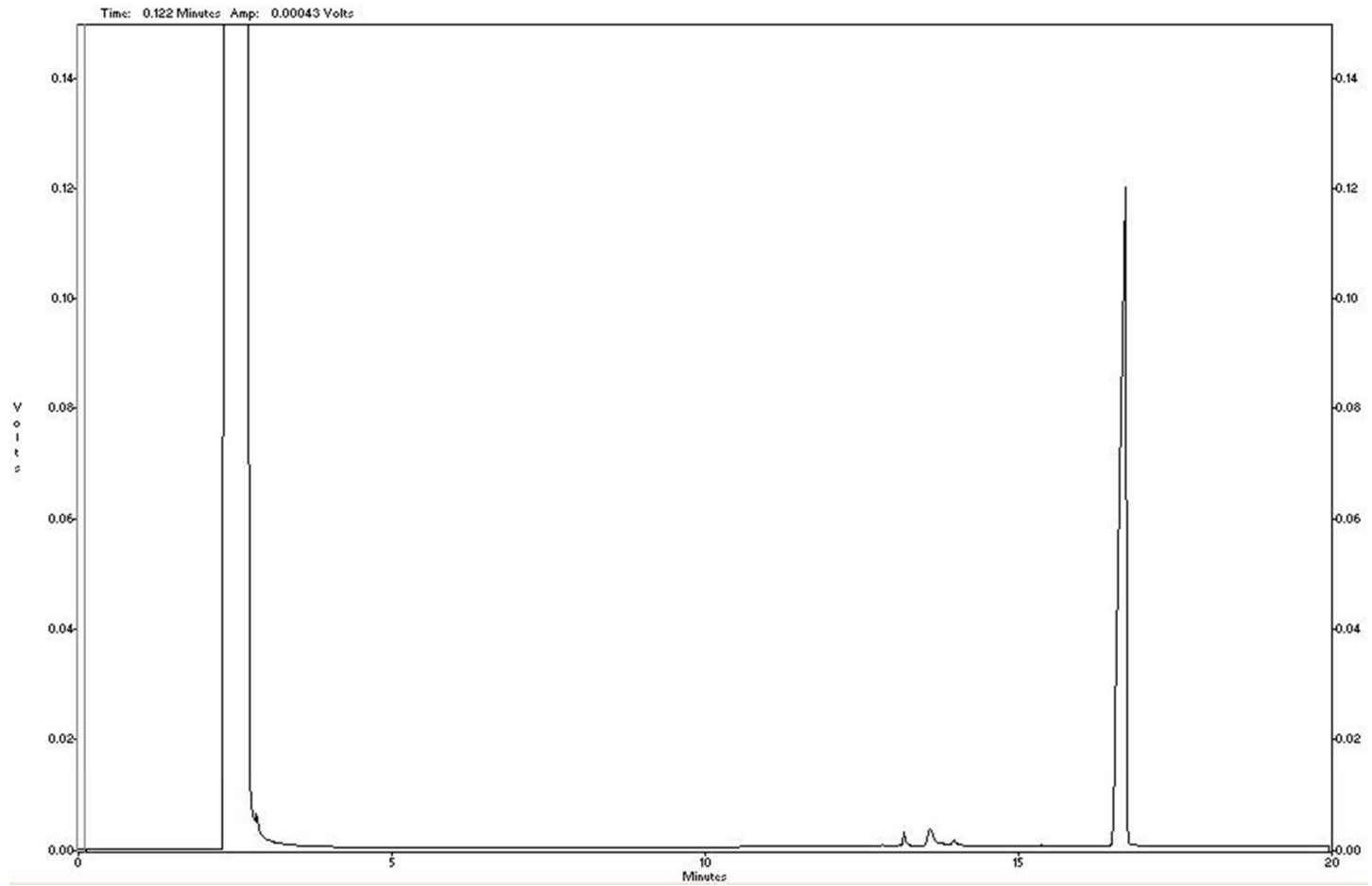

Irradiation using $447 \mathrm{~nm}$. Time $=0$ mins. NO DONOR used in this photolysis. Peak above represents octyl ether $\mathbf{2 a}$. 


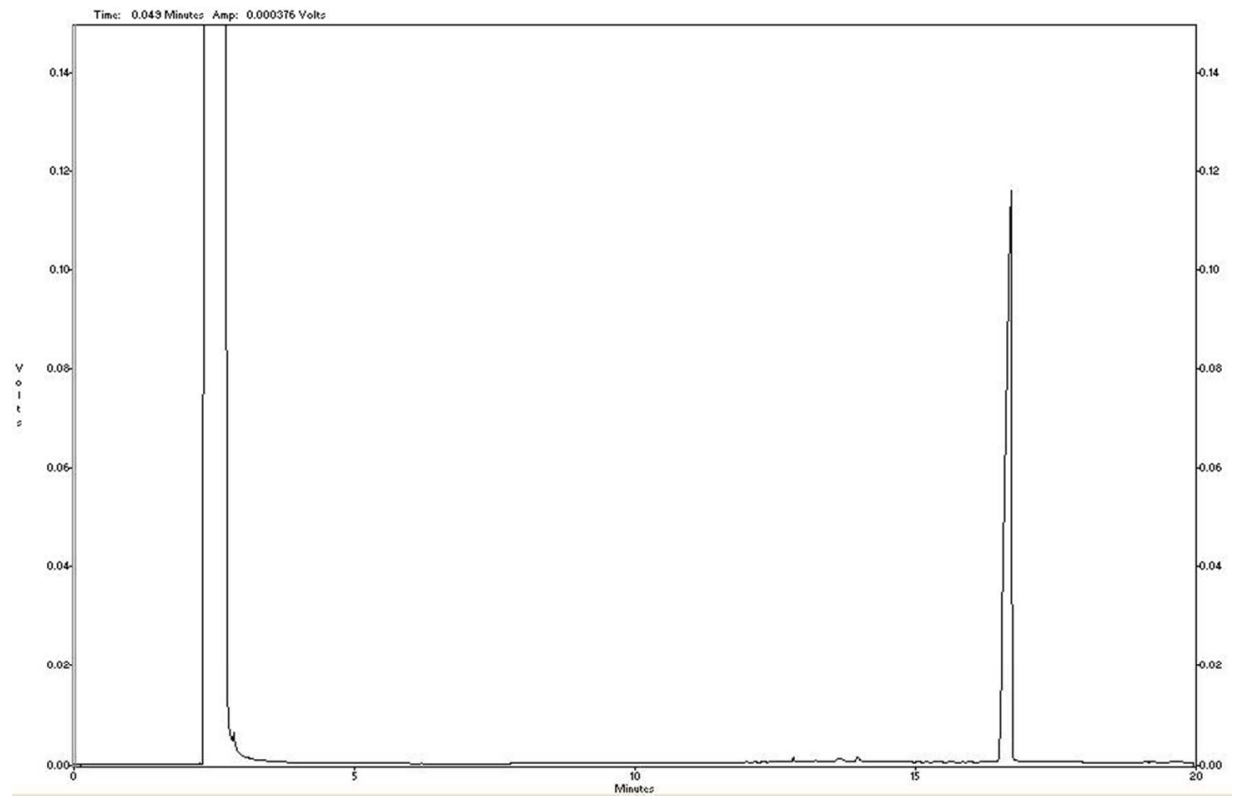

Irradiation using $447 \mathrm{~nm}$. Time $=2$ hours. NO DONOR used in the photolysis. Peak above represents octyl ether 2a. No decomposition of starting material or release of 1-octanol.

Photolysis on ether $\mathbf{2 b}$ was conducted using a 1-watt, $447 \mathrm{~nm}$ laser provided by Laserglow Technologies. The sample was prepared in a 4-sided, $1 \mathrm{~cm}$ quartz cuvette capped with a septum and purged with $\mathrm{N}_{2}$. The sample was placed in a temperature controlled cuvette holder at $20{ }^{\circ} \mathrm{C}$ and stirring occurred while being irradiated. Approximately, 100 microliter aliquots were taken out of the photolysis solution at designated times and subjected to HPLC for analysis. Conditions for analysis and operation were as follows: A Shimadzu LC-20AT with an SPD-20AV detector and 20 microliter injection loop was used. An Eclipse Plus C18, 5 micrometer, 4.6 x 155 mm column was used. A flow rate of $1.0 \mathrm{~mL} / \mathrm{min}$ with an initial ratio of $55 \%$ water and $45 \%$ methanol that linearly decreased the water and increased the methanol to where at 20 minutes it was $100 \%$ methanol. Elution of ether $\mathbf{2 b}$ came at $\sim 14.4$ minutes, tris(bipyridine)ruthenium(II) chloride at $\sim 1.5$ minutes and the deprotected 3'-O-acetylthymidine at $\sim 2.5$ minutes. A calibration curve for the alcohol was used to quantify the amount of deprotection. Detection occurred at 260 nm. 
The visible light photocatalyst used in these experiments is tris(bipyridine)ruthenium(II) chloride and its structure is shown below.
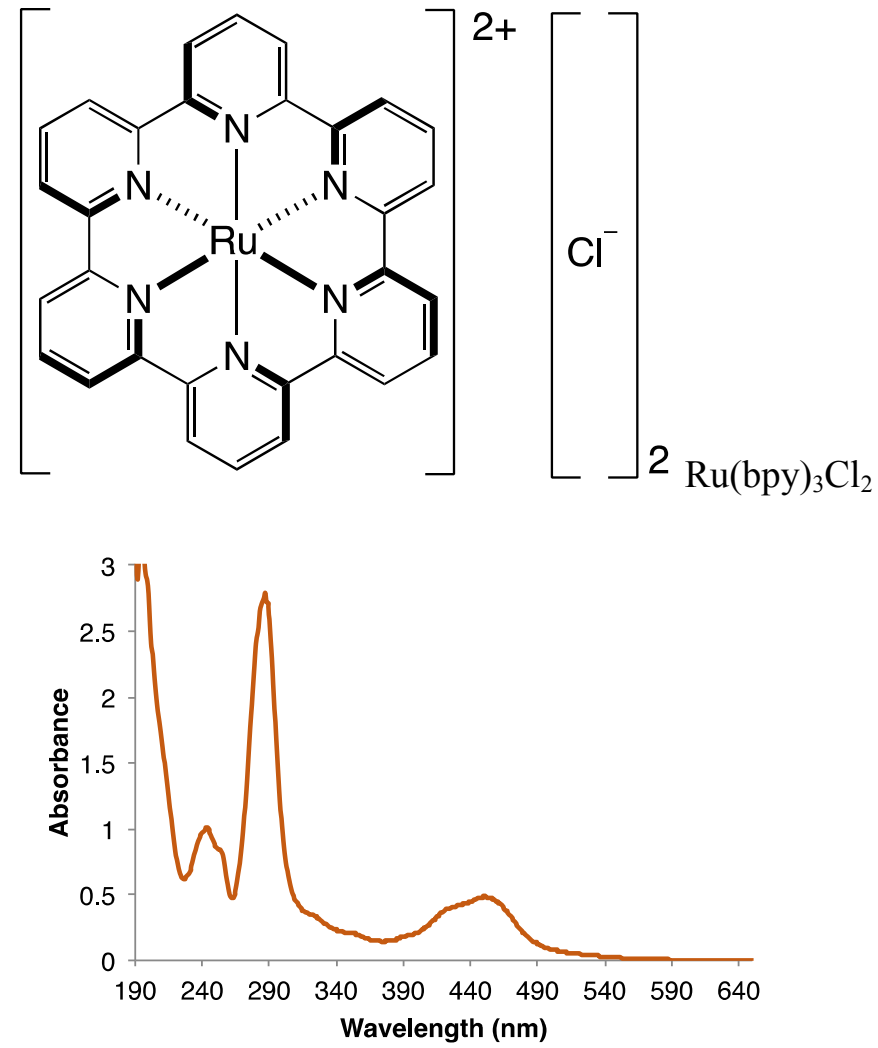

Above is the absorbance spectrum of $\mathrm{Ru}(\mathrm{bpy})_{3} \mathrm{Cl}_{2}(0.035 \mathrm{mM})$ in acetonitrile.

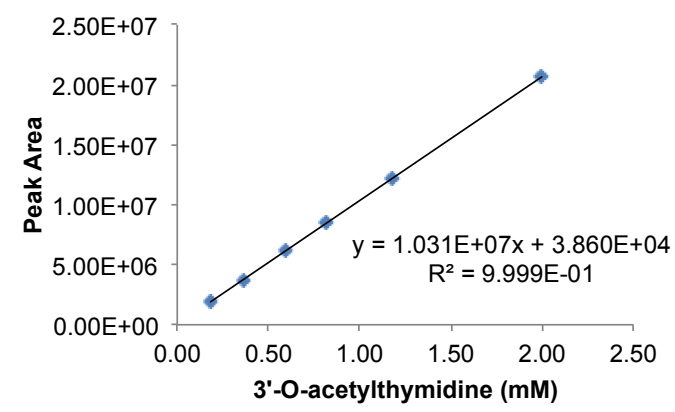


Calibration curve for 3'-O-acetylthymidine (deprotected alcohol).

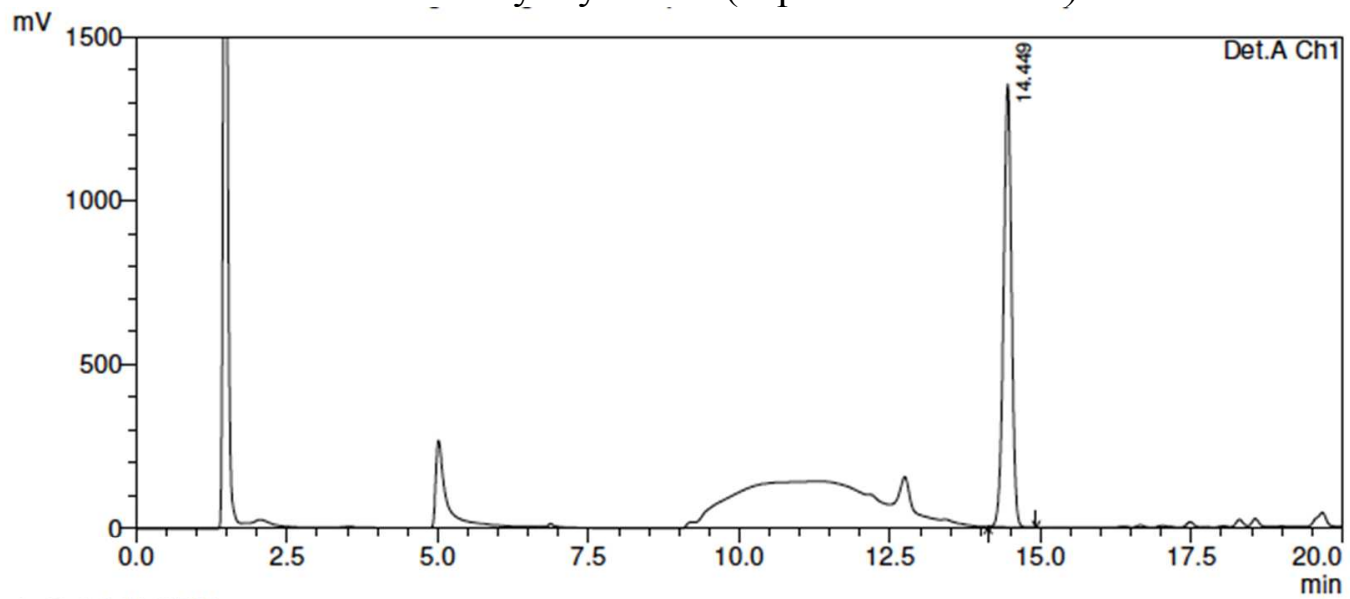

1 Det.A Ch $1 / 260 \mathrm{~nm}$

Detector A Ch1 260nm
\begin{tabular}{|r|c|l|r|r|r|}
\hline Peak\# & Ret. Time & Area & Height & Area \% & Height \% \\
\hline 1 & 14.449 & 12448708 & 1349620 & 100.000 & 100.000 \\
\hline Tota & & 12448708 & 1349620 & 100.000 & 100.000 \\
\hline
\end{tabular}

HPLC chromatogram of ether $\mathbf{2 b}(0.832 \mathrm{mM})$, triethylamine $(0.108 \mathrm{M})$ and tris(bipyridine)ruthenium(II) chloride $(2.11 \mathrm{mM})$ at $\mathrm{t}=0$ minutes.

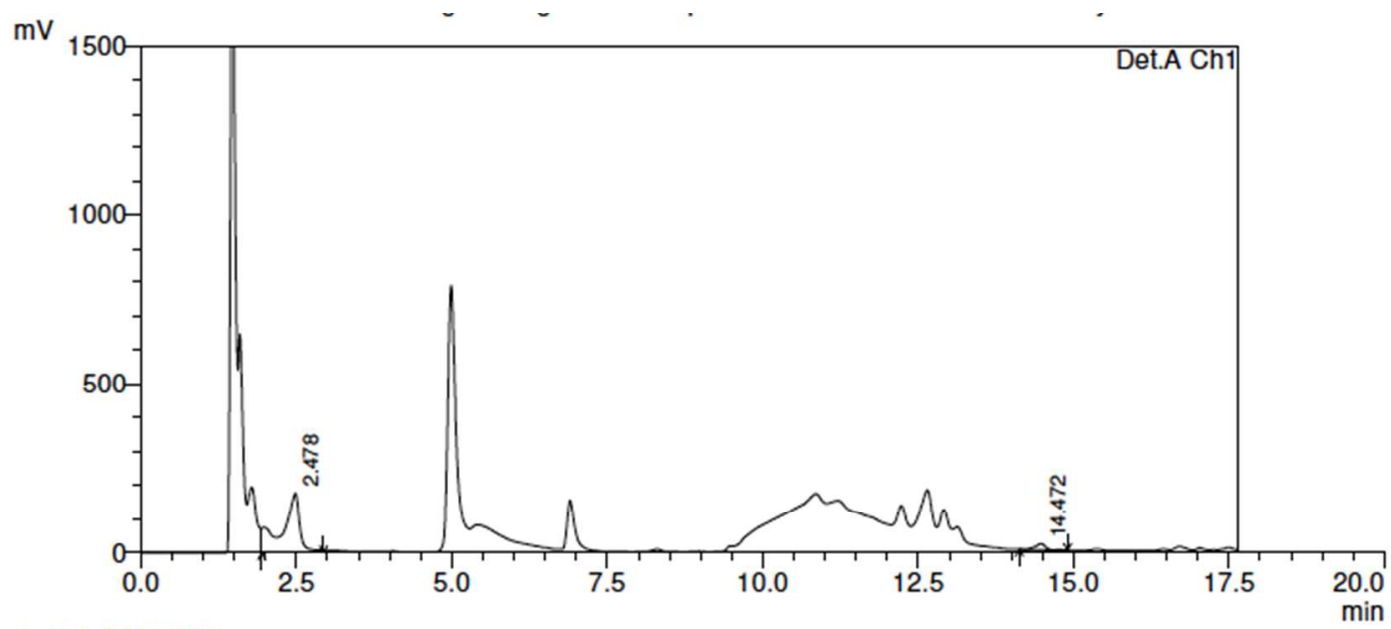

1 Det.A Ch1/260nm

Detector A Ch1 260nm
\begin{tabular}{|r|r|r|r|r|r|}
\hline Peak\#t & Ret. Time & \multicolumn{1}{|c|}{ Area } & Height & Area $\%$ & \multicolumn{1}{|c|}{ Height $\%$} \\
\hline 1 & 2.478 & 3600364 & 179049 & 94.763 & 90.901 \\
\hline 2 & 14.472 & 198988 & 17922 & 5.237 & 9.099 \\
\hline Total & & 3799352 & 196971 & 100.000 & 100.000 \\
\hline
\end{tabular}

HPLC chromatogram of ether $\mathbf{2 b}(0.832 \mathrm{mM})$, triethylamine $(0.108 \mathrm{M})$ and tris(bipyridine)ruthenium(II) chloride $(2.11 \mathrm{mM})$ at $\mathrm{t}=20$ minutes. 


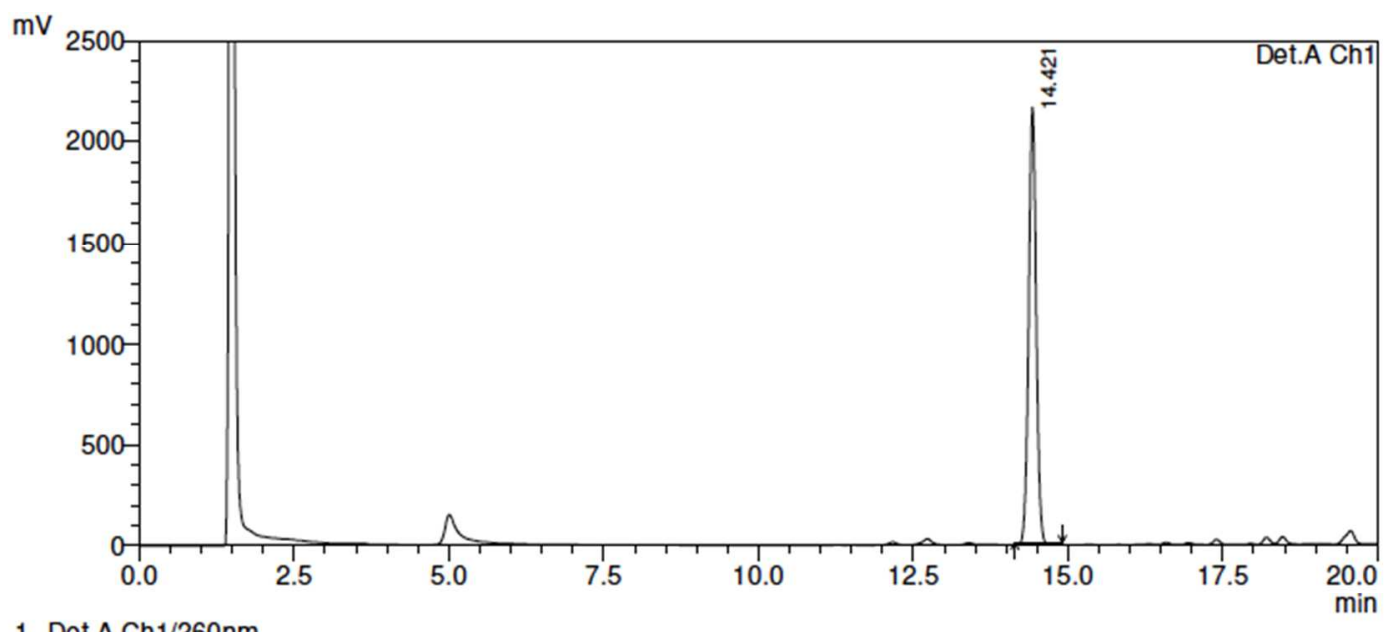

1 Det.A Ch1/260nm

PeakTable
\begin{tabular}{|r|c|c|r|r|r|}
\hline \begin{tabular}{|l} 
Detector A Ch1 260nm \\
\hline Peak\#
\end{tabular} Ret. Time & Area & Height & Area \% & Height \% \\
\hline 1 & 14.421 & 17800873 & 2156108 & 100.000 & 100.000 \\
\hline Total & & 17800873 & 2156108 & 100.000 & 100.000 \\
\hline
\end{tabular}

HPLC chromatogram of the same photolysis at $\mathrm{t}=0$ minutes, however no triethylamine was used in this photolysis.

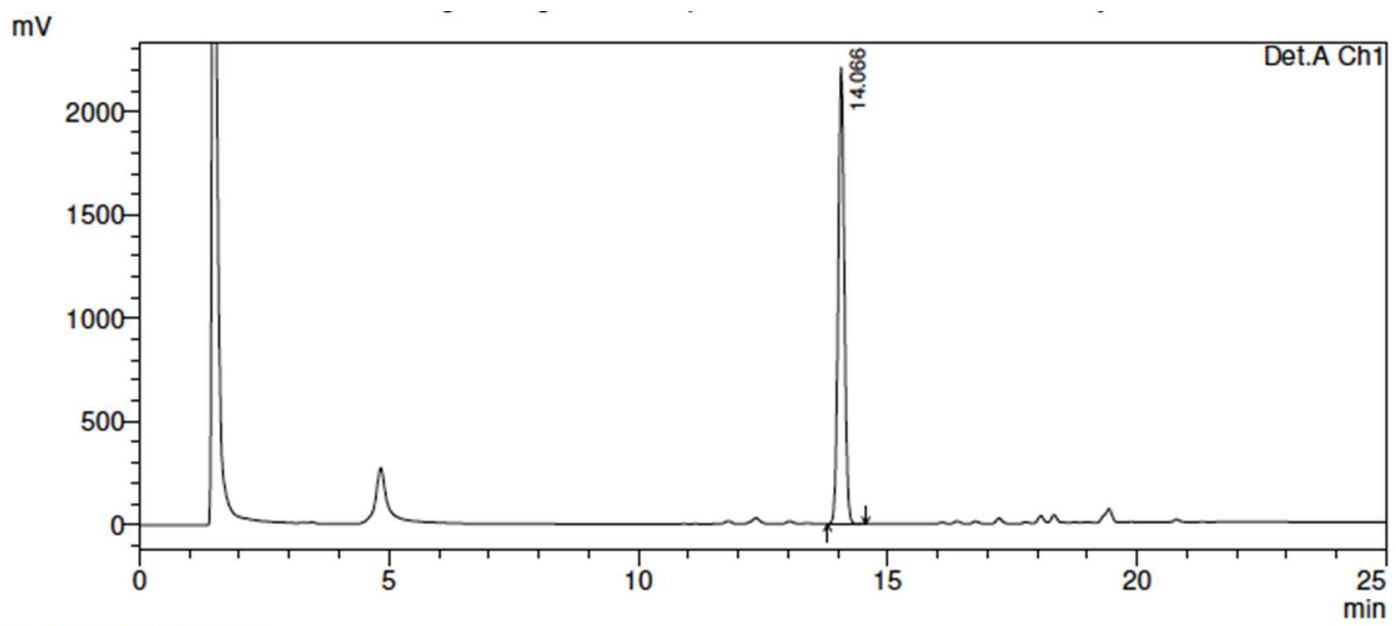

1 Det.A Ch1/260nm

PeakTable

Detector A Ch1 260nm
\begin{tabular}{|r|r|r|r|r|r|}
\hline Peak\# & Ret. Time & \multicolumn{1}{l|}{ Area } & Height & Area \% & Height \% \\
\hline 1 & 14.066 & 18909224 & 2208297 & 100.000 & 100.000 \\
\hline Total & & 18909224 & 2208297 & 100.000 & 100.000 \\
\hline
\end{tabular}

HPLC chromatogram at $\mathrm{t}=20$ minutes when no triethylamine was used in the photolysis. No conversion of the starting material ether and no yield of deprotected alcohol.

Below is the GC calibration curve for 4-(4'-methyoxyphenyl)-1-butanol and the subsequent photolysis time course for ether $\mathbf{2 d}$. Using the same concentration of $\operatorname{Ir}(\mathrm{ppy})_{3}$ as noted above, as well as the same $447 \mathrm{~nm}$ source the concentration of alcohol was monitored over time by GC. Starting concentration of $\mathbf{2 d}=8.58 \mathrm{mM}$. Starting concentration of TEA was $47.3 \mathrm{mM}$. The 
solution was irradiated in $\mathrm{MeCN}$ in a sealed quartz cuvette at 20 degrees Celsius and purged under $\mathrm{N}_{2}$ atmosphere. Approximately 200 microliters were taken out of the stock photolysis solution and subjected to GC analysis.
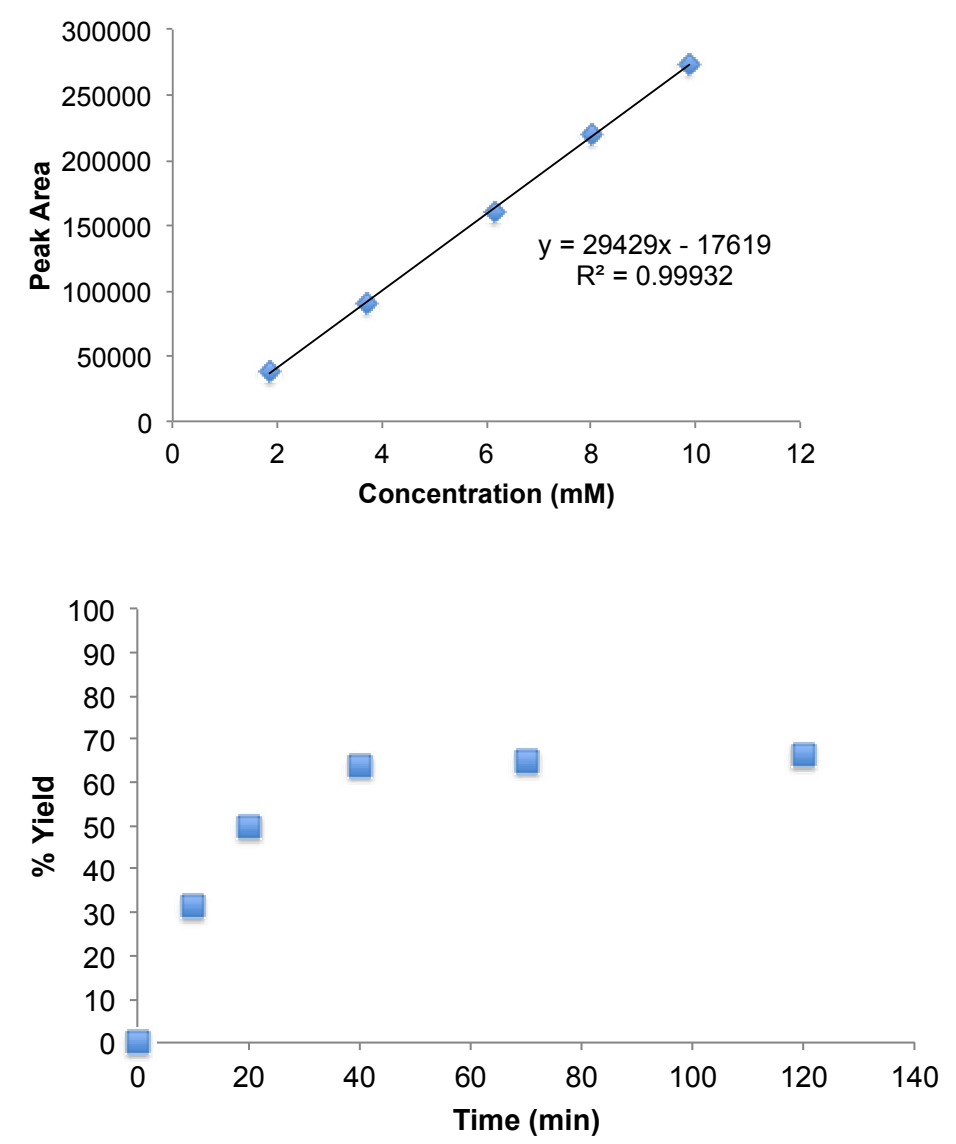

The UV-vis spectrum shown below is the result of a photolysis experiment consisting of $\left[\mathrm{Ru}(\mathrm{bpy})_{3}\right] \mathrm{Cl}_{2}(0.844 \mathrm{mM})$, octyl ether $\mathbf{2 a}(2.08 \mathrm{mM})$ and TEA $(15.2 \mathrm{mM})$. A $2 \mathrm{~mL}$ solution was placed into a cuvette, capped and purged with $\mathrm{N}_{2}$. The solution was irradiated using the $447 \mathrm{~nm} 1$ W laser for short amounts of time and monitored by UV-vis. The characteristic peak for the photocatalyst around $450 \mathrm{~nm}$ is diminished as the photolysis progresses. 


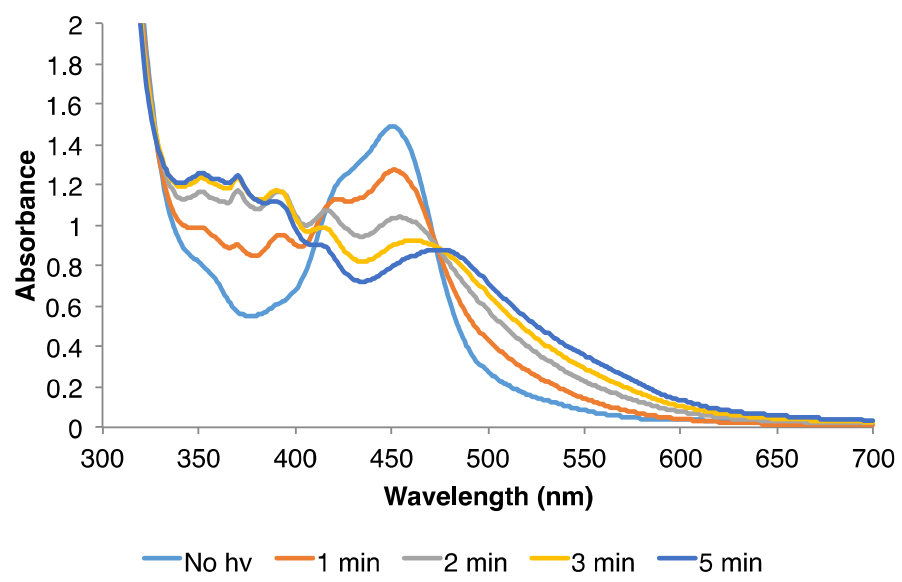

\section{- Mass spectrometry experiment:}

The following experiment was conducted on a JEOL AccuTOF-CS mass spectrometer using direct analysis in real time (DART) positive mode as the ionization source. Two samples were submitted for analysis. The first (top spectrum) consisted of $0.542 \mathrm{mM}$ of ether $2 \mathrm{a}$ and 20 microliters of TEA in $2 \mathrm{~mL}$ of $\mathrm{MeOH}$. The solution was placed into a small vial, capped with a septum and purged with $\mathrm{N}_{2}$ and irradiated for 3 minutes under $350 \mathrm{~nm}$ light. The septum was removed and exposed to air for approximately 15 minutes and the screw cap was placed back on. More exposure to $\mathrm{O}_{2}$ likely came from the MS analysis. The second (bottom spectrum) consisted of a photolysis equivalent to what was just mentioned above, however it was exposed to 30 minutes of $350 \mathrm{~nm}$ light. Exposure to air and further $\mathrm{O}_{2}$ during MS analysis is consistent. The samples were not submitted for high-resolution MS. 


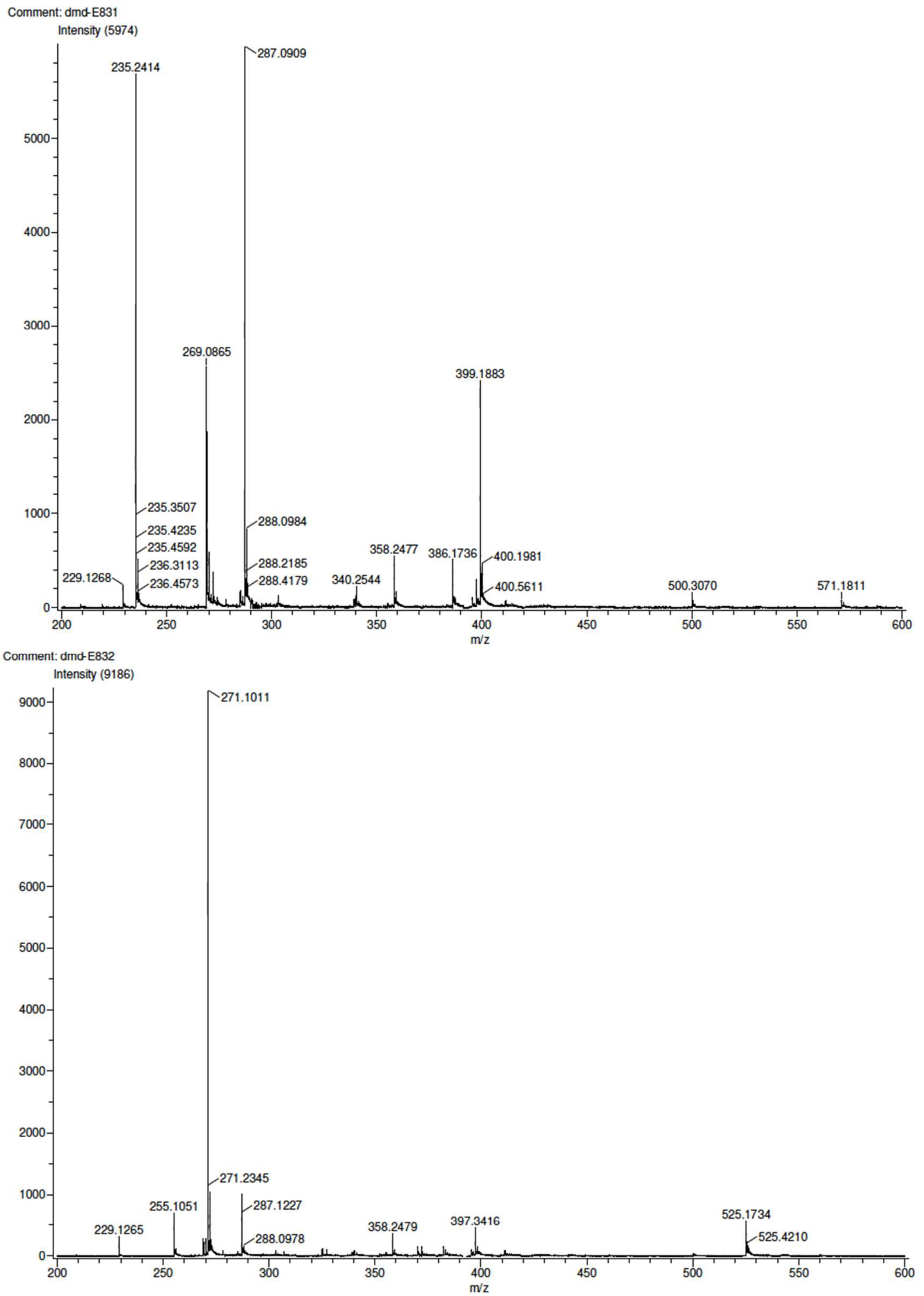


<smiles>O=C1c2ccccc2C(O)(c2ccccc2)c2ccccc2C1(O)c1ccccc1</smiles>

Compound 6: $\mathrm{C}_{40} \mathrm{H}_{26} \mathrm{O}_{6}[\mathrm{M}+\mathrm{H}]^{+}:$: 571.1909, Found: 571.1811<smiles>CCCCON=O</smiles>

\section{- Characterization spectra:}

\section{(1)}<smiles>O=C1c2ccccc2C(O)(c2ccccc2)c2ccccc21</smiles>

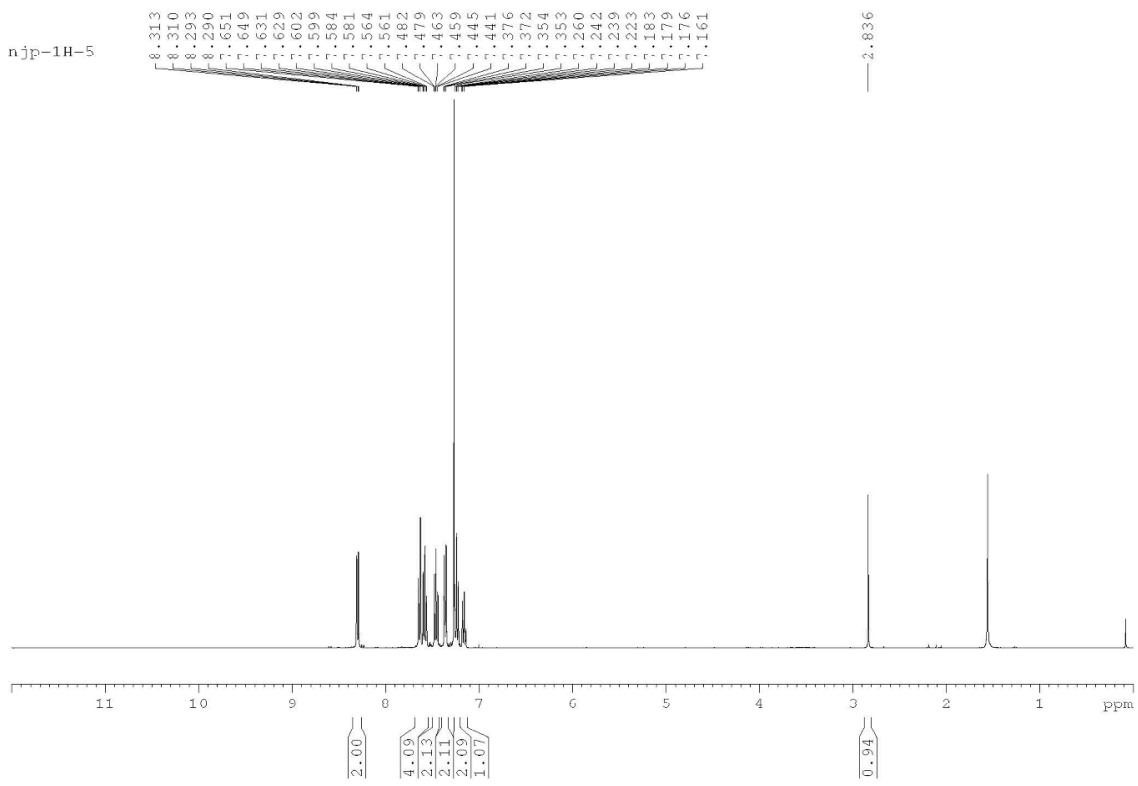



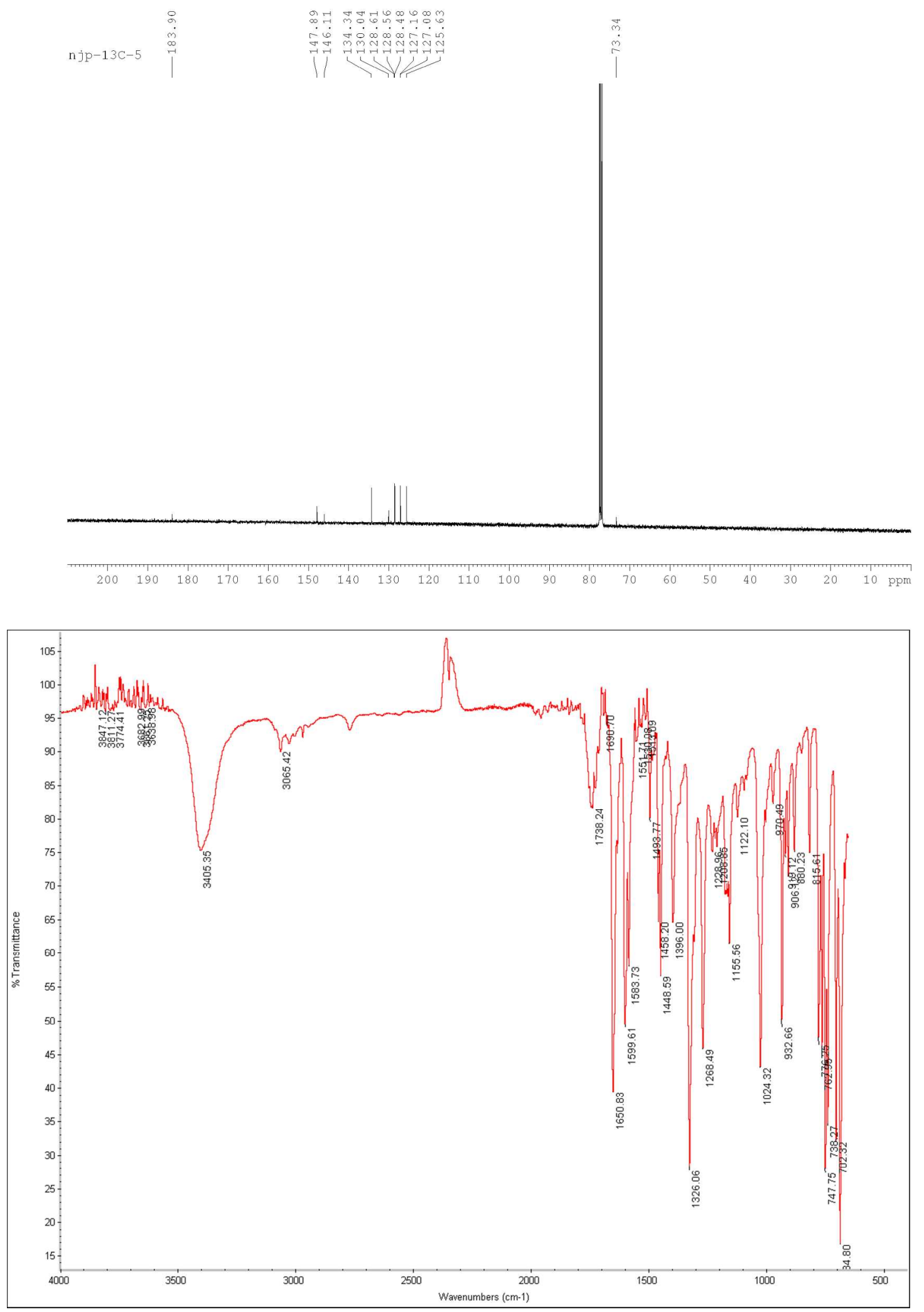


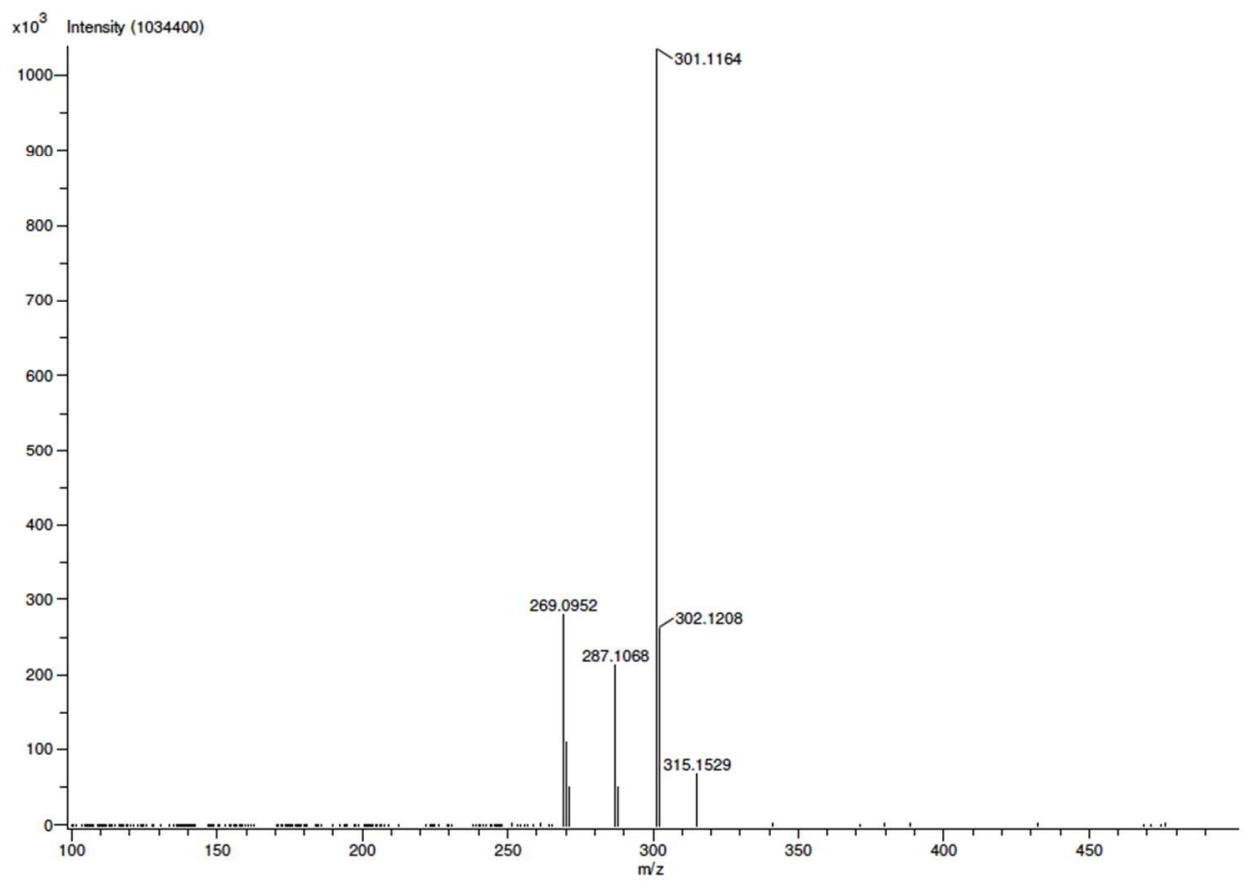


(2a)
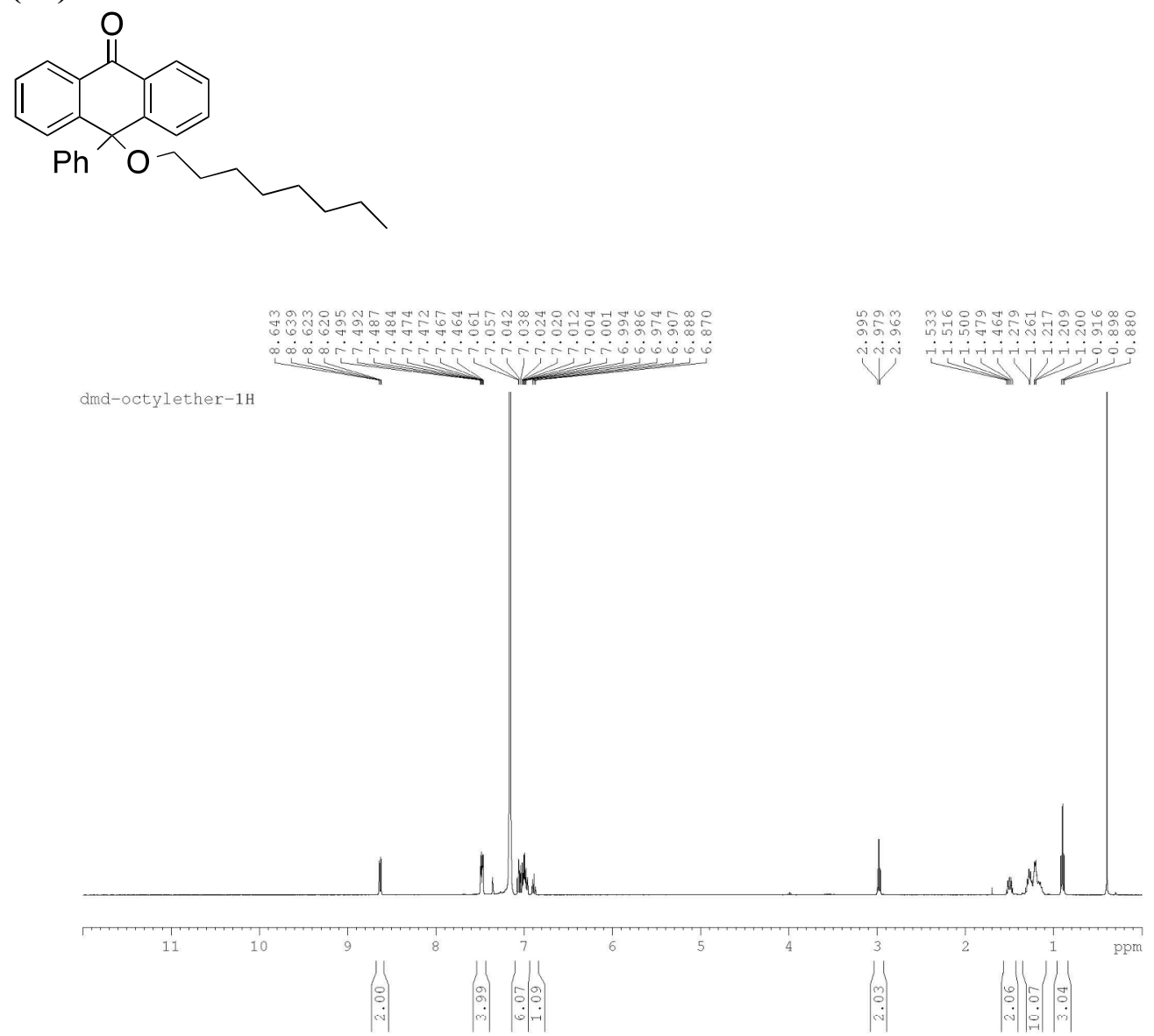

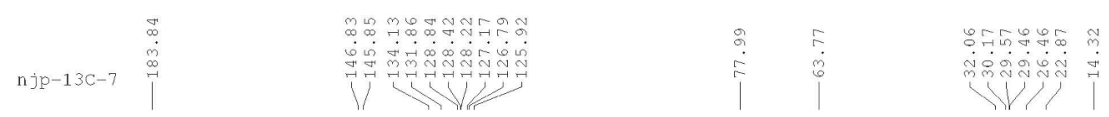

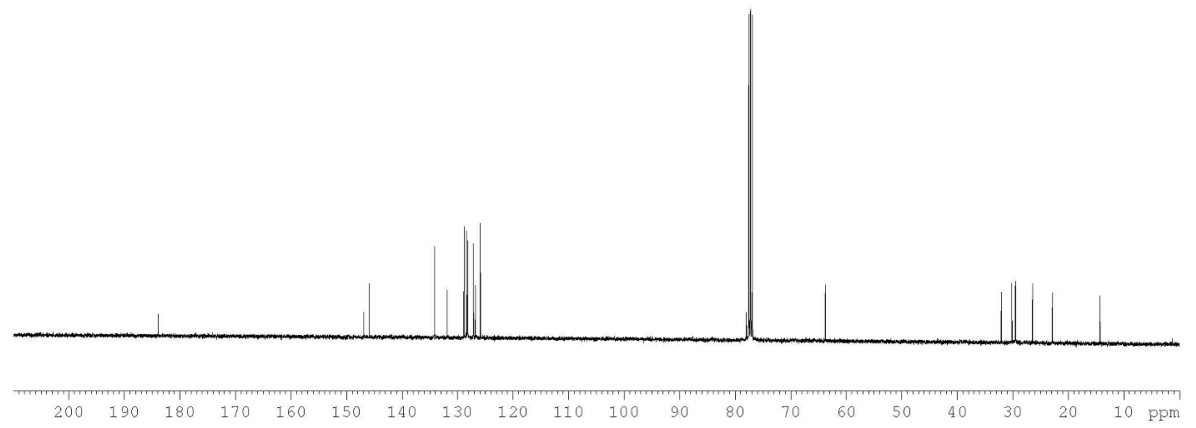



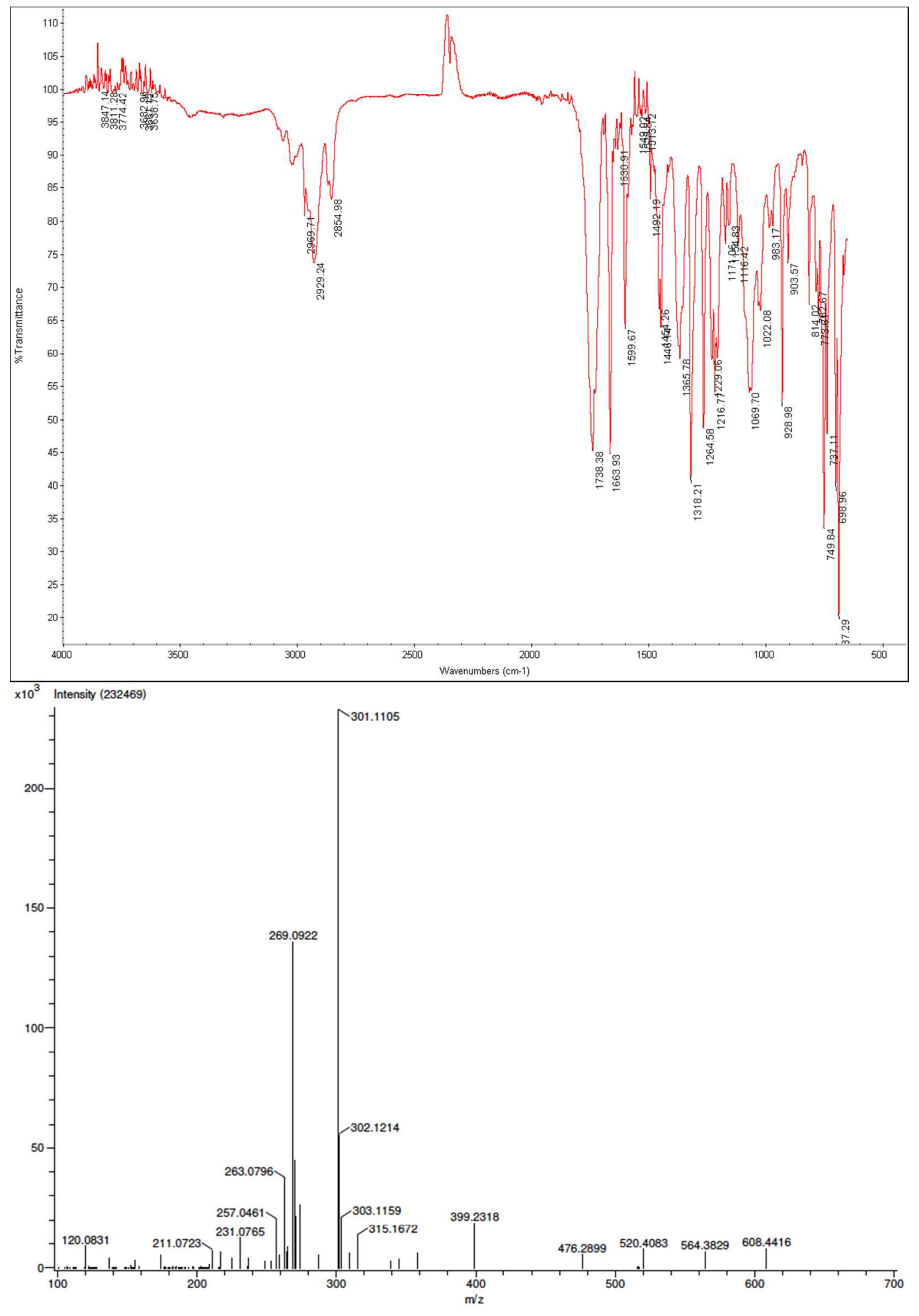
(2b)
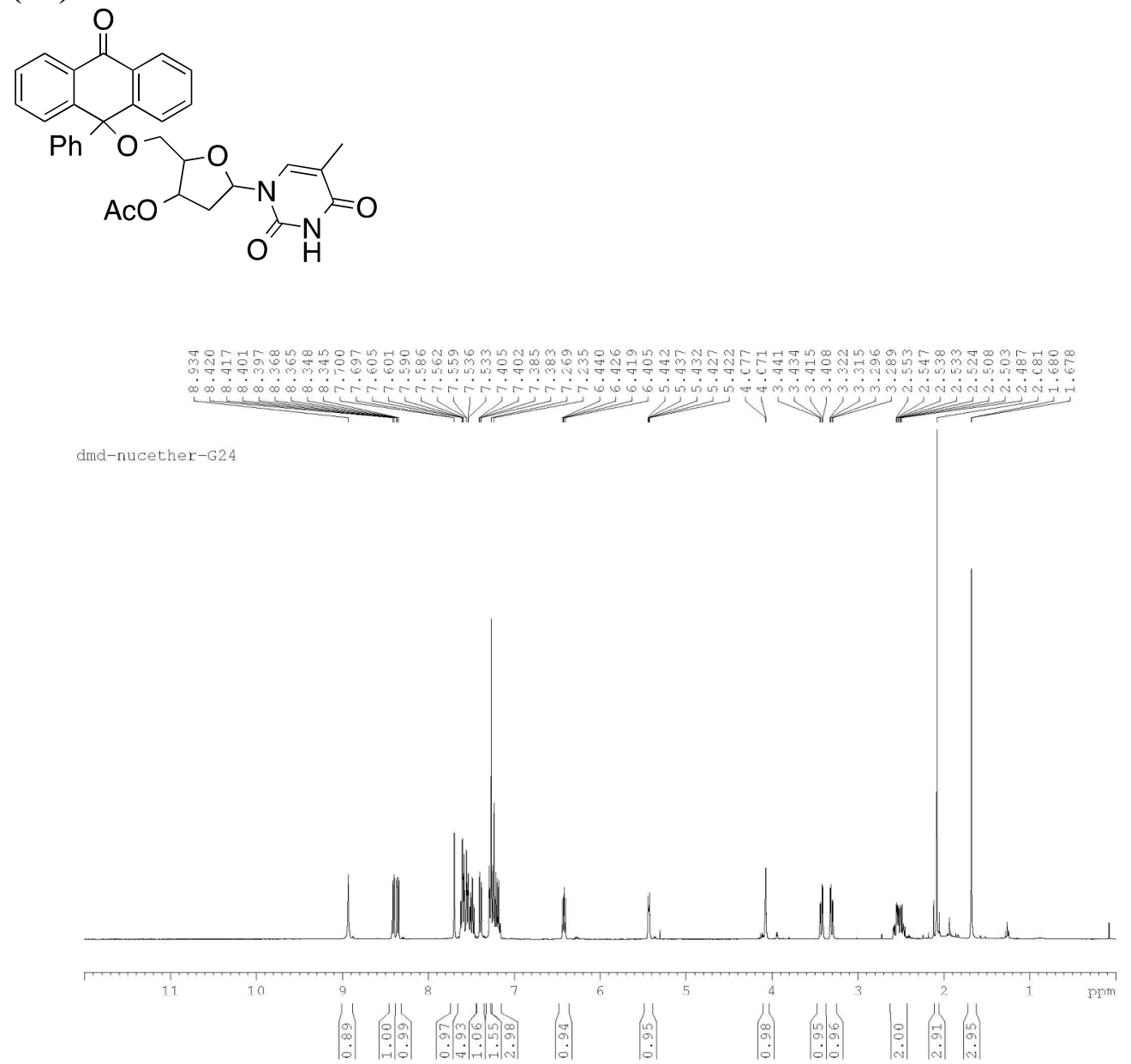

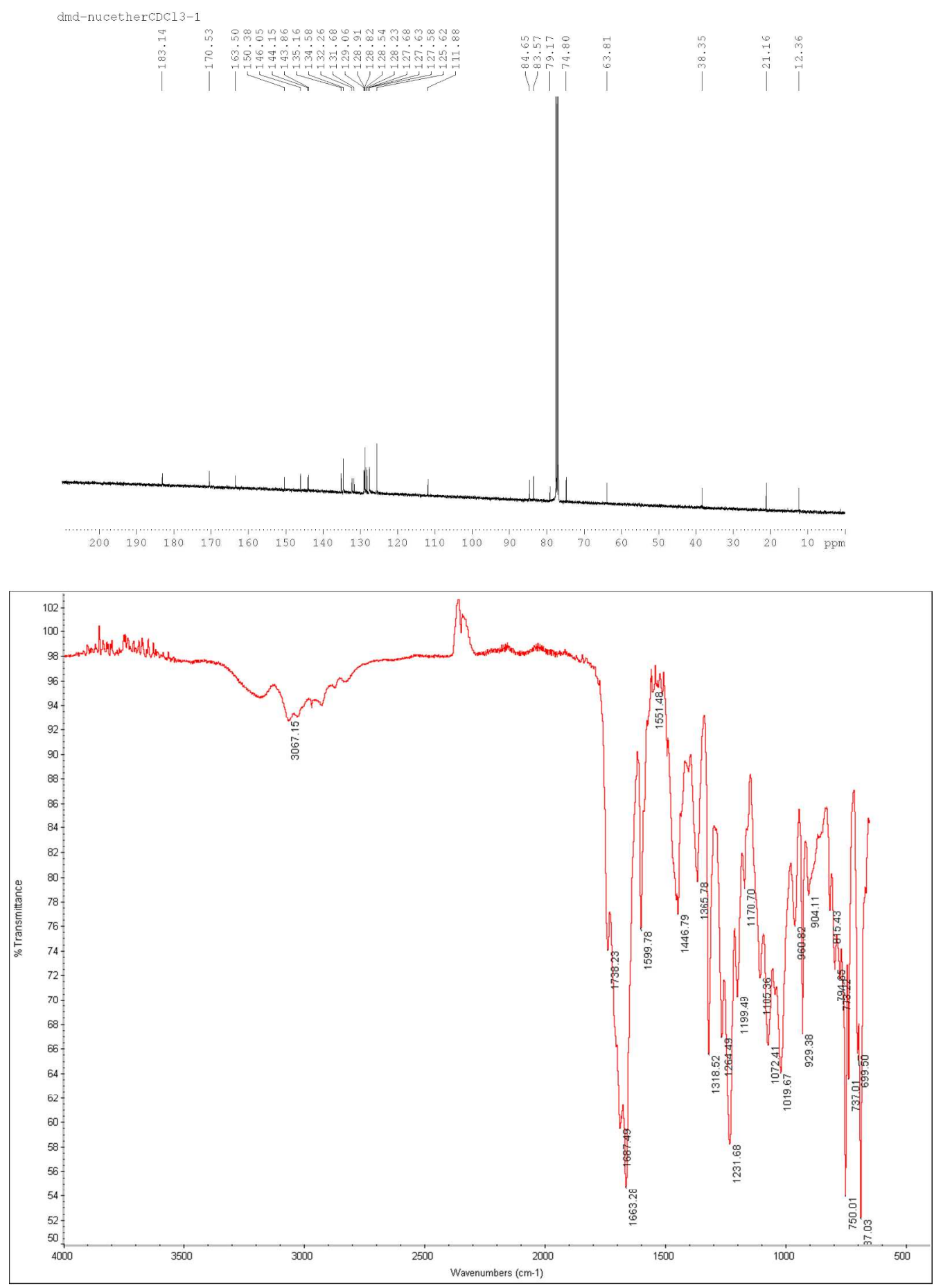


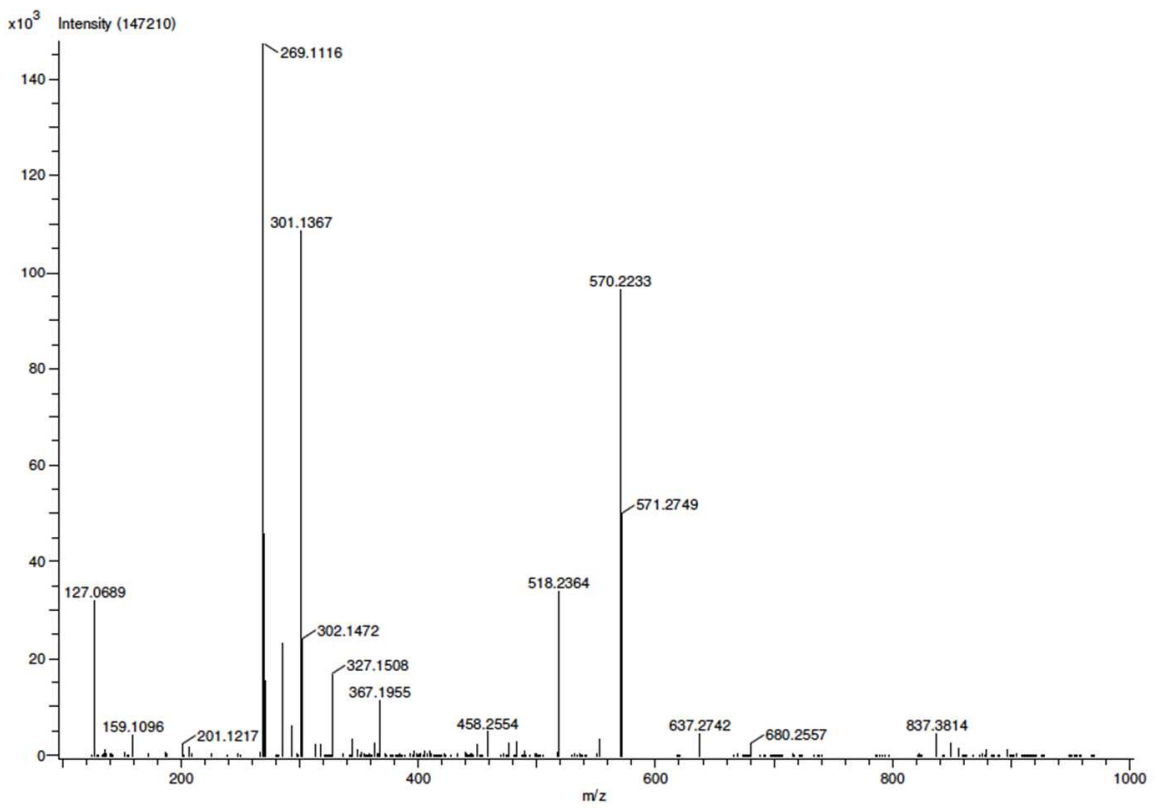


(2c)<smiles>O=C1c2ccccc2-c2ccccc2C1(Oc1ccccc1)c1ccccc1</smiles>

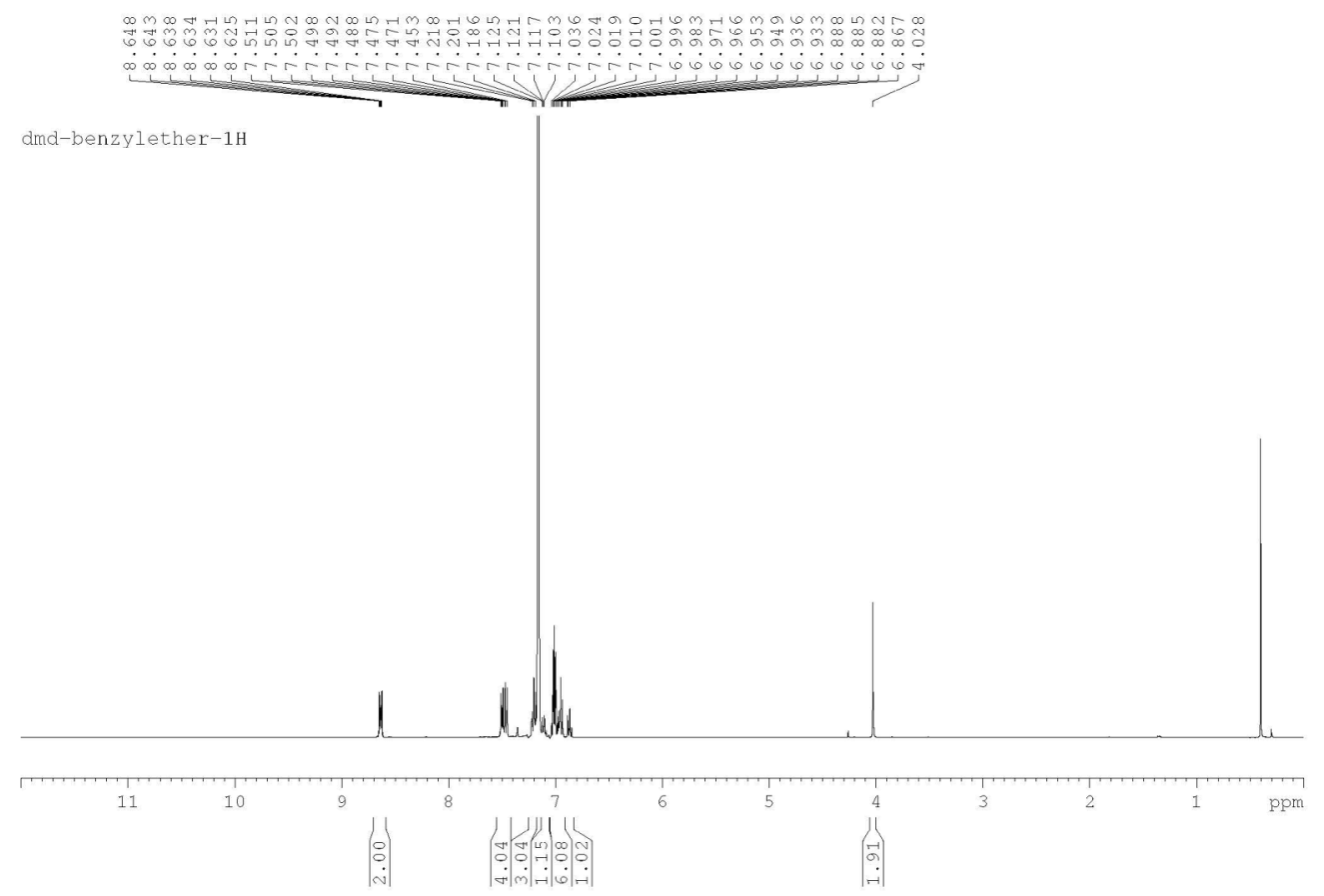



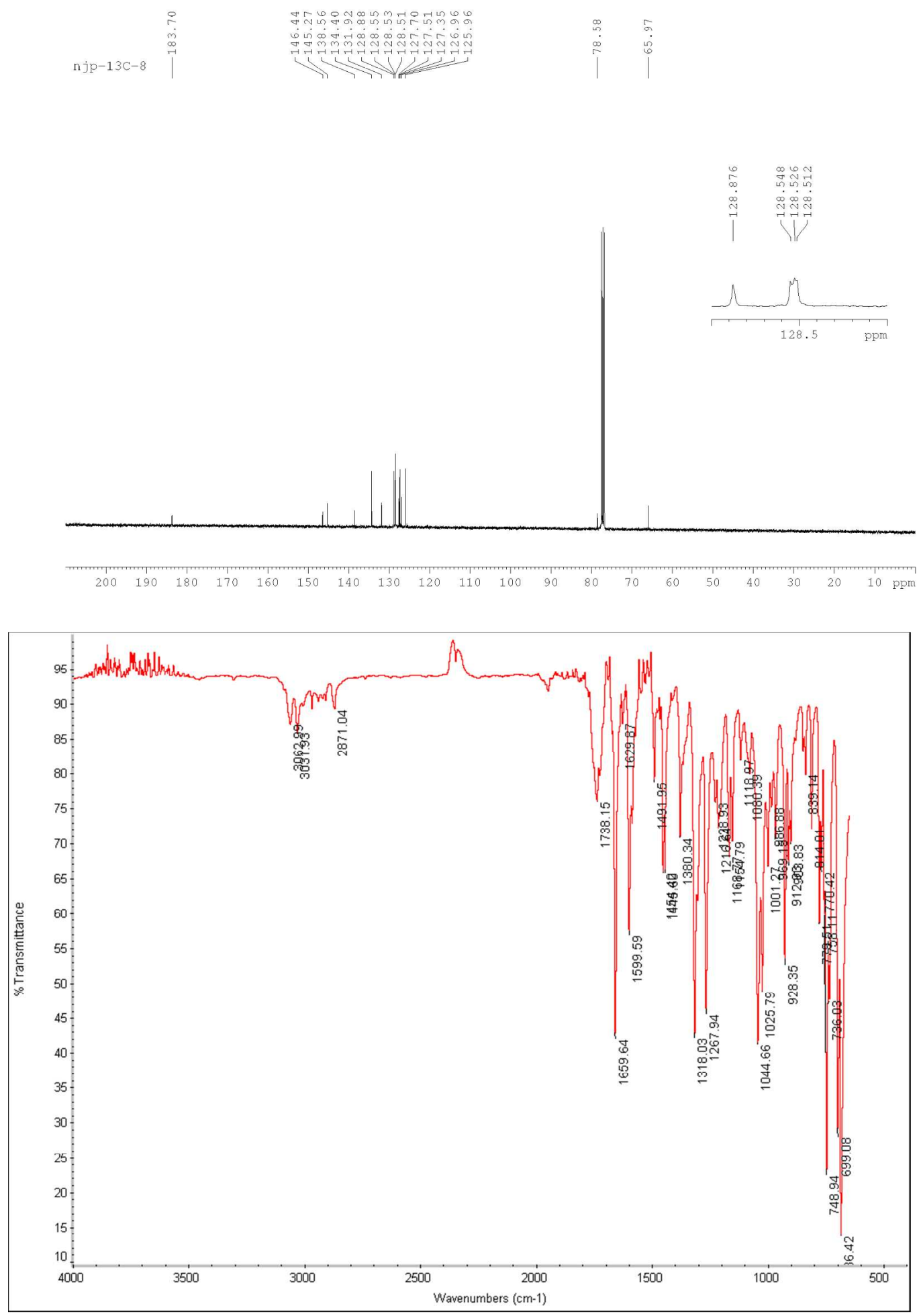


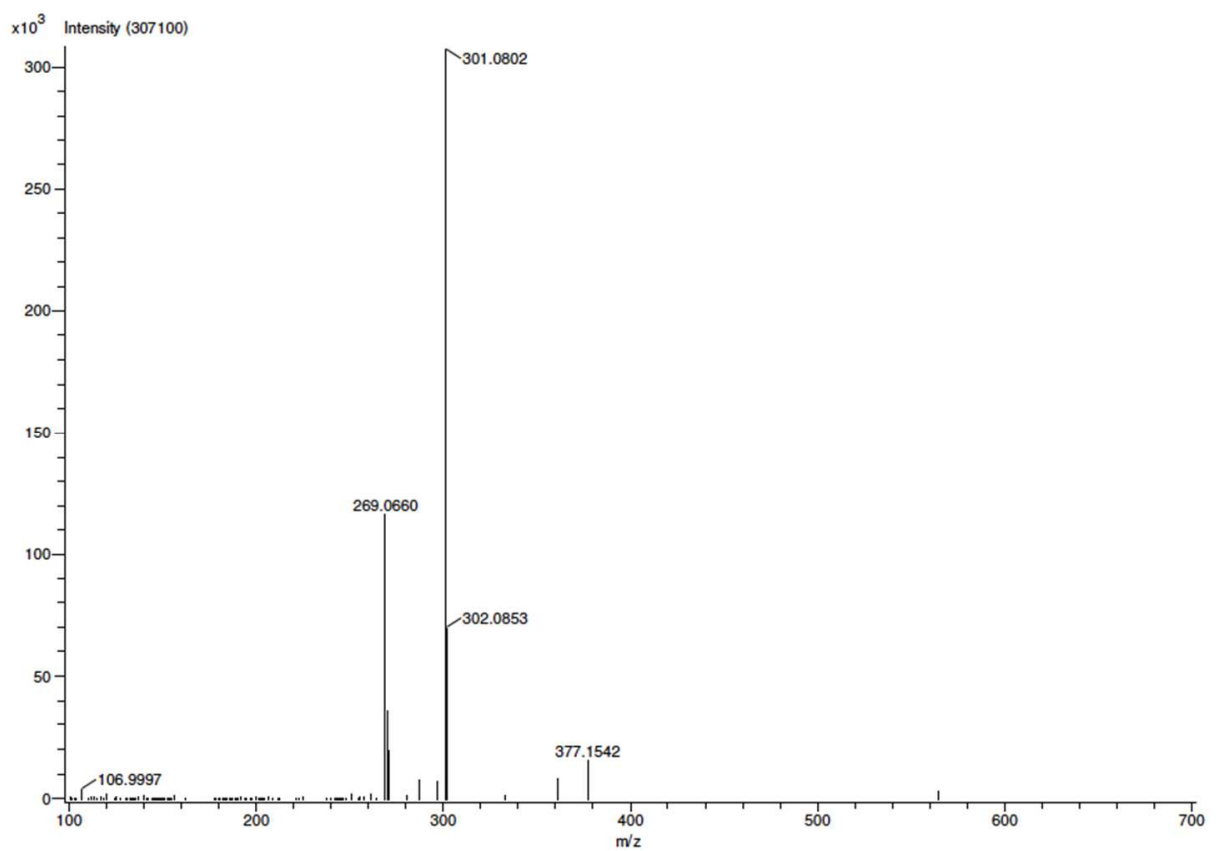


(2d)<smiles>COc1ccc(CCCCOC2(c3ccccc3)c3ccccc3C(=O)c3ccccc32)cc1</smiles>

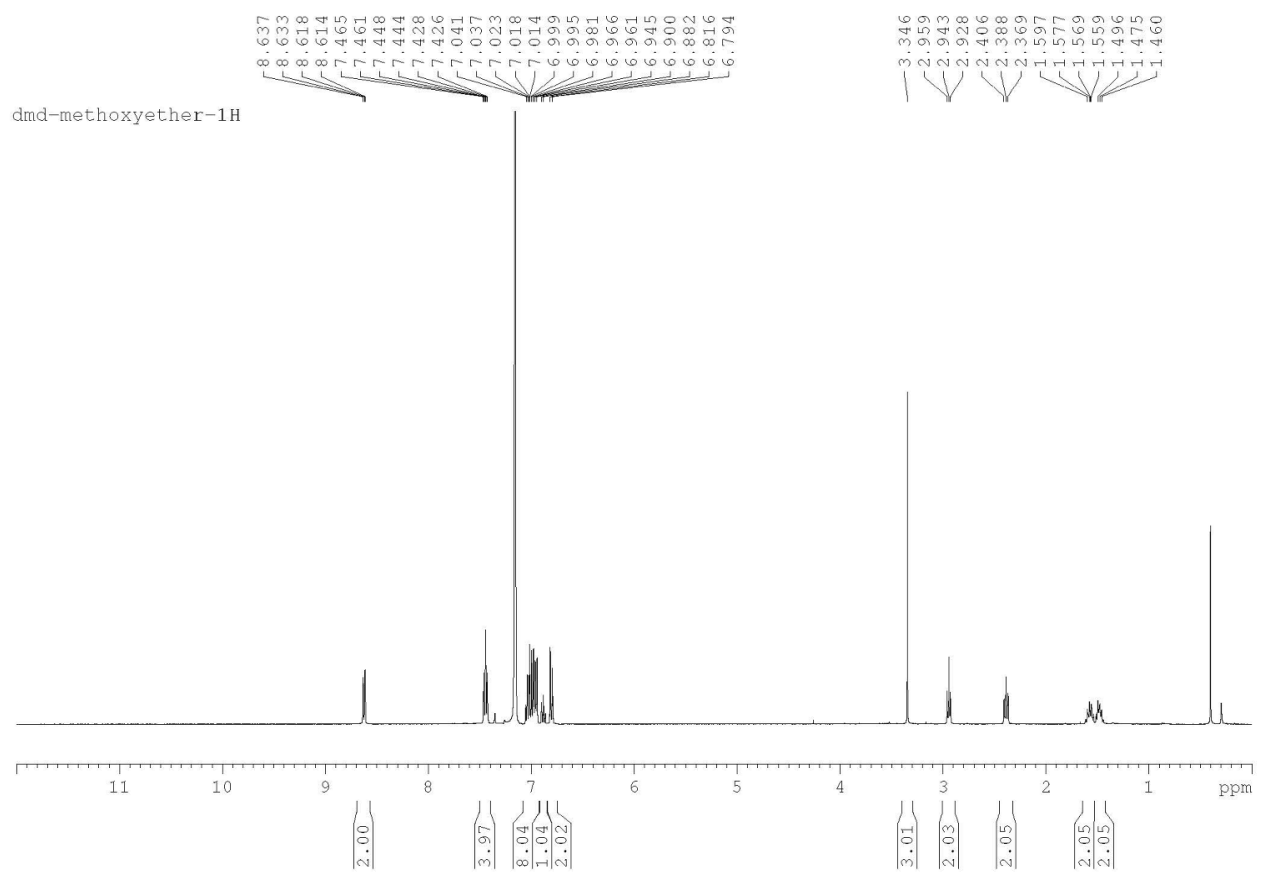




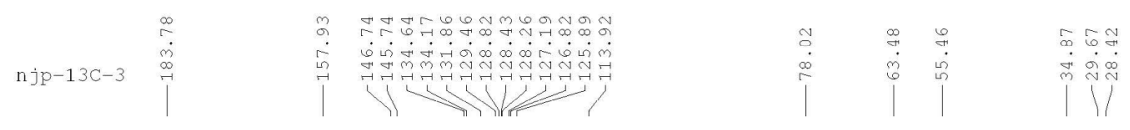
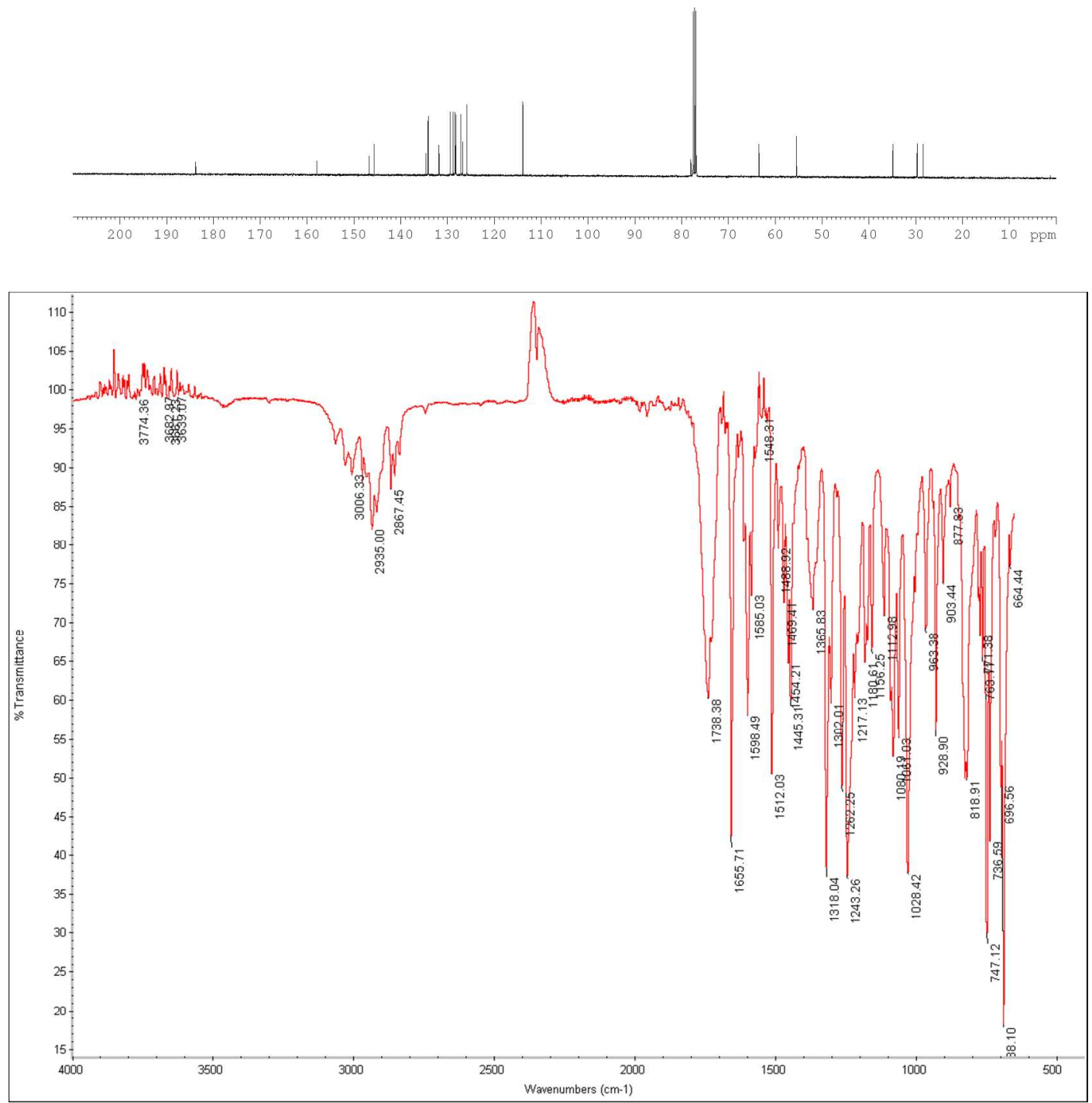


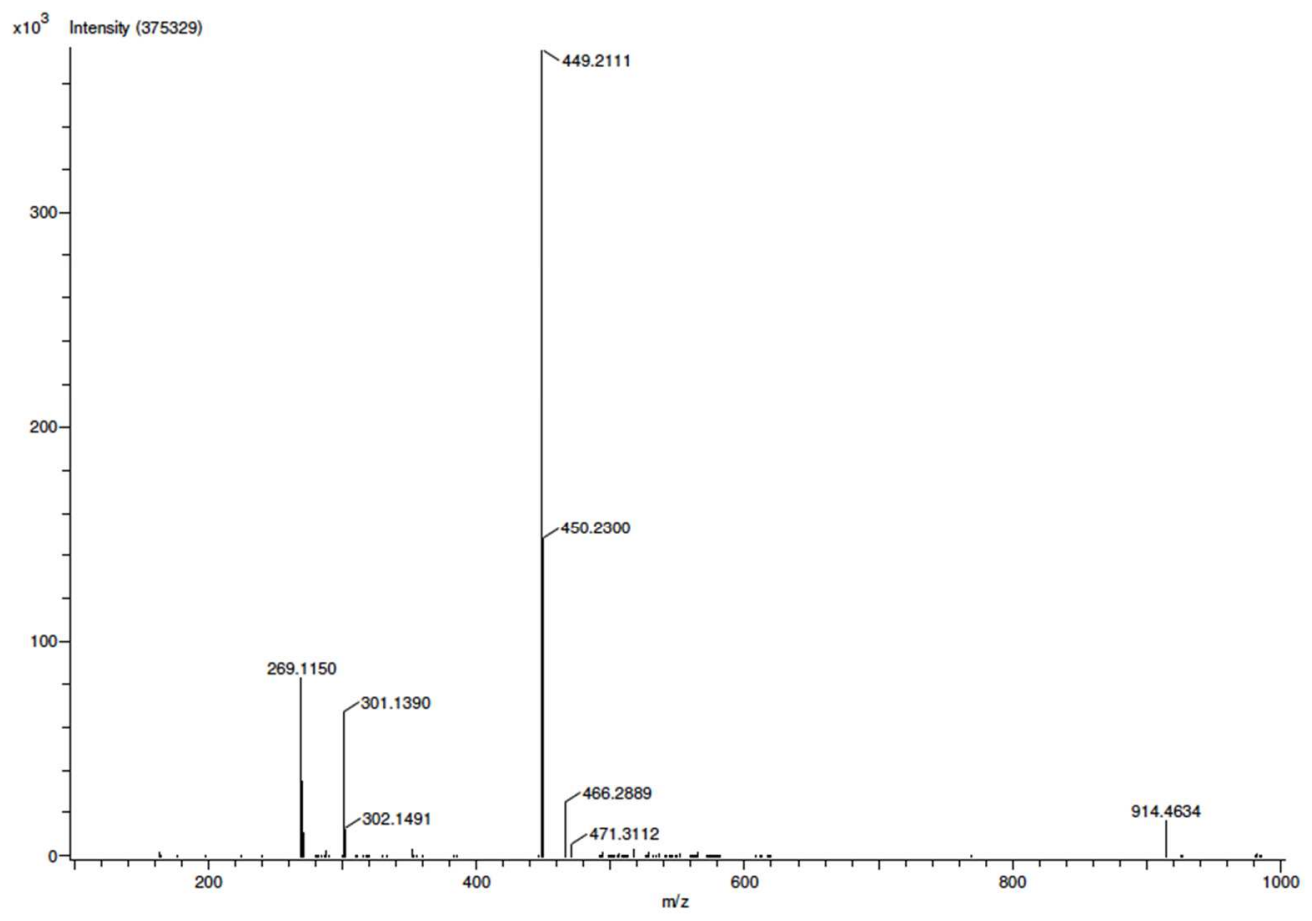


(2e)<smiles>O=C1c2ccccc2C(OC2CCCCC2)(c2ccccc2)c2ccccc21</smiles>
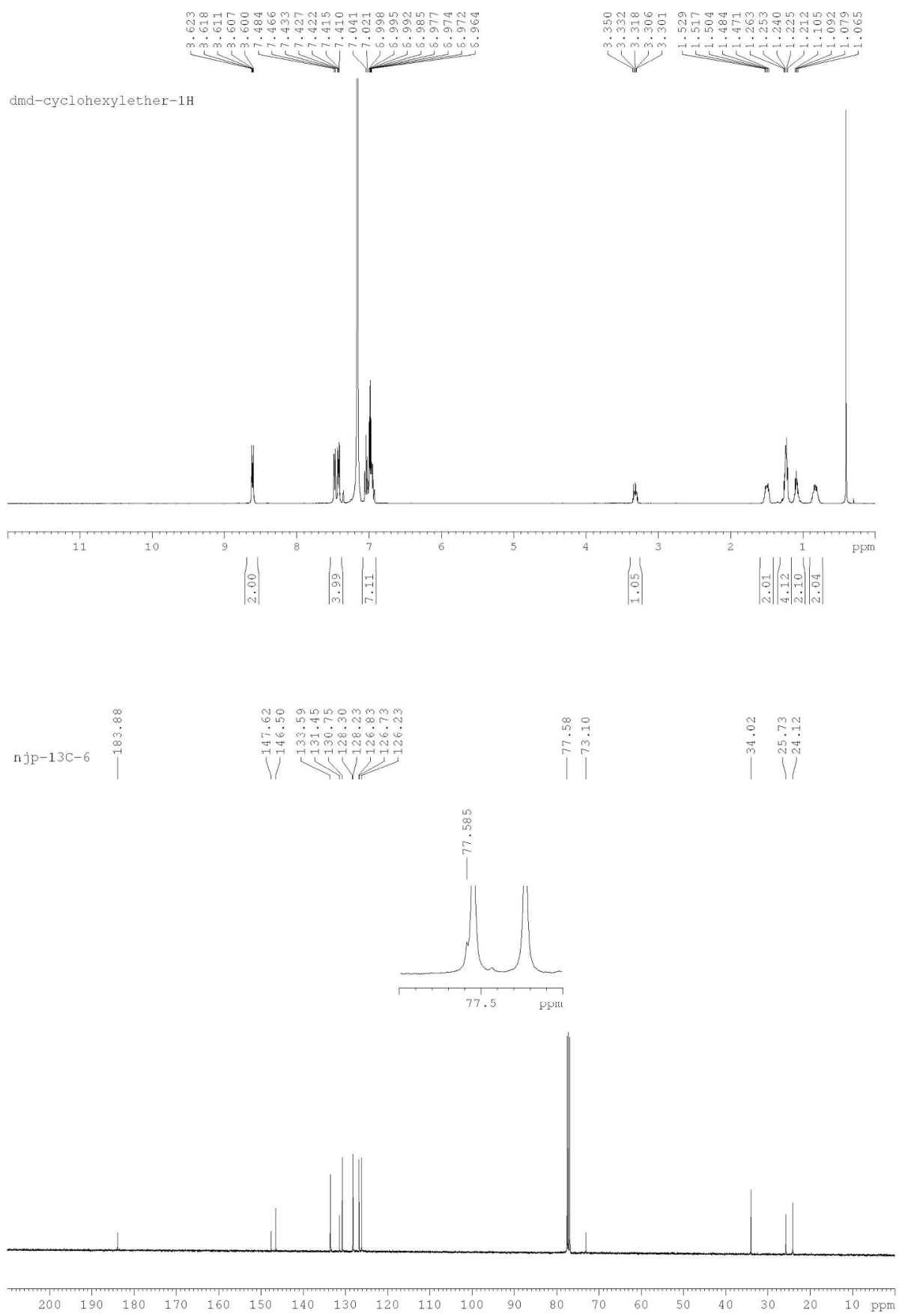

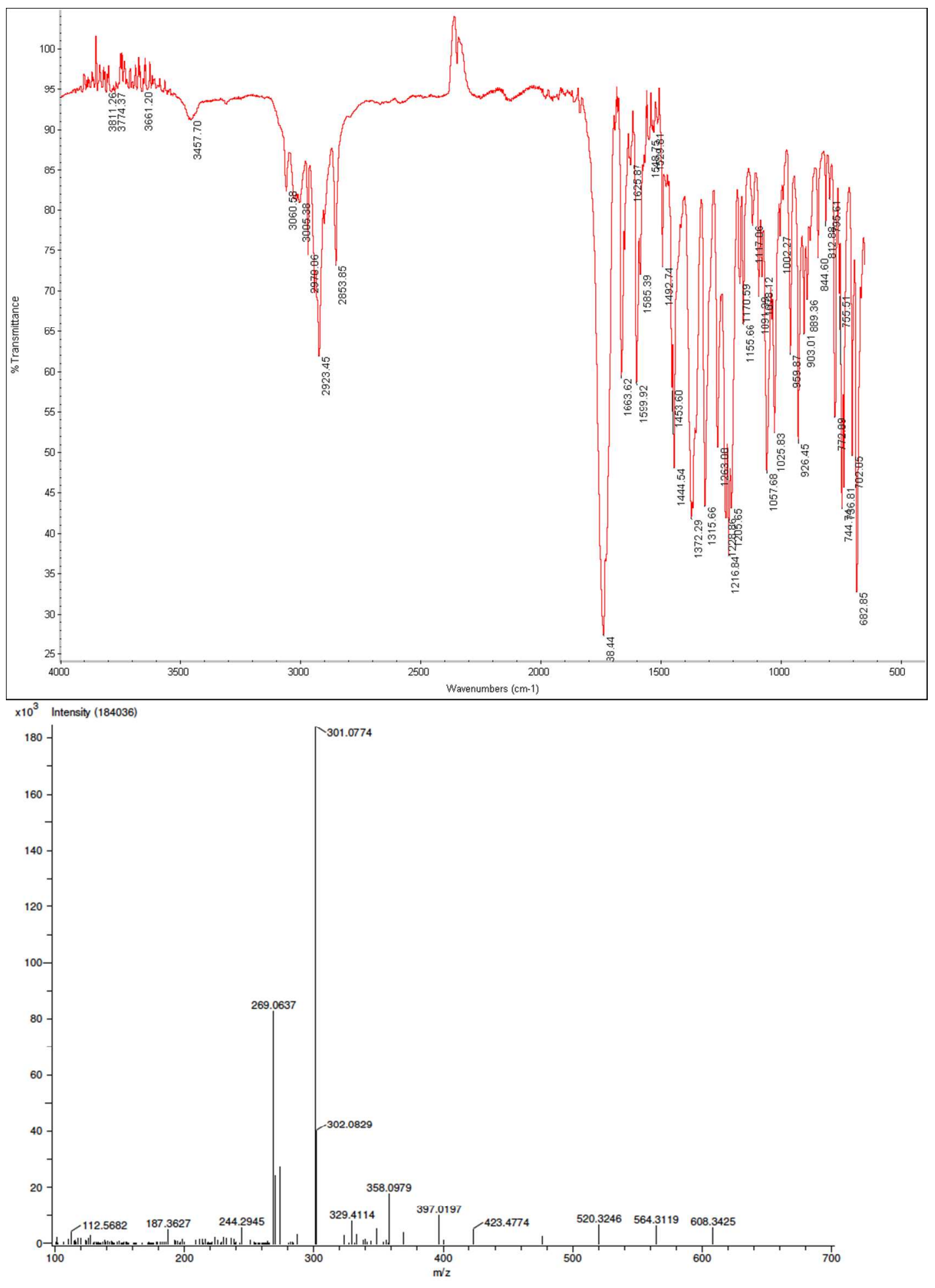

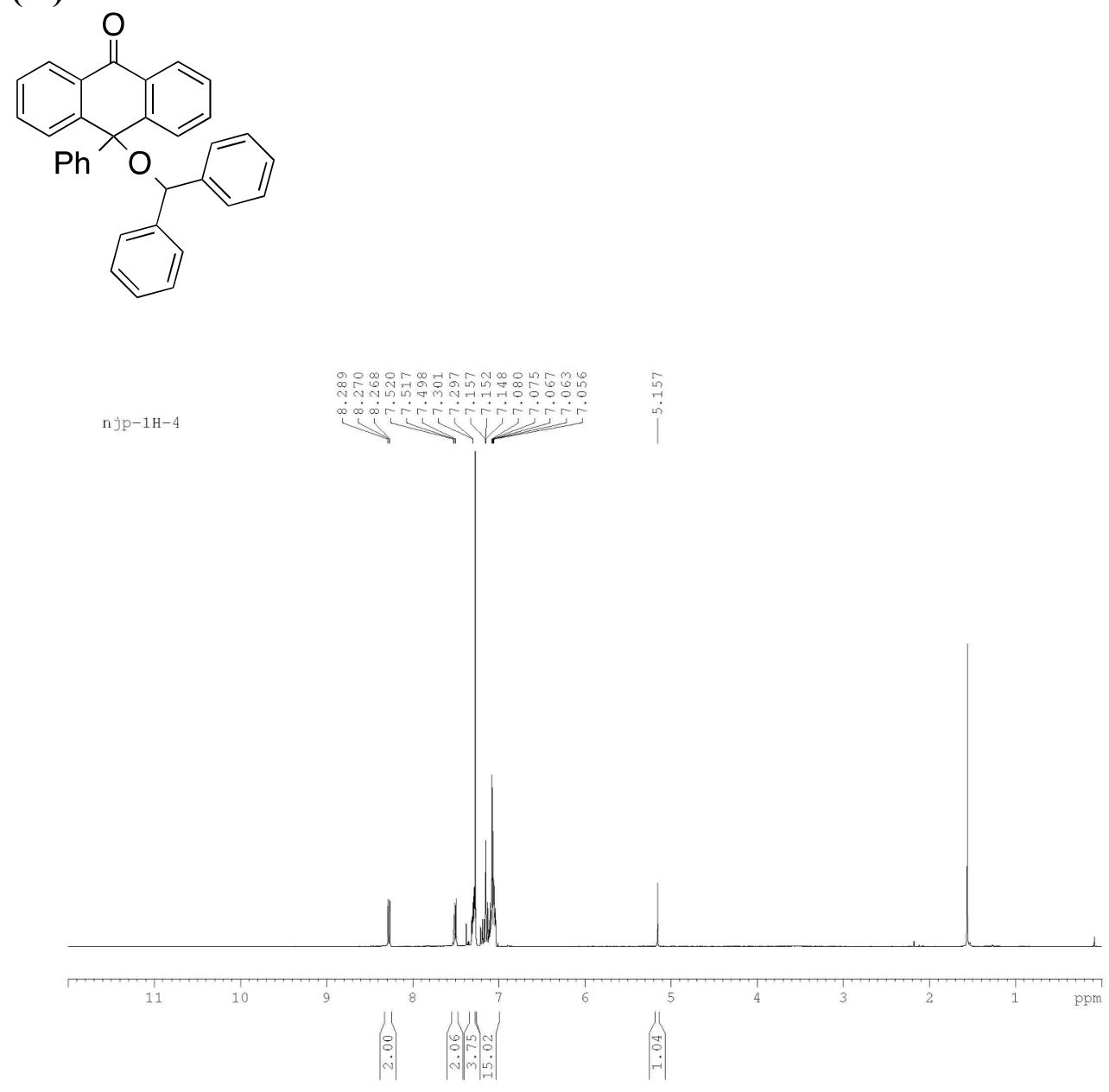

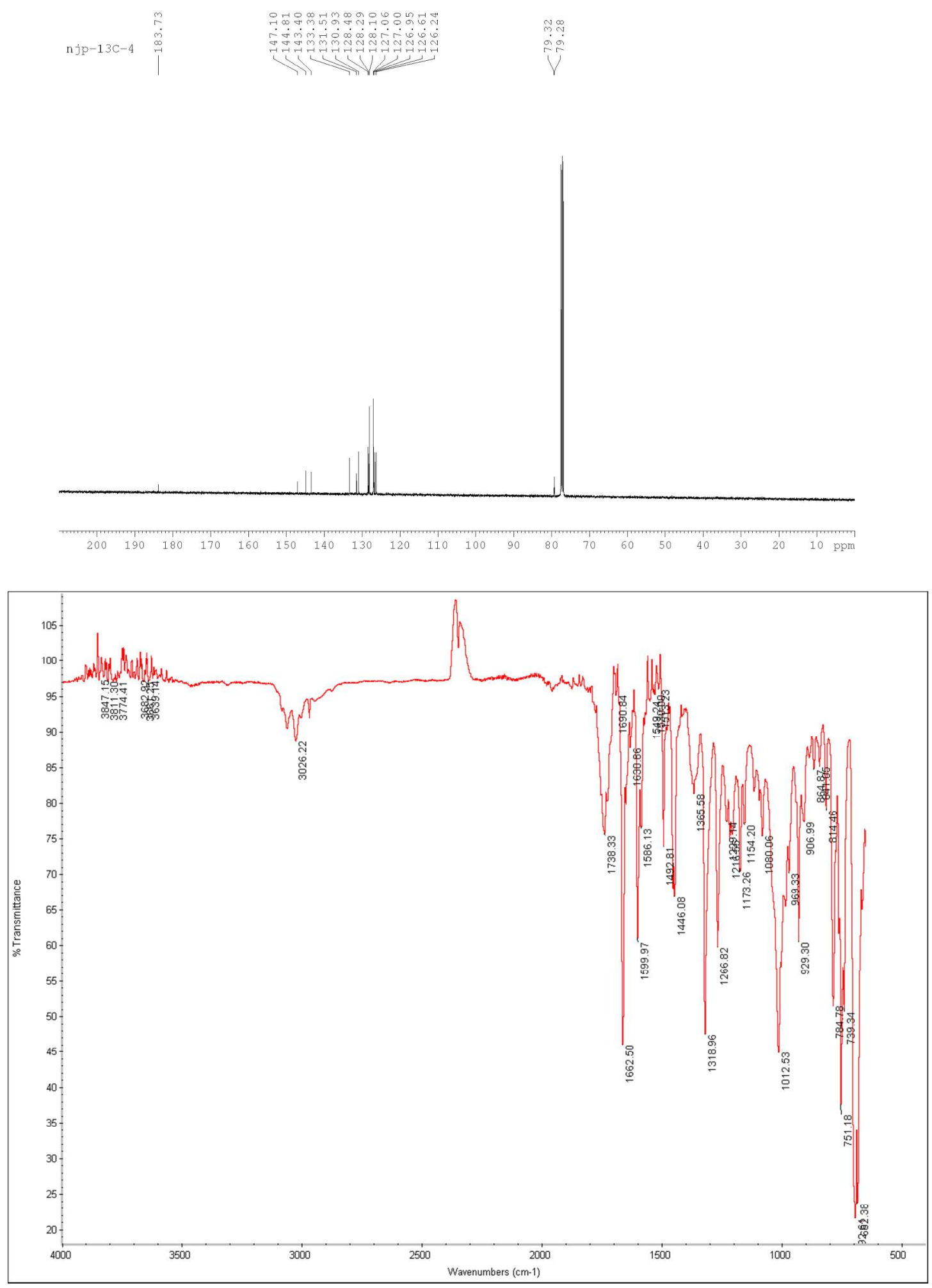


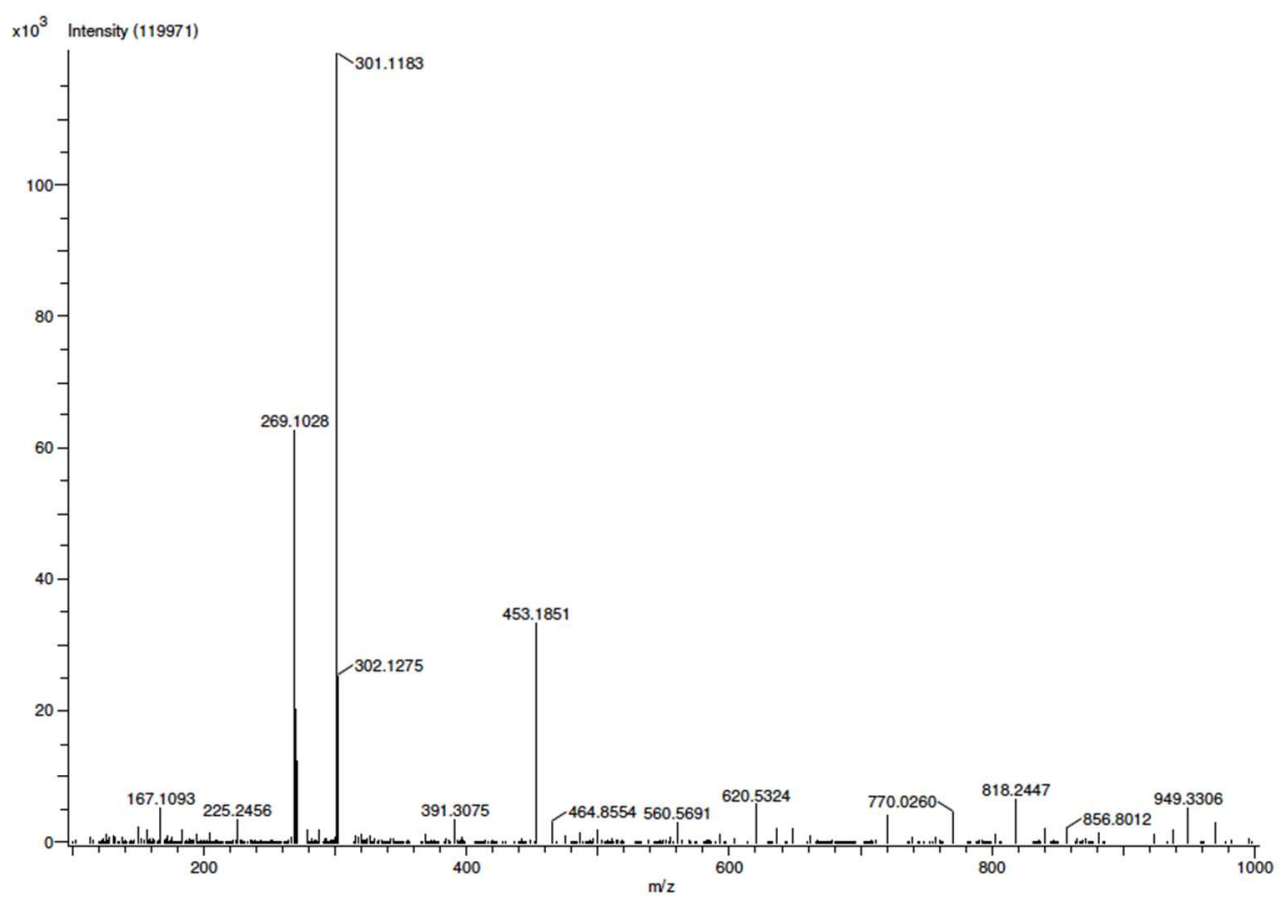


(2g)

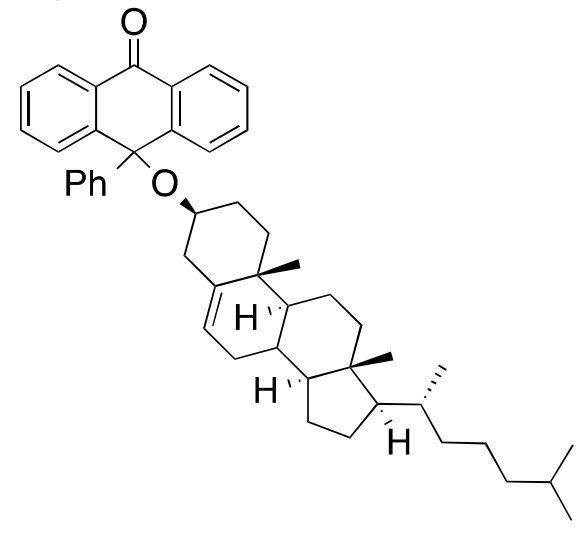

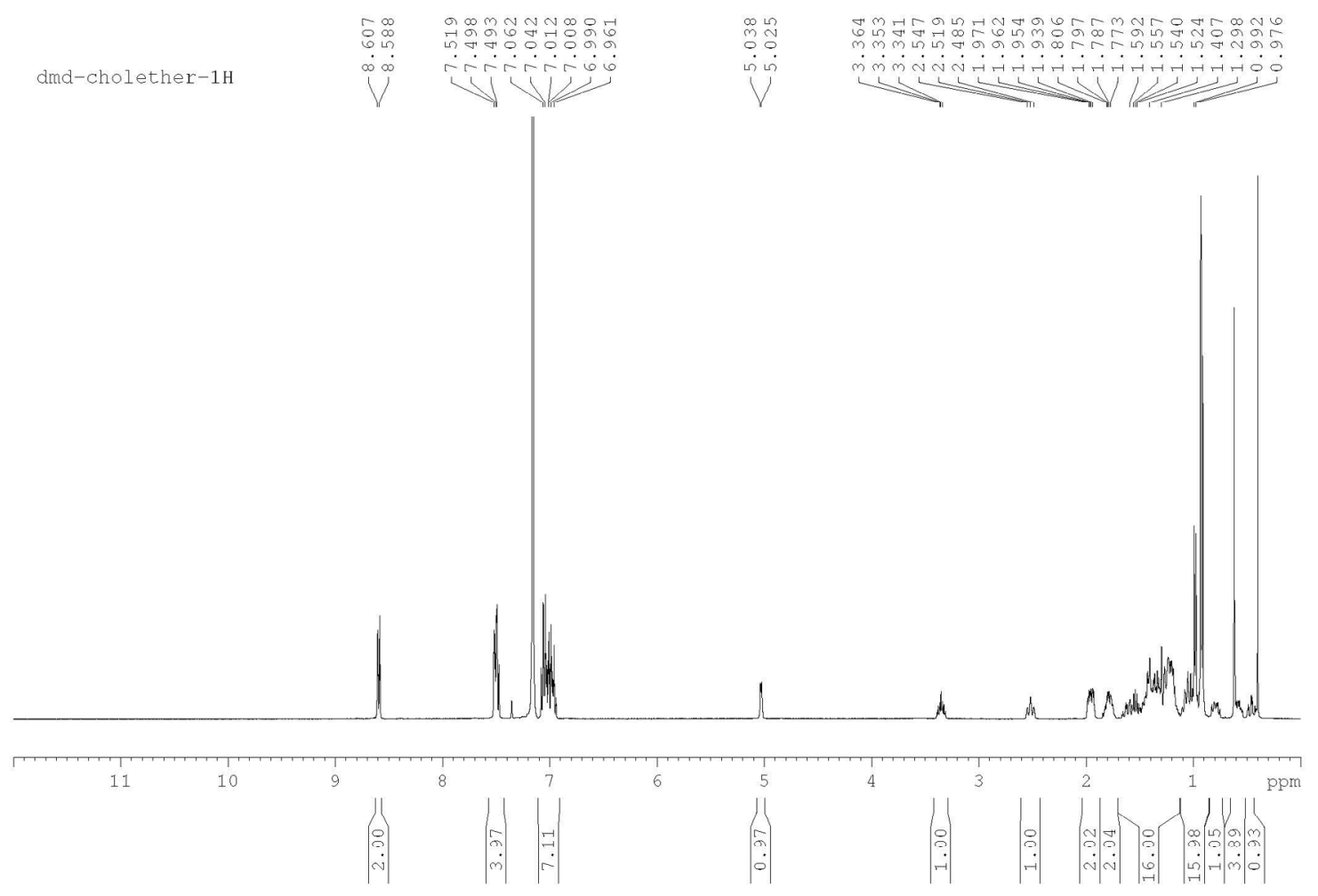




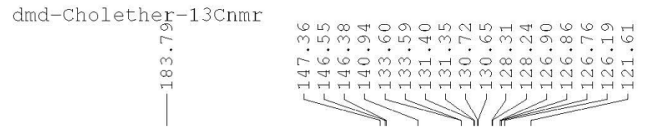

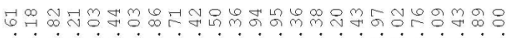

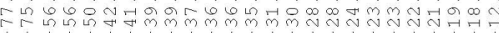

11 -
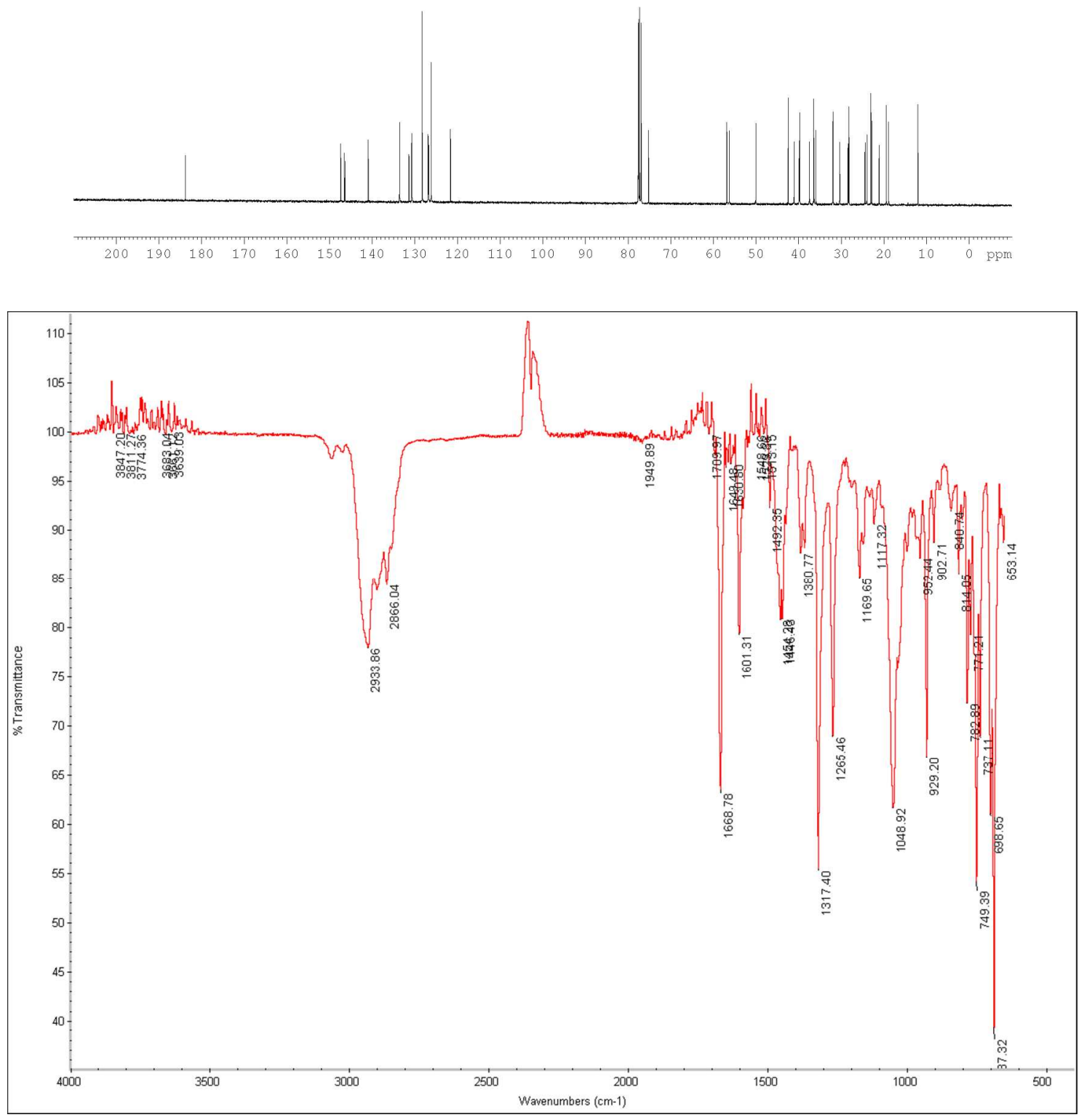


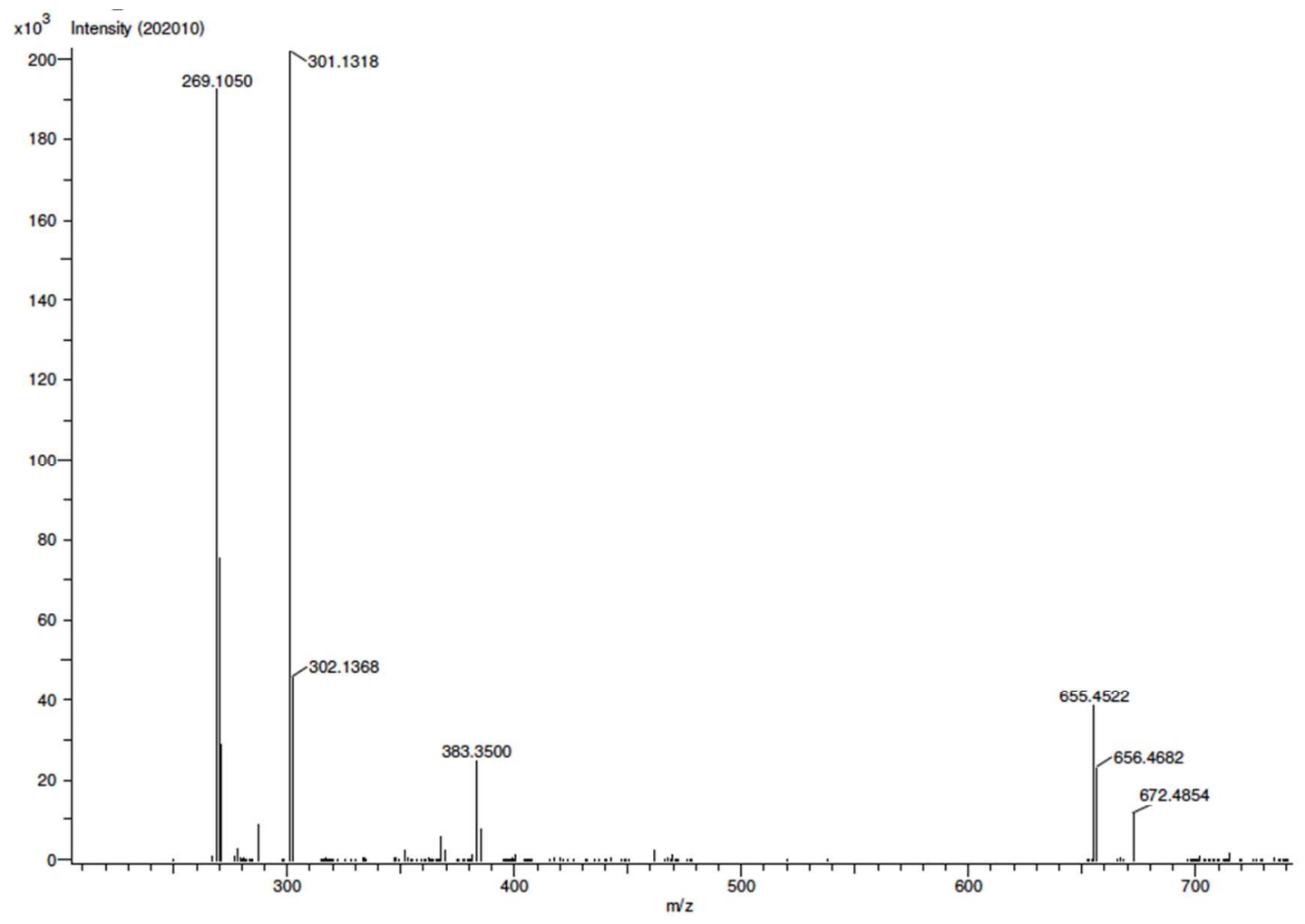

